\title{
Die Assanierung der Stadt Wien im Kontext internationaler Stadtplanungstendenzen
}

Die Assanierung der Stadt Wien in den Jahren des Ständestaats begleitete somit ein Diskurs zwischen Vertretern der Stadterneuerung und der Stadterhaltung, die sich nicht nur in Wien - schon ab dem späten 19. Jahrhundert gegenüberstanden. Die Erneuerer, die gegen die „unhygienischen“ und vermeintlich minderwertigen Bauten vergangener Epochen wetterten und dem Verkehr umso mehr Bedeutung zugestanden, gegen die Bewahrer von „Alt-Wien“, die eine bauliche Veränderung nur in beschränktem Maße zulassen wollten.

Die Stadterneuerung erfolgte ab 1934 vor allem durch die private Hand und orientierte sich an den Regulierungsplänen des späten 19. Jahrhunderts. Die Gemeinde selbst trat nur in wenigen Fällen als Bauwerber auf, erwarb „abbruchreife“ Objekte, um sie in weiterer Folge durch Neubauten zu ersetzen (vgl. Kap. 3). Die Assanierung diente der Schaffung gesunden Wohnraumes, der Begradigung der Straßenverläufe und damit gleichzeitig der „Verbesserung“ des Stadtbildes. Gewisse, „korrigierende“ Eingriffe in das Stadtbild wurden allerdings auch von der amtlichen Denkmalpflege unterstützt.

Nach der Abschwächung des Stadterneuerungsprozesses durch den Ersten Weltkrieg und die folgende schlechte Wirtschaftslage nahm man in den späten 1920er- und 1930er-Jahren nicht nur in Wien, sondern europaweit die Regulierungstätigkeit und „Stadtgesundung“ wieder auf. Die außerhalb Österreichs dafür eingesetzten Maßnahmen und Methoden wurden hierzulande - vor allem in Wien - interessiert wahrgenommen. So erläuterte etwa Siegfried Theiss im Dezember 1934 die damaligen Pläne, die Innenstadt Stockholms aufzulockern, und Karl Holey berichtete in Zeitungsartikeln und Vorträgen über die Regulierungstätigkeit in Rom. ${ }^{\mathbf{1}}$ Auch Erwin Ilz verwies neben den diversen Methoden der „Stadtgesundung“ auf „die bemerkenswertesten Beispiele“ aus Italien und England, wo man „ganz Hervorragendes“ leiste. ${ }^{2}$

In den vorangegangenen Kapiteln wurde versucht, die Regulierungstätigkeit der 1930er-Jahre in der Wiener Stadtbaugeschichte zu „verorten“ und mit dem Stadtumbau des 19. Jahrhunderts in Beziehung zu setzen. Fragen der Stadtregulierung und insbesondere das Thema der Altstadtsanierung waren jedoch in den 1930er-Jahren in ganz Europa präsent, weshalb sich dieses letzte Kapitel der Analyse und Diskussion der Assanierung im Kontext der internationalen Stadtplanungstendenzen widmet. Welche Ansätze gab es in den 1930er-Jahren im Bereich der Altstadtsanierung und woran hat man sich in Wien möglicherweise orientiert? Parallelen und Unterschiede zu Maßnahmen in anderen Staaten können hier aufgezeigt werden.

Laut Harald Bodenschatz stellte der Umgang mit der historischen Stadt gerade in totalitär geführten Systemen, vor allem in Italien, Deutschland und der Sowjetunion, in denen Architektur und Städtebau für politische Zwecke vereinnahmt wurden, eine zentrale Frage dar. ${ }^{\mathbf{3}}$ Neben der Errichtung monumentaler Verwaltungsbauten, eindrucksvoller Sportstätten und zahlreicher Siedlungen waren es die "gesunden“ Altstädte, die den wirtschaftlichen, politischen und sozialen Aufschwung des Landes 
verdeutlichen sollten. Daher liegt hier die Vermutung nahe, dass man sich in Österreich - und im Speziellen in Wien - an den Methoden der Stadtregulierung und Altstadtsanierung in den erwähnten Ländern orientierte. Die Entwicklungen im Deutschen Reich und in Italien sind es auch, die Karl Holey im Dezember 1937 in einem Artikel in der Reichspost zur städtebaulichen Zukunft Wiens als beispielgebend anführt: die „gründliche Erneuerung von innen heraus“ im faschistischen Italien und die „Gesundung“ einiger Altstädte durch „diktatorisch ausgerüstete Baukünstler“ in Deutschland. Es seien zu begrüßende, „tiefgreifende Veränderungen“, die zwar „mit starker Hand [...], aber nicht rücksichtslos“ durchgeführt würden. ${ }^{\mathbf{4}}$ Nicht zuletzt aufgrund dieser bewundernden Einschätzung eines der führenden Architekten zur Zeit des Ständestaats, Mitglied des Bundeskulturrates und bis 1932 Generalkonservator der Zentralstelle, müssen die Stadtregulierungsmaßnahmen in Rom sowie die „Altstadtgesundung“ im Dritten Reich im Folgenden näher betrachtet werden.

Die Forschung versuchte bisher, die Assanierung der Stadt Wien in den 1930er-Jahren mit den Maßnahmen des risanamento im faschistischen Italien gleichzusetzen oder zumindest in Verbindung zu bringen. ${ }^{\mathbf{5}}$ Eine tiefgreifende Untersuchung und ein Vergleich der jeweiligen Maßnahmen der Altstadtsanierung fanden bis dato allerdings nicht statt. Die in Italien gegebenen politischen Voraussetzungen - Mussolinis Machtergreifung erfolgte bereits im Jahr 1922 - stellten schon geraume Zeit vor der Ausschaltung der Demokratie in Österreich die Weichen für eine ideologische Beeinflussung von Architektur und Städtebau. Bis zum Zweiten Weltkrieg war dadurch eine weitgehende Instrumentalisierung des Städtebaus möglich. In dieser Hinsicht waren die Bedingungen für den österreichischen Ständestaat, durch die kurze Herrschaftsdauer und die schwierigen wirtschaftlichen Voraussetzungen, sicherlich weitaus „ungünstiger“. Die kulturellen Beziehungen des österreichischen Ständestaats mit dem faschistischen Italien unter Mussolini wurden durch das bilaterale Kulturabkommen von 1935 intensiviert. ${ }^{6}$ Diese Verbundenheit der beiden Staaten sollte sich hier wie dort auch im Bereich der bildenden Kunst und in einer verstärkten Ausstellungstätigkeit äußern. Inwiefern man sich in Wien an den Regulierungsmaßnahmen, vorrangig jenen in Rom, orientiert haben könnte und welche Unterschiede und Parallelen im Bereich der Stadtregulierung und Altstadtsanierung zu erkennen sind, soll im Folgenden genauer analysiert werden.

Auch im Deutschen Reich wurden Fragen der Stadterneuerung intensiv diskutiert.7 Bereits seit 1933, also mit der Machtergreifung Adolf Hitlers, stellte die „Altstadtgesundung“ ein zentrales Anliegen dar. Erste Sanierungen setzten bereits 1933 ein, unter anderem in Hamburg, Berlin, Köln und Frankfurt am Main. ${ }^{8}$ Dabei wurden nicht nur Regulierungsmaßnahmen und „Auflockerungen“ des historischen Stadtgefüges, sondern unter dem Stichwort der „Entschandelung“ auch Harmonisierungen des Stadtbildes durchgeführt: Fassaden wurden beispielsweise „entstuckt“, also ihres Fassadendekors „entledigt“ - eine Maßnahme, die Parallelen zur „Hausreparatur“ in Wien vermuten lässt. Stadtbild wie Stadtgefüge wurden durch kommunale Sanierungsprogramme „korrigiert“. Ein Vergleich soll hier ebenfalls zu einer Einschätzung der Regulierungsund Stadterneuerungsmaßnahmen in Wien beitragen. 
Vorweg müssen allerdings noch einige allgemeine Beobachtungen zum Städtebau der 1930er-Jahre festgehalten und der Fokus also etwas erweitert werden. Die Stadterneuerung aus „hygienischen“, verkehrstechnischen und auch aus ästhetischen Gründen war ein Phänomen dieser Zeit, dessen Anfänge allerdings ins 19. Jahrhundert zurückreichen. In ganz Europa wurden Fragen der „Stadtgesundung“ - von den Disziplinen Städtebau und Denkmalpflege gleichermaßen - diskutiert und auch durchgeführt. Der Altstadt und ihrer Erhaltung wurde dabei unterschiedlich große Bedeutung beigemessen, oft war der Umgang mit der historischen Bausubstanz ungemein radikal.

Teilzerstörungen in den Altstädten begegnen in der Zwischenkriegszeit nicht allein in Diktaturen, sondern lagen laut Bodenschatz ,im internationalen Trend“ und wurden vor allem von Vertretern der internationalen Moderne befürwortet. ${ }^{9}$ Lampugnani verweist auf die bereits mit der Avantgardebewegung beginnende „Ablehnung“ der historischen Stadt im frühen 20. Jahrhundert und hier in erster Linie auf das Manifest der Futuristen von 1909, die gar zur Zerstörung der historischen Städte aufriefen. ${ }^{10}$ Seit den 1920er-Jahren wurden zum Teil äußerst radikale Stadtumbau- und Stadtregulierungskonzepte publiziert, wie Le Corbusiers Plan Voisin von 1925, demzufolge eine „Auflockerung“ der Pariser Innenstadt durch Hochhäuser mit kreuzförmigem Grundriss umgesetzt werden sollte, oder Ludwig Hilberseimers Vorschlag einer Neubebauung der Berliner Innenstadt mit Hochhauszeilen aus dem Jahr 1929. Derart radikale und ebenso utopische Visionen fanden in den 1930er-Jahren in StädtebauPublikationen auch Erwähnung, wie beispielsweise in Cesare Chiodis La città moderna. Tecnica urbanistica von 1935."1

Tagungen und Kongresse dienten dem internationalen Meinungsaustausch und der Diskussion neuer und alter Planungsmethoden und aktueller städtebaulicher Fragen zum Umgang mit der historischen Stadt. Wesentlich unter den internationalen Städtebaukongressen in diesen Jahren waren die Congrès Internationaux d'Architecture Moderne (CIAM, gegründet 1928) und die - heute weniger bekannten, aber weitaus größeren - Kongresse der International Federation of Housing and Town Planning (IFHTP) und des Internationalen Verbandes für Wohnungswesen.12 Letztere werden in diesem Kapitel noch öfters Erwähnung finden. Die CIAM sind im vorliegenden Zusammenhang weniger relevant und seien hier daher nur am Rande erwähnt, denn an sämtlichen Tagungen zwischen 1929 und 1936 war unter den Delegierten keine österreichische Landesgruppe vertreten. ${ }^{\mathbf{1 3}}$ Der Kongress CIAM IV im Jahr 1933 stand unter dem Thema „Die funktionelle Stadt“ und brachte als Ergebnis die Charta von Athen mit elementaren Grundsätzen für den zukünftigen Städtebau hervor. Im Vorfeld des Kongresses hatte man 33 Großstädte, darunter Rom, Berlin, Genf, Budapest und Prag, in einer systematischen Analyse untersucht und die Gleichartigkeit der städtebaulichen Probleme aufgezeigt, für die im Rahmen des Kongresses Lösungen gesucht werden sollten. ${ }^{\mathbf{1 4}}$ Die Diskussion der Stadtanalysen fand auf einem Passagierschiff mit insgesamt über 100 Teilnehmenden aus 16 Ländern statt. ${ }^{\mathbf{1 5}}$ Die in Folge ausgearbeitete Charta von Athen richtete ihre Forderungen nach einer stärkeren Belichtung, Belüftung und Unterteilung des Stadtraumes nach Funktionen entschieden gegen die historisch gewachsene, dicht bebaute Stadt und die dort vorzufindenden „ungeordneten“ Verhältnisse. Erstmals publiziert wurde die von Le Corbusier erweiterte und kommentierte Fassung der Charta von Athen allerdings erst 1943. ${ }^{\mathbf{1 6}} \mathrm{Im}$ Kongress von Paris im Jahr 1937, an dem aus Österreich lediglich Walter Loos teilnahm, wurden die Fragen der 
Stadtsanierung erneut aufgegriffen. ${ }^{\mathbf{1 7}}$ Von unmittelbaren Auswirkungen auf die Praxis in Österreich ist allerdings nicht auszugehen.

6.1 Die Altstadt als „gesamteuropäisches Problem“ für Städtebau und Denkmalpflege

Städtebau und Denkmalpflege befassten sich ab dem frühen 20. Jahrhundert gleichermaßen mit Fragen der Altstadterneuerung - mit mehr und weniger großem Interesse an der Erhaltung der historischen Stadt. Die erneute Aktualität der Altstadtsanierung und -regulierung in den späten 1920er- und beginnenden 1930er-Jahren wird anhand der Themen der Städtebaukongresse deutlich. Laut Albers waren die Kongresse des Internationalen Verbandes für Wohnungswesen und Städtebau (IFHTP) in den 1920erund 1930er-Jahren hier ,gewiss die wichtigste und wirksamste Plattform für den Austausch" zwischen den Ländern. ${ }^{\mathbf{1 8}}$

Der im Jahr 1929 von der IFHTP veranstaltete Internationale Wohnungs- und Städtebaukongress in Rom ${ }^{\mathbf{1 9}}$ widmete sich, ebenso wie jener in Berlin ${ }^{\mathbf{2 0}}$ zwei Jahre später, Fragen zur Zukunft und zum planerischen Umgang mit der historischen Stadt. ${ }^{21}$ Die im Rahmen des Kongresses in Rom von Marcello Piacentini geleitete Sektion zur „Neuplanung alter und historischer Städte im Rahmen moderner Verhältnisse“ und die zahlreichen Länderberichte zeigen auf, dass in Europa Altstadtsanierungen vorrangig als eine kommunale, von der Gemeinde gelenkte Maßnahme durchgeführt wurden. Die Gemeinde erwarb oder enteignete Grundstücke und zum Abbruch bestimmte Objekte und realisierte eine Neubebauung nach einem einheitlichen Plan. ${ }^{22}$

Aufbauend auf dem 1931 in Berlin abgehaltenen Kongress und der begleitenden Internationalen Ausstellung für Städtebau und Wohnungswesen versuchte eine Publikation des Deutschen Vereins für Wohnungsreform von 1935 eine ebenfalls umfangreiche Darstellung internationaler Positionen und aktueller Aufgaben des Städtebaus. Auch anhand dieses Kompendiums, mit Berichten und Beispielen von den USA über China bis Europa, wird die Bedeutung des Themas der Altstadtsanierung im europäischen Städtebau der 1930er-Jahre deutlich. ${ }^{23}$ Hierin findet man auch einen umfangreichen Bericht zum Städtebau und Wohnungswesen in Österreich, verfasst von Karl Heinrich Brunner, der an der Technischen Hochschule Wien bei Karl König und Karl Mayreder studiert und sich in den späten 1920er-Jahren in Südamerika einen Namen gemacht hatte. ${ }^{\mathbf{2 4}}$ Brunner berichtet in seinem vermutlich 1932 verfassten Text ausführlich über Regulierungsmaßnahmen in ganz Österreich, wobei er Wien nicht erwähnt, da hier „zufolge der wirtschaftlichen Not ein nahezu vollkommener Stillstand der Entwicklung“ eingetreten sei, sondern Graz, Salzburg und Steyr. ${ }^{25}$ Er berichtet von Maßnahmen mit überwiegender Rücksicht auf den historischen Bestand. In Salzburg liege „das Hauptaugenmerk der Baupflege auf der Erhaltung der architektonischen Struktur, der Proportionen und der charakteristischen Art des Stadtbildes“, während man in Steyr das „baukünstlerisch wertvolle Gesamtbild“ der Altstadt durch die Anlage von Umfahrungsstraßen erhalten habe.

Der 1935 in Prag vom Internationalen Verband für Wohnungswesen veranstaltete Kongress befasste sich erneut mit dem Thema der Altstadtsanierung. Der programmatische Titel „Elendsviertelsanierungen“ zeigt die in den Städtebaukreisen vorherrschende Auffassung, dass es sich bei den historischen Quartieren der Stadt in erster Linie um „unhygienische“ sowie sozial bedenkliche und städtebaulich rückständige Bereiche handle. Im Rahmen einer begleitenden Ausstellung wurden unterschiedliche 
1
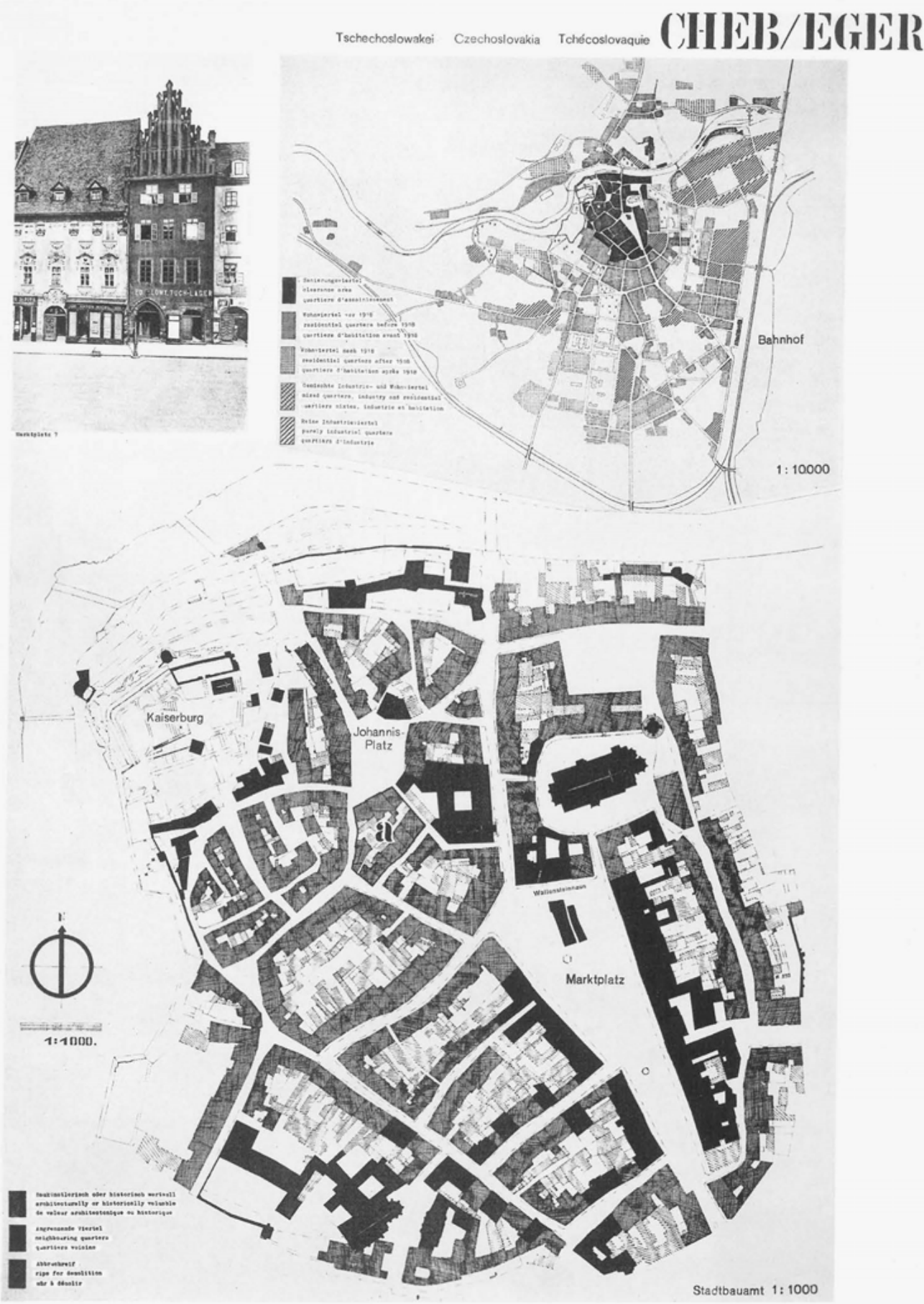

vor-und nachher before and after clearance avant et après l'assainissement

Abb. 96 Altstadtsanierung in Eger/Cheb (damalige Tschechoslowakei), Auskernung des Blockinneren, Publikation aus dem Jahr 1935 
Maßnahmen der Stadtsanierung aus 35 Städten vorgestellt und Kurzberichte dazu in einer Publikation festgehalten. ${ }^{\mathbf{2 6}}$ Diese Zusammenstellung verdeutlicht einmal mehr das zu diesem Zeitpunkt vorherrschende Interesse an der Lösung des „Problems Altstadt" und auch den Einfluss der Gesetzeslage und wirtschaftlichen Situation auf Umfang und Umsetzung der Sanierungen. Generalsekretär des Verbandes war damals Franz Schuster ${ }^{\mathbf{2 7}}$, überraschenderweise steuerte Österreich jedoch nur einen überschaubaren Beitrag zu Linz bei, der nicht einmal in den Textband aufgenommen wurde. Dass keine Wiener Beispiele angeführt wurden, mag daran liegen, dass die Assanierung zum Erhebungszeitpunkt 1934/35 noch nicht weit fortgeschritten war.

Unter den in der Ausstellung gezeigten geplanten oder abgeschlossenen Altstadtsanierungen waren hingegen zahlreiche Beispiele aus deutschen und skandinavischen Städten sowie aus London, Prag, Brünn und Rom. Veranschaulicht wurden die Eingriffe vor allem anhand eindrücklicher Vorher-nachher-Darstellungen im Stadtgrundriss und in Fotografien. In den dreisprachigen Erläuterungen (deutsch, englisch, französisch) werden die Ähnlichkeit der Herausforderungen und Probleme, denen sich die Stadtverwaltungen stellen mussten, deutlich. Die gezeigten Beispiele bilden eine große Bandbreite an Regulierungsmaßnahmen ab: von „sanfteren“ Methoden wie der Auslichtung der Altstadtstruktur (Abb. 96) bis hin zu radikalen Lösungen wie der Auflockerung oder gar Neustrukturierung ganzer Stadtbereiche (Abb. 97).

Die Materialsammlung für Ausstellung und Publikation erfolgte über den Versand von Fragebögen an maximal zwei Städte in allen Ländern. Erfragt wurden Informationen zur Gesetzeslage, zu den Enteignungsbestimmungen sowie die Organisation, die Finanzierung, die baukünstlerischen Grundsätze und die Probleme bei bisher durchgeführten Sanierungen. ${ }^{\mathbf{2 8}}$ Beispielhaft wurde von den Städten sodann Plan- und Bildmaterial zur Verfügung gestellt. Nicht überall hatte man allerdings Erfolg, wie Franz Schuster in seinem Vorwort erläutert - und die Vermutung liegt nahe, dass er damit auch auf Wien anspielte:

„Einige von ihnen, darunter Weltstädte, entschuldigten sich, nicht berichten zu können, da ihre neuen Sanierungsmaßnahmen wenig umfangreich oder erst am Anfang seien, andere konnten ihren Bericht erst zu so später Zeit in Aussicht stellen, daß sie leider nicht mehr berücksichtigt werden konnten.“29

Wie die Beiträge an den erwähnten Städtebaukongressen verdeutlichen, waren in den 1930er-Jahren planmäßig durchgeführte, kommunale, also von der Gemeinde veranlasste Altstadtsanierungen vorherrschend. Nach dem gezielten Ankauf von Objekten oder der Enteignung der Grund- bzw. Hausbesitzer durch die Gemeinde erfolgten Abbruch und Neubebauung. Letztere wurde von der Gemeinde oder von gemeinnützigen Baugesellschaften oder Genossenschaften übernommen, zumeist nach Zusammenlegung der Parzellen. So etwa in Amsterdam, Kopenhagen oder in Londoner Arbeitervierteln. In Brünn war hingegen eine planmäßige Durchführung der Assanierung aufgrund der „ungünstigen“ Gesetzeslage und dadurch langwieriger und kostspieliger Enteignungsverfahren nicht möglich. Wie in Wien lag die Regulierung dort vor allem in der Hand privater Eigentümer, Investoren und Baugesellschaften. ${ }^{\mathbf{3 0}}$

In direktem Zusammenhang mit der „Altstadt-Debatte“ stand die Frage des Wohnbaus und der Bewältigung der in den meisten Großstädten Europas vorherrschenden 
Wohnungsnot. Durch den Abriss historischer (Wohn-)Quartiere in den Stadtzentren stellte sich gleichzeitig auch das Problem des Baus von Ersatzwohnungen für die delogierten Mieter. Vor allem für die einkommensschwachen Schichten der Bevölkerung, die eben gerade die zum Abriss bestimmten Altstadtquartiere bewohnten, bestand ein Mangel an Kleinwohnungen. Die entscheidende Frage, ob hier die öffentliche Hand oder die Privatwirtschaft eingreifen solle, wurde etwa im Rahmen der Kongresse in Rom 1929 und vor allem in Berlin 1931 diskutiert. Die Stadt Wien unter der neuen christlich-sozialen Stadtregierung entschied sich 1934, nach der Realisierung des umfangreichen kommunalen Wohnbauprogrammes der 1920er-Jahre, für den privatwirtschaftlichen Weg, der allerdings keine Lösung des Problems herbeiführte. Als eines der wenigen Länder kehrte auch Finnland in den 1920er-Jahren zu einem vorrangig privatwirtschaftlichen Wohnbau zurück. ${ }^{31}$ In zahlreichen Länderberichten zu den genannten Städtebaukongressen wird hingegen auf die zwangsläufig notwendige Lenkung und Förderung des Wohnbaus durch die Gemeinden verwiesen, da der Bau von Kleinwohnungen für die Privatwirtschaft (auch aufgrund der Mietzinsregelung) schlichtweg nicht lukrativ genug sei.32

Nach einigen Jahren der Unterbrechung durch den Ersten Weltkrieg wurde in den späten 1920er-Jahren die Diskussion der Altstadtfragen auch durch die Denkmalpflege wiederaufgenommen und schließlich in den 1930er-Jahren intensiviert. Im Jahr 1928, als für zahlreiche deutsche Städte die Planung von „Gesundungsmaßnahmen“ bereits weit fortgeschritten war, ${ }^{\mathbf{3 3}}$ stand der Tag für Denkmalpflege und Heimatschutz in Würzburg und Nürnberg, an dem auch einige Mitarbeiter der Zentralstelle teilnahmen, ${ }^{\mathbf{3 4}}$ ganz im Zeichen des scheinbar ewigen Widerspruchs zwischen der „alten Stadt“ und der „neuen Zeit“. ${ }^{35} 1931$ hielt man in der Charta von Athen zur Restaurierung von historischen Denkmälern ${ }^{\mathbf{3 6}}$ erstmals denkmalpflegerische Richtlinien für den Umgang mit der historischen Stadt fest. Die Leitsätze waren Ergebnis des ersten Internationalen Kongresses der Architekten und Techniker in der Denkmalpflege. Die große Gruppe der Italiener an dieser Tagung war am Inhalt dieser ersten internationalen Übereinkunft zur Restaurierung maßgeblich beteiligt, allen voran Gustavo Giovannoni, von dem hier noch die Rede sein wird. ${ }^{\mathbf{3 7}}$ Bei Neubauten sollte der Charakter der Städte respektiert werden. Die Umgebung von Denkmalen, Ensembles und malerische Perspektiven bedürften ganz besonderer Sorge. ${ }^{\mathbf{3 8}}$

An der Tagung für Denkmalpflege und Heimatschutz 1933 in Kassel hielt Wilhelm Pinder schließlich seinen wegweisenden Vortrag über „Die Rettung der deutschen Altstadt", womit der Denkmalpflege basierend auf den Heimatschutzbestrebungen gleichsam der „offizielle Auftrag“ zum aktiven, „schöpferischen“ Mitwirken an der „Stadtgesundung" erteilt und neben der Verbesserung der Wohnverhältnisse auch die ästhetische Korrektur der Altstädte zum allgemeinen Ziel erklärt wurde (siehe dazu noch Kap. 6.3.2.). Die Zusammenkunft der Denkmalpfleger 1936 in Dresden stand ebenfalls ganz im Zeichen der Altstadt-Problematik und der Diskussion von Fragen der Sanierung und Verkehrsbewältigung. Die Tagung sollte allerdings keine wesentlichen neuen Erkenntnisse bringen, wie zumindest Karl Giannonis Abschlussbericht deutlich machen möchte. Seiner Einschätzung nach hätten die Referate der Dresdner Tagung kaum über die Ergebnisse der Tagung von 1928 hinausgereicht und lediglich interessante Beispiele gezeigt. Bewusst gemacht habe die Konferenz aber, dass sich „das Problem der Altstadt- 

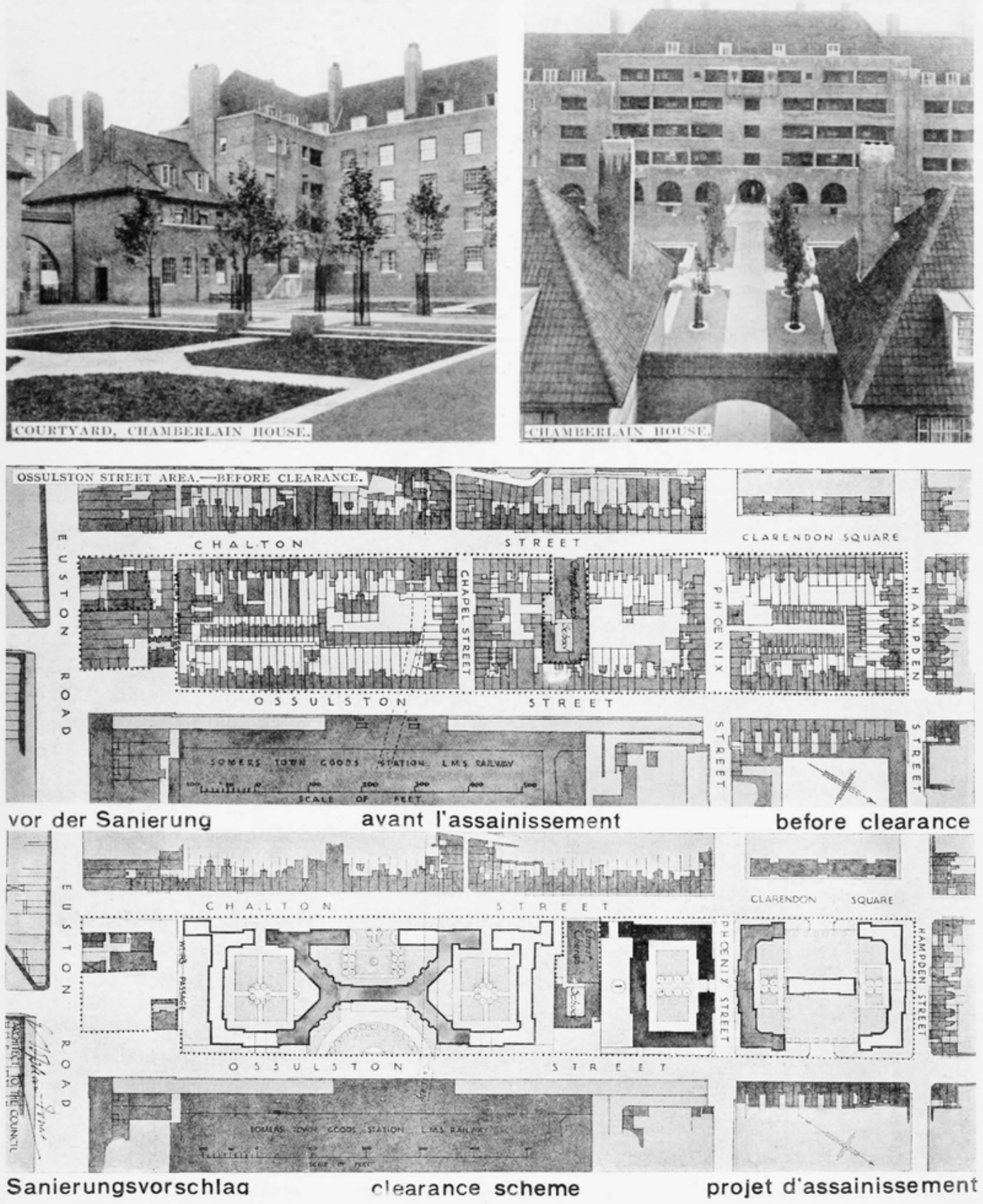
Sanierung immer mehr zu dem einer Verkehrssanierung auswächst und künftighin nur mehr mit Korreferaten [sic!] von Verkehrstechnikern behandelt werden sollte“.39

Ebenfalls in diesen Jahren erschienen umfangreiche Publikationen zum Thema der Altstadtsanierung aus dem Bereich der Denkmalpflege, nachdem sich Cornelius Gurlitt schon 1920 in seinem Handbuch des Städtebaues ${ }^{\mathbf{4 0}}$ mit dem Thema der Erhaltung und Umgestaltung des historischen Stadtkerns und ein Jahr später Otto Schilling $\mathbf{4 1}$ mit der Tradition des Stadtumbaus der damals jüngsten Vergangenheit befasst hatten. Die weitere Publikationstätigkeit zeigt die Präsenz des „Problems Altstadt“ im denkmalfachlichen Diskurs der 1930er-Jahre nicht nur im deutschsprachigen Raum. Der zuvor erwähnte Gustavo Giovannoni veröffentlichte 1931 seine bereits 1913 ausformulierte Theorie des diradamento als selbstständige Publikation zum Städtebau.42 Und Karl Kühns ${ }^{\mathbf{4 3}}$ Die schöne Altstadt. Ihr Schutz, Ihr Umbau, ihre Verbesserung, erschienen 1932, steht ebenso beispielhaft für diese Entwicklung. ${ }^{\mathbf{4 4}}$

Die Lösung des „Problems Altstadt“ nahm im Diskurs der 1930er-Jahre somit eine zentrale Rolle ein, für Stadtplaner und Architekten ebenso wie für Vertreter der (städtebaulichen) Denkmalpflege, wenngleich sie der Altstadtsubstanz und dem Stadtbild unterschiedlich große Bedeutung beimaßen. Der Umgang mit dem baulichen Erbe stellte in dieser komplexen Diskussion nur eine Frage von vielen dar, neben jener der Verkehrslenkung, der Finanzierung, der Entschädigung der Enteigneten, der Umsiedelung der delogierten Mieter und der damit zusammenhängenden Errichtung von neuen Wohnbauten und Stadtrandsiedlungen und nicht zuletzt neben der Frage der Gestaltung der Neubauten im historischen Umfeld.

\subsection{Die „Gesundung“ der Altstädte im faschistischen Italien}

Vorweg lässt sich festhalten, dass die durchgeführten Maßnahmen der Altstadtsanierung in den 23 Jahren faschistischer Diktatur in Italien (1922-1945) weitaus umfangreicher waren als jene in Wien ab der Mitte der 1930er-Jahre. Nicht zuletzt aufgrund der zeitlichen Distanz - zum Beginn des Ständestaats erreichten die in den 1920er-Jahren anlaufenden Stadtumbaumaßnahmen des Faschismus bereits ihren Höhepunkt - stellt sich dennoch die Frage nach einer möglichen Vorbildfunktion des Städtebaus in Italien unter Mussolini für die Ereignisse in Wien. Der Vergleich der Entwicklungen gerade in den beiden Hauptstädten liegt nahe, wurde den städtebaulichen Maßnahmen in den jeweils bedeutendsten Städten des Landes doch besondere Relevanz und Dringlichkeit attestiert.

In den folgenden Ausführungen zum Stadtumbau in Rom wird vor allem auf die umfangreiche Studie von Harald Bodenschatz und Daniela Spiegel aus dem Jahr 2011 zurückgegriffen. 45

\subsection{1 „Freischaufeln“ und in Szene setzen}

In den trockengelegten Sümpfen der Küstenebene südwestlich von Rom wurden nach der Machtübernahme Mussolinis neue Städte aus dem Boden gestampft (Littoria, Sabaudia, Mussolinia u. a.), während man zahlreiche Altstädte im ganzen Land mittels städtebaulicher Maßnahmen an die moderne Zeit anzupassen versuchte. Diese umfassenden Regulierungs- und Erneuerungsmaßnahmen wurden sowohl in den Großstädten wie Rom, Mailand oder Bologna als auch in den kleineren Provinzstädten umgesetzt. Der Neubau „gesunder“ Wohnungen und die Erschließung über die Anlage neuer 


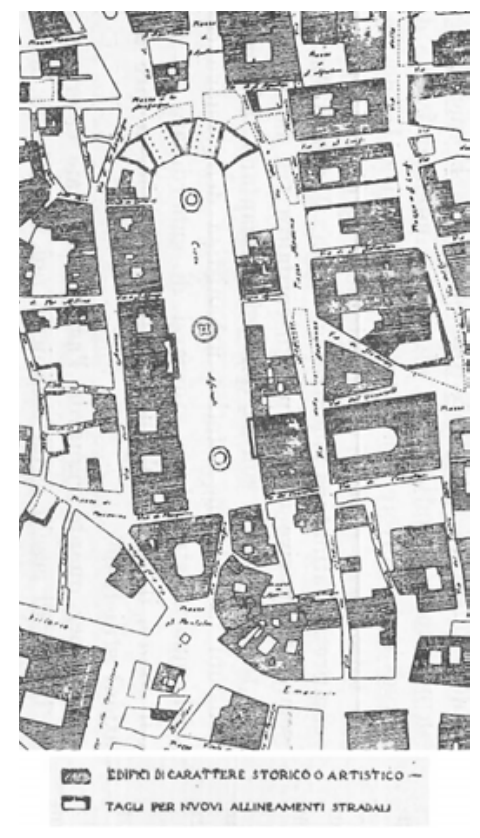

Abb. 98 Projekt eines diradamento im Renaissance-Quartier von Rom, Regulierungsabsichten für den Corso del Rinascimento, präsentiert im Rahmen des IFHTP-Kongresses in Rom 1929, Ausschnitt und Legende, durchgeführt ab April 1936
Verkehrsachsen ergänzten die „Sanierung“ ganzer Stadtviertel zu einem umfassenden städtebaulichen Konzept. ${ }^{46}$

Diese "Gesundung“ der Altstädte, die Beseitigung der „Elendsviertel“ und der dort vorherrschenden „unhygienischen Verhältnisse" stellte für den Faschismus eine besonders dringliche Aufgabe dar. Diese Maßnahmen des risanamento wurden mit staatlichen Mitteln gefördert, allerdings nicht überall mit derselben Vehemenz umgesetzt. Einerseits wurden mitunter weitläufige Gebiete in zahlreichen Altstädten abgerissen und neu aufgebaut. Andernorts verwies man auf die künstlerische oder historische Bedeutung bestimmter Altstadtbereiche, deren charakteristische Bebauung und Baudenkmale „unter allen Umständen“ zu erhalten wären. ${ }^{47}$

Um „das alte Stadtdickicht dem modernen Leben anzupassen“48, sollten nur gezielte Abbrüche durchgeführt und in den Hinterhöfen Anbauten entfernt werden, nach der Methode der „Stadtbild-Restaurierung“ Gustavo Giovannonis, die er unter dem Begriff des diradamento ${ }^{\mathbf{4 9}}$ bereits rund zehn Jahre vor der faschistischen Machtergreifung formuliert hatte (Abb. 98). In Altstadtbereichen von hoher künstlerischer und geschichtlicher Bedeutung sollte "aufgelockert“ und Licht und Luft in die Stadt gebracht werden, ohne dabei die „charakteristischen Eigentümlichkeiten“ und die „städtebauliche Einheit" zu zerstören.50 Durch die Anlage von neuen, notwendigen Verbindungsstraßen und kleinen Plätzen sollte unter „Wahrung des besonderen stadtbildlichen Charakters“ wieder ein „organisch gegliedertes, gefälliges Ganzes“ entstehen. ${ }^{\mathbf{5 1}}$

Gustavo Giovannoni war Denkmalpfleger und Architekt und nahm in der Theorie und Entwicklung des italienischen Städtebaus im frühen 20. Jahrhundert bis in die 1930er-Jahre eine zentrale Rolle ein.52 Für Mussolini zählte er, wie auch „Staatsarchitekt" Marcello Piacentini, zu den regimetreuen Architekten. ${ }^{53}$ Giovannoni argumentierte vehement gegen die noch immer übliche Methode der Freistellung von Monumentalbauten und führte den Begriff des ambiente in den städtebaulichen und denkmalpflegerischen Diskurs ein, womit er dem städtischen Ensemble, als zusammengehörige bauliche Einheit, künstlerische Bedeutung zuerkannte. ${ }^{\mathbf{5 4}}$ Er trat für eine "erhaltende Stadterneuerung" ein und kritisierte die im Faschismus häufig praktizierte, radikale Maßnahme des sventramento („Ausweiden“). 55

Mit seiner Methode der „Auflockerung“ dicht bebauter, „unhygienischer“ Altstadtviertel (diradamento) konnten Stadt- und Straßenbilder bewahrt werden, da sich die Abbruchmaßnahmen auf das Blockinnere oder weniger bedeutsame historische Bauten beschränkte. Nach Giovannonis Konzept sollte eine bessere Belichtung und Belüftung der Häuser nicht durch den radikalen Durchbruch neuer, monotoner Straßen durch die Altstadt bewerkstelligt werden, sondern durch ein allargamento irregolare der Stadtstruktur. Dafür war im Vorfeld, auf Basis einer genauen Kenntnis der Geschichte und Kultur der Stadt, eine detaillierte Analyse und gewissenhafte Bewertung des 
Bestandes erforderlich. ${ }^{\mathbf{5 6}}$ Giovannonis Methode zielte also nicht auf die Herstellung geradliniger Straßenverläufe und einheitlicher Straßenzüge ab, sondern beabsichtigte eine bessere Durchlüftung der dicht bebauten Altstadt durch gezielte Abbrüche weniger bedeutsamer Bauten und die Beschränkung von Neubauten auf ein Mindestmaß.57 Gleichzeitig konnten dadurch aber auch verkehrstechnische Probleme bewältigt und die „Erschließung“ bedeutender historischer Bauwerke ermöglicht werden. Es handelte sich somit um eine die Verkehrs- und Wohnverhältnisse verbessernde Methode, die den bedeutsamen historischen Baubestand weitgehend unangetastet ließ. Als eines „der größten und lehrreichsten Beispiele“ für eine vorbildliche Umsetzung des diradamento galt der Durchbruch des Corso del Rinascimento in Rom (Abb. 99).58

In Rom, der wichtigsten Stadt für den Faschismus, wurden in den 1920er- und 1930erJahren Abbruchmaßnahmen von unvergleichbarem Ausmaß durchgeführt ${ }^{\mathbf{5 9}}$ - einerseits, um unhygienische Stadtviertel zu entfernen, und andererseits, um die antiken Zeugnisse sichtbar zu machen und nahezu museal zu präsentieren (Abb. 100). Das Bild von Rom durchlief in der Ära des Faschismus dabei einen entscheidenden Wandel, der mit städtebaulichen Maßnahmen einherging. In den frühen Jahren des Faschismus galt Rom als Inbegriff für Korruption und soziale Missstände. ${ }^{60}$ Zwar war Rom seit 1871 Hauptstadt Italiens, aber bei der Machtübernahme durch Mussolini immer noch nicht als solche anerkannt. ${ }^{\mathbf{6 1}}$ Die neue Hauptstadt Rom, auch Terza Roma genannt, sollte als solche ausgebaut und erneuert, an die große Vergangenheit der Stadt der römischen Antike und der Päpste anknüpfen und auch wieder zur bedeutendsten Stadt des Landes aufsteigen. ${ }^{62}$ Die imperiale, römische Vergangenheit wurde durch den Faschismus mythisch aufgeladen und diese sogenannte Romanità als Leitkultur und gesellschaftliches Ideal für die eigenen Ziele vereinnahmt (Romanità fascista). Der Rückgriff auf die antike Vergangenheit wird in der Architektur durch eine entsprechende Gestaltung und Symbolik besonders deutlich, worauf später noch eingegangen wird. Diese Anleihen dienten der Vermittlung von Kontinuität und der Legitimation des neuen Regimes. Die Stadt sollte dabei nicht konserviert, sondern durch einen städtebaulichen Kraftakt erneuert werden, die Schätze der Antike freigelegt und als solche präsentiert werden. Das neue Rom sollte das alte noch übertreffen. ${ }^{63}$

Diese Freilegung der antiken Bauten und Ruinen, aber auch herausragender Bauten der darauffolgenden Epochen, wurde als Akt der Verbesserung und Aufwertung gesehen. Ihre gestärkte Präsenz im Stadtbild sollte „das faschistische Volk“ zu ähnlichen Leistungen anspornen oder diese noch übertreffen lassen. ${ }^{64}$ Die große Geschichte des römischen Imperiums wurde nun stolz zur Schau gestellt. Die Minderwertigkeit und den miserablen Zustand der dafür abgetragenen Altbauten betonte man in diesem Zusammenhang nur allzu gerne.65 Im Zuge der Erneuerung Roms wurden die „bedeutendsten Denkmäler der Römerzeit [...] von allem überflüssigen Beiwerk, das sich in Jahrhunderten angesammelt hatte, befreit und in den Kreislauf des modernen Lebens wieder eingeschaltet“.66 Auf den neu angelegten Prachtstraßen und Verkehrswegen im Herzen Roms, den „arterie della Roma di Mussolini“67, deren Bau „ein Gewimmel elender Häuser“68 beseitigt hatte, konnte man nunmehr die „offen gelegte“ Geschichte der Stadt und die Größe des Imperiums bewundern. Durch die Freilegung und die Erschließung vereinigte sich - so die Auffassung der Faschisten - das „Neue Rom“ mit dem antiken Rom. Und die Steine der Antike gewannen „vita e valore“ zurück.69 
1

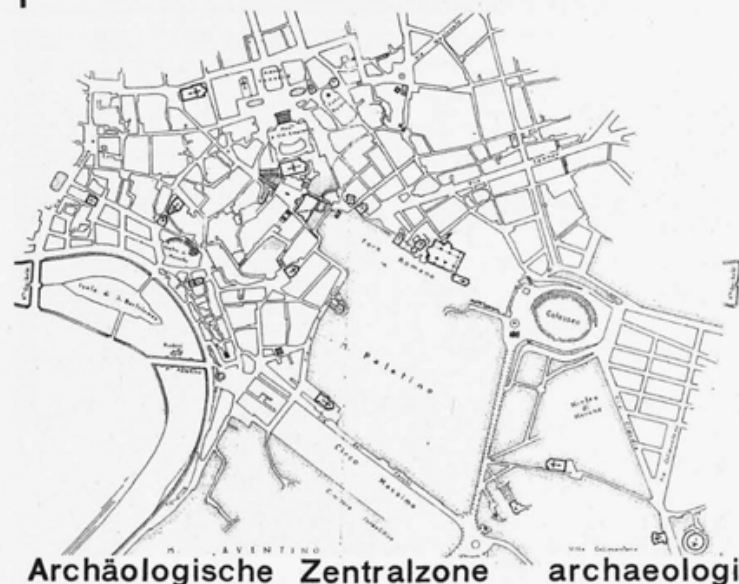

2

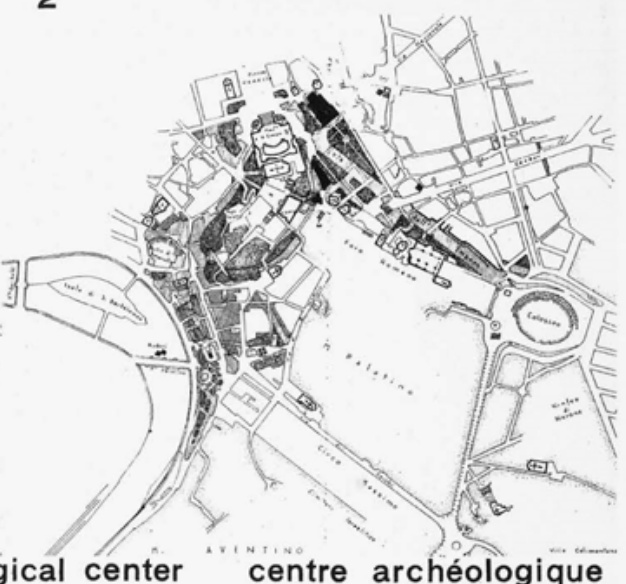

3

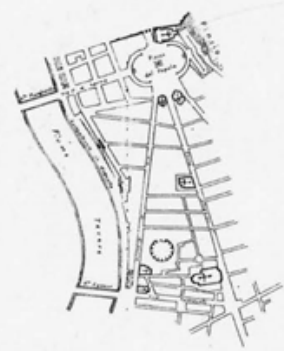

\section{„Augusteum “}

\section{5}

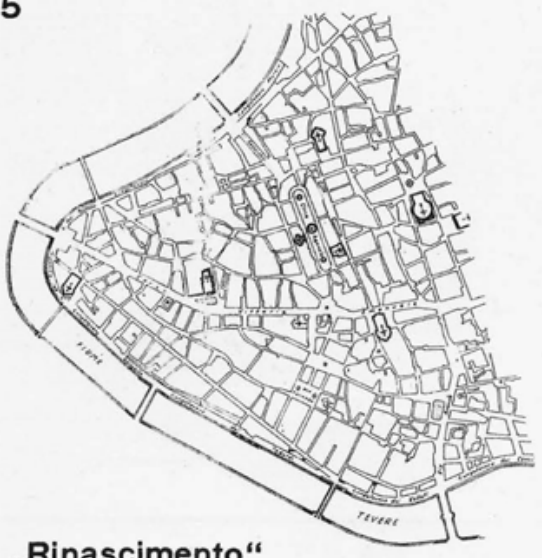

„Rinascimento“

vor der Sanierung before clearance avant l'assainissement
4

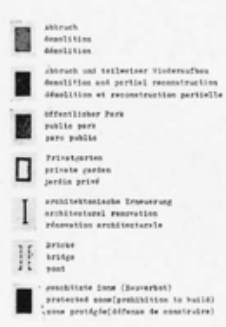




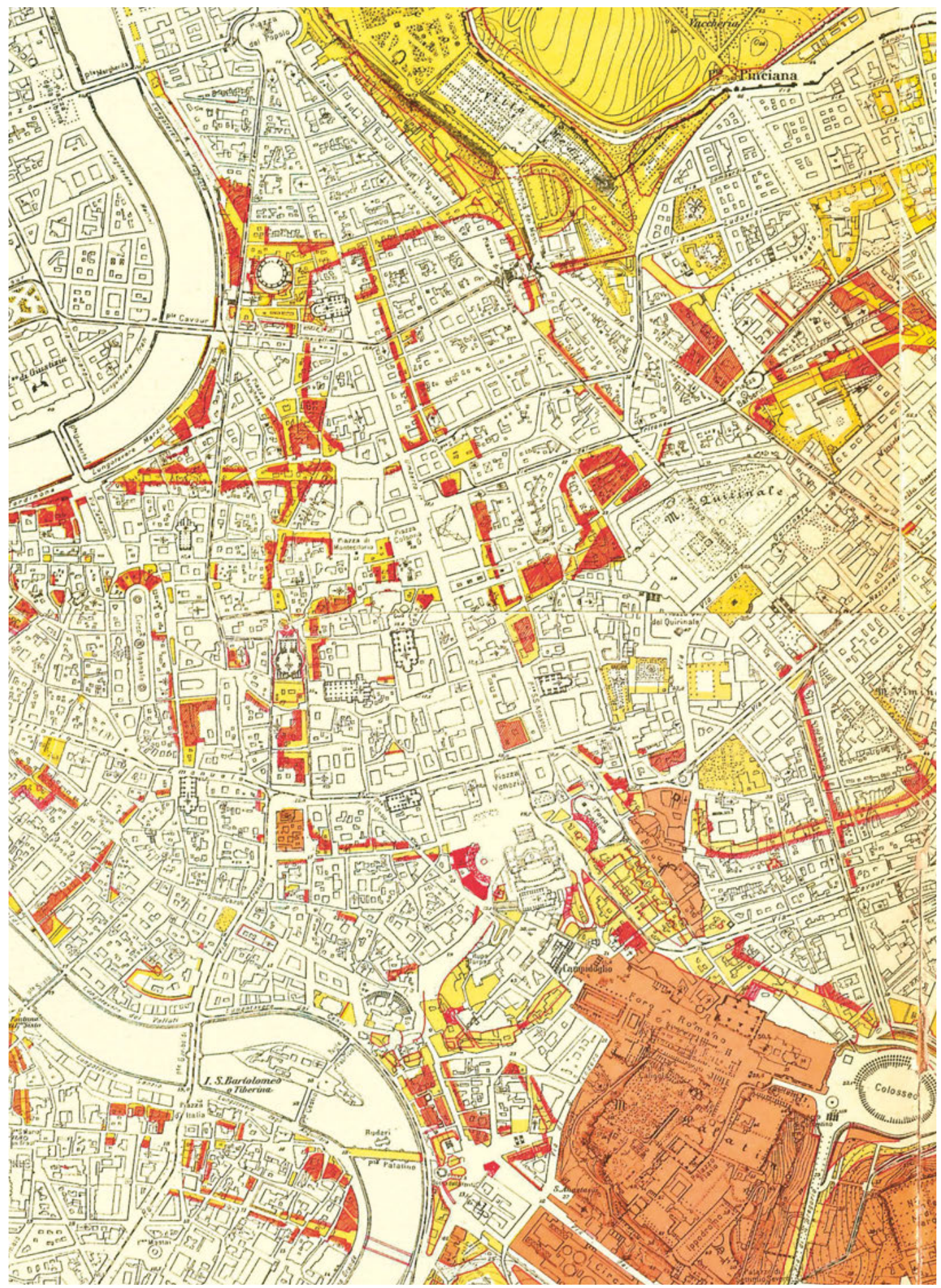

Abb.100 Ausschnitt aus dem Generalbebauungsplan für Rom mit den geplanten Regulierungsmaßnahmen (gelb die Ab- bzw. Durchbrüche, rot die vorgesehenen Neubauten, orange die Schutzzonen), 1931 


\subsection{2 „Im neuen Rom das alte Rom“}

Die städtebaulichen Eingriffe der 1920er- und 1930er-Jahre in der Altstadt Roms waren enorm und stellten, nach den radikalen Maßnahmen im späten 19. Jahrhundert, einen neuerlichen Höhepunkt der Demolierungstätigkeit dar. Der Freilegung antiker Monumente, ihrer „Befreiung“ von späteren Überbauungen, und der Umgestaltung des „Renaissance-Quartiers“ in der Tiberschleife wurde dabei besondere Aufmerksamkeit geschenkt. ${ }^{70}$

Seit 1873, zwei Jahre nach der Hauptstadtwerdung Roms, erstellte man Generalbebauungspläne für die „Ewige Stadt“ (Piano Regolatore Generale di Roma). Der letzte Plan vor der Machtergreifung Mussolinis aus dem Jahr 1909 wurde sodann bis in die 1920er-Jahre mehrfachen Revisionen unterzogen - durch eine eigens einberufene Kommission, der unter anderem Gustavo Giovannoni angehörte -, ohne allerdings zu einem Ergebnis und zu einem rechtsgültigen neuen Generalbebauungsplan ${ }^{\mathbf{7 1}}$ zu gelangen. ${ }^{\mathbf{7 2}}$ In diesem Punkt war man Wien also einen Schritt voraus, wo man erst in den späten 1930er-Jahren die Gründung einer Kommission zur Überprüfung des Generalregulierungsplanes andachte. Verabschiedet wurde der neue Generalbebauungsplan für Rom, erarbeitet vom Gruppo Urbanisti Romani, dem neben Piacentini auch ehemalige Schüler, wie Luigi Piccinato oder Cesare Valle, angehörten, schließlich im Jahr 1931 (Abb.100). ${ }^{\mathbf{7 3}} \mathrm{Er}$ enthielt zahlreiche der später durchgeführten Regulierungen, wurde aber nicht zur Gänze bzw. in abgeänderter Form und mit ergänzenden Planungen realisiert. ${ }^{\mathbf{7 4}}$ Der Vergleich mit dem Baualterplan der Stadt Rom zeigt die Abweichungen zwischen Planung und tatsächlicher Ausführung der Regulierungsmaßnahmen deutlich auf. ${ }^{75}$

Bereits in den 1920er-Jahren setzte die Freilegung archäologischer Zonen ein, die die Niederlegung ganzer Altstadtbereiche erforderlich machte. ${ }^{76}$ Schon ab 1924 erfolgten die Freilegungen der Trajansmärkte und mehrerer Tempel an der Piazza della Bocca della Verità sowie ab 1925 des Marcellus-Theaters. Zur Verbesserung der Verkehrssituation wurden erste Straßendurchbrüche im Osten der Altstadt durchgeführt. Bis Ende der 1920er-Jahre folgten weitere schwerwiegende Abbrüche großer Altstadtbereiche, etwa zwischen dem Altare della Patria (Denkmal für Vittorio Emanuele II.) an der Piazza Venezia und der Piazza della Bocca della Verità, denen vor allem die städtebaulich bedeutende Piazza d'Aracoeli am Fuße des Kapitols, trotz vehementen Protests Giovannonis, zum Opfer fiel (Abb.101). ${ }^{\mathbf{7 7}}$ Ebenfalls ab den späten 1920er-Jahren entfernte man die Altbauten um die Engelsburg und umfasste das symbolträchtige Gebäude mit einer weitläufigen Parkanlage. ${ }^{\mathbf{7 8}}$

In den frühen 1930er-Jahren wurden der Umbau der Altstadt und die Freilegung der antiken Monumente weiterverfolgt, während die Verkehrsmaßnahmen zunehmende Bedeutung erhielten. ${ }^{\mathbf{7 9}}$ Die Abbrucharbeiten für die 30 Meter breite „Prachtstraße“Via dell'Impero starteten 1930 (Abb. 102). Gemeinsam mit den das antike „Herz“ Roms umfassenden Straßen um das Kolosseum, den Kapitolshügel und den Circus Maximus ${ }^{\mathbf{8 0}}$ wurden dadurch bis 1933 dem Verkehr neue Dimensionen ermöglicht, gleichzeitig die antike Geschichte „herausgeschält“ und das neue Zentrum der Stadt, die Piazza Venezia, hervorgehoben.

In den späten 1930er-Jahren trieb man die Regulierung der Altstadt weiter voran mit der Anlage des „Kultplatzes“ um das Augustus-Mausoleum (ab Oktober 1934), dem 


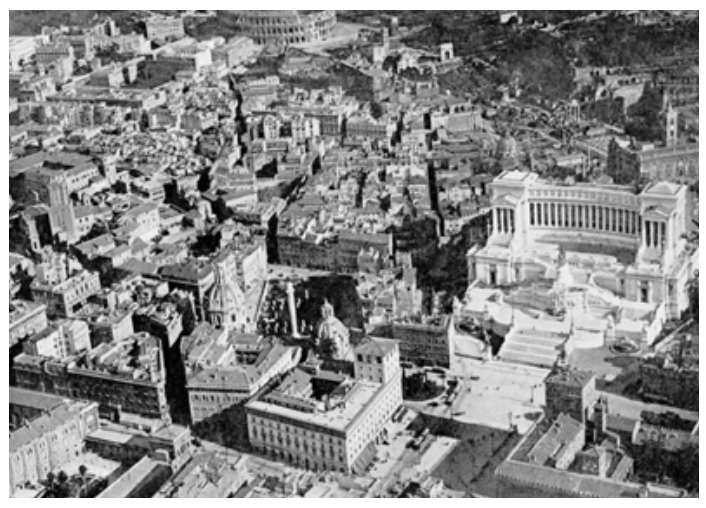

Abb.101 Gebiet um das Denkmal für Vittorio Emanuele II., Blick Richtung Kolosseum, vor dem Beginn der Abbrucharbeiten, Luftbild, vermutlich vor 1930

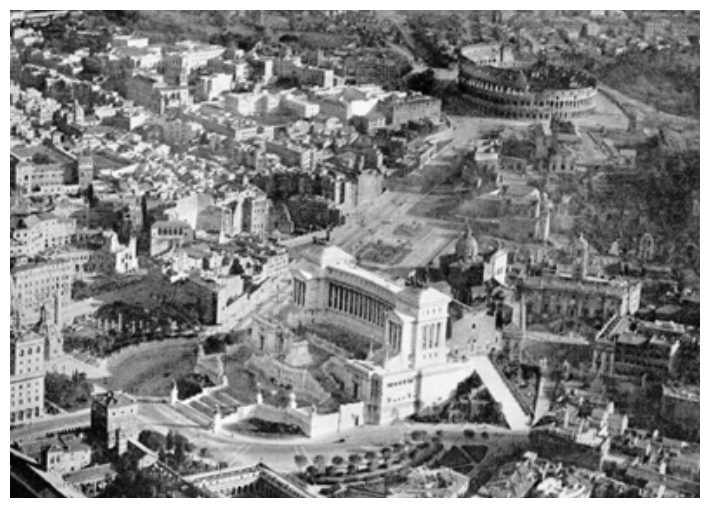

Abb.102 Neu angelegte Via dell'Impero, Luftbild, vermutlich 1933

Corso del Rinascimento samt Abbruch des nördlichen Platzendes der Piazza Navona, der Zerstörung kleiner Plätze und Gassen (ab April 1936) und dem Durchbruch und der neobarocken Ausgestaltung der Via della Conciliazione zwischen Engelsburg und Petersdom (ab Oktober 1936). ${ }^{\mathbf{8 1}}$

Die Altstadtregulierungen in Rom zeigen kein einheitliches Bild, wie auch generell im Umgang mit der historischen Stadt im Faschismus mit dem - seltener eingesetzten - diradamento und der radikaleren Variante des sventramento zwei unterschiedliche Methoden angewandt wurden. Die folgenden Beispiele sollen diese Zweigleisigkeit im Umgang mit der historischen Stadt nochmals verdeutlichen. Die sanftere Methode des diradamento wurde bei „Elendsvierteln“ ohne „Elemente von geschichtlichem, künstlerischem, monumentalem Wert“ und in den Fällen, wo man „dringliche Verkehrsgründe“ ortete oder wirtschaftliche Beweggründe für einen Abbruch sprachen, als „ungenügend“ erachtet. ${ }^{\mathbf{2}}$ So setzte man bei der Anlage der Vie Imperiali in Rom oder der Neugestaltung der Piazza della Vittoria in Brescia nach Plänen von Marcello Piacentini die rigorosere Form des sventramento ein.83 Durchbrüche sollten sich nach Möglichkeit jedoch auf jene Stadtviertel beschränken, „die schlechte hygienische Bedingungen und wenig oder gar keine historischen Denkmäler besaßen“.84

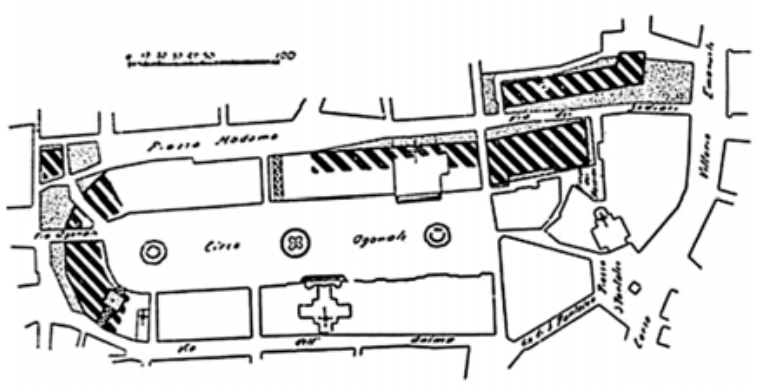

Abb.103 Arnaldo Foschini, Regulierungsplan für die Anlage des Corso del Rinascimento, 1935

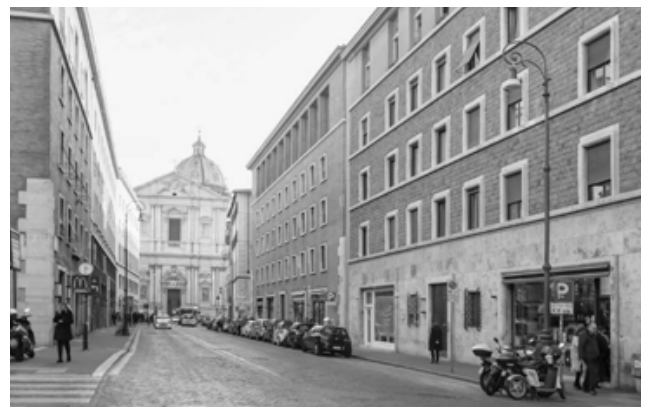

Abb.104 Rom, Neubauten der 1930er-Jahre am Corso del Rinascimento mit Blick Richtung Sant'Andrea della Valle, Aufnahme Dezember 2019 
Letzteres blieb allerdings lediglich ein guter Vorsatz, zumeist musste man doch „ins lebende Fleisch des Stadtbildes schneiden [...], um dem Verkehr die notwendige Bewegungsfreiheit zu geben".85

Die Analyse der Abbrüche führt gezwungenermaßen zur Frage nach der Gestaltung der realisierten Neubauten. Die ergänzenden Bauten an den neu gezogenen Straßen wurden zum Großteil in formaler Anpassung an die Umgebung gestaltet, etwa durch die Angleichung der Gesimshöhe und der Materialien an die umgebende Bebauung. ${ }^{\mathbf{8 6}}$ Als eines der besten Beispiele hierfür erscheint der bereits

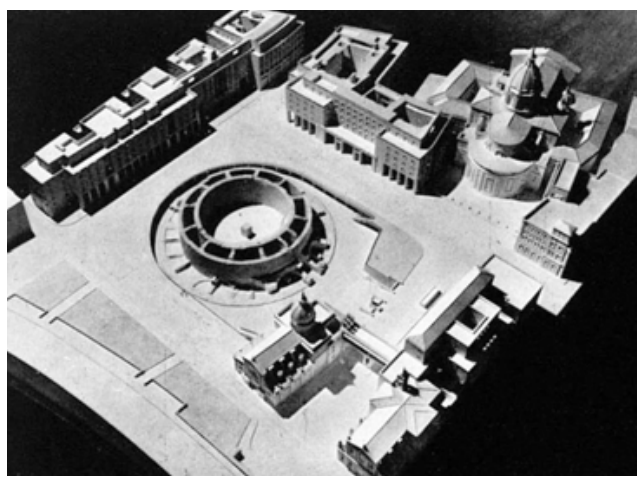

Abb. 105 Vittorio Morpurgo, Modell des ersten Projektes zur Freilegung des Augustus-Mausoleums in der Zeitschrift Architettura, 1936 erwähnte Corso del Rinascimento. ${ }^{\mathbf{8 7}}$ Die Regulierung betraf hier vor allem den südlichen Teil des Straßenzuges zwischen dem Palazzo Madama und der Kirche Sant'Andrea della Valle und äußerte sich vor allem in - zumindest heute - unscheinbaren Neubauten (Abb.103,104). Die Anlage der Verbindungsstraße zum Corso Vittorio Emanuele und die angrenzenden Neubauten entstanden nach einem städtebaulichen Gesamtkonzept und Entwürfen von Arnaldo Foschini. ${ }^{\mathbf{8 8}}$ Durch die angemessenen Dimensionen der Neubauten und die Farbigkeit und Beschaffenheit traditioneller Baustoffe (v. a. Ziegel, Putz, Travertin) wird kein ästhetischer Bruch erzeugt. Augenfällig sind bei den hier realisierten Neubauten die markanten Fensterrahmen, die ausladenden Kranzgesimse und das zur Zeit des Faschismus sehr häufig auftretende Zusammenziehen der Fensterachsen und ihr Abrücken von den Gebäudekanten. Durch den entstehenden starken Kontrast zwischen Wandfläche und Wandöffnungen wird eine Massivität der Konstruktion suggeriert und damit Beständigkeit symbolisiert.

Im Gegensatz dazu sollte die Platzrandbebauung um das „herausgeschälte“ Augustus-Mausoleum als faschistische „Rahmenarchitektur“ für das antike Monument wirken und einen bewussten Kontrast zur umliegenden Altstadt setzen (Abb. 105-107). Zwar sind die Gebäude, geplant von Vittorio Morpurgo, in ihrer Materialität der Umgebung verbunden, aber vor allem durch ihre Monumentalität, verursacht durch die

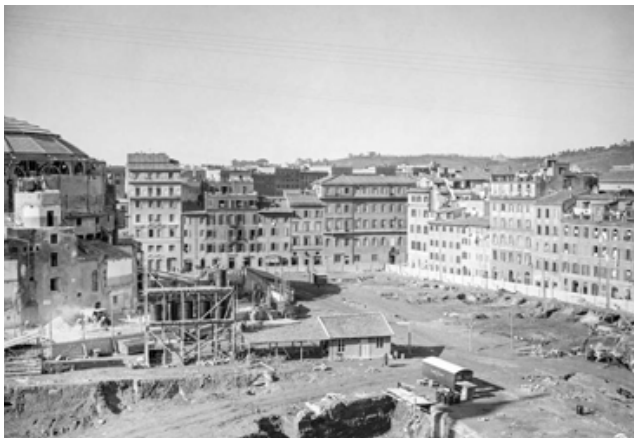

Abb.106 Piazza Augusto Imperatore, während der Abbruch- und Freilegungsarbeiten, Jänner 1937

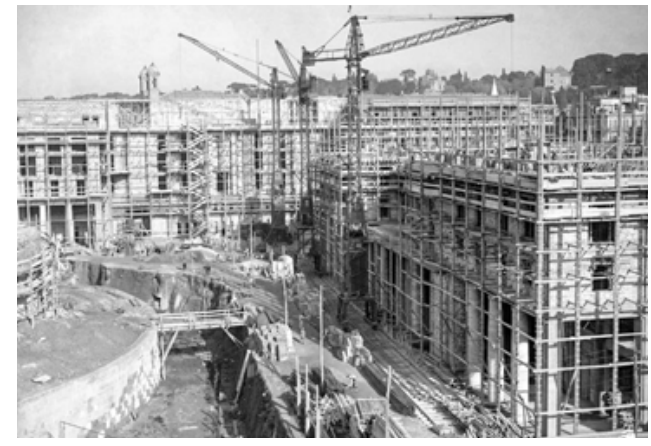

Abb.107 Piazza Augusto Imperatore, Baustelle der angrenzenden Neubauten, November 1938 


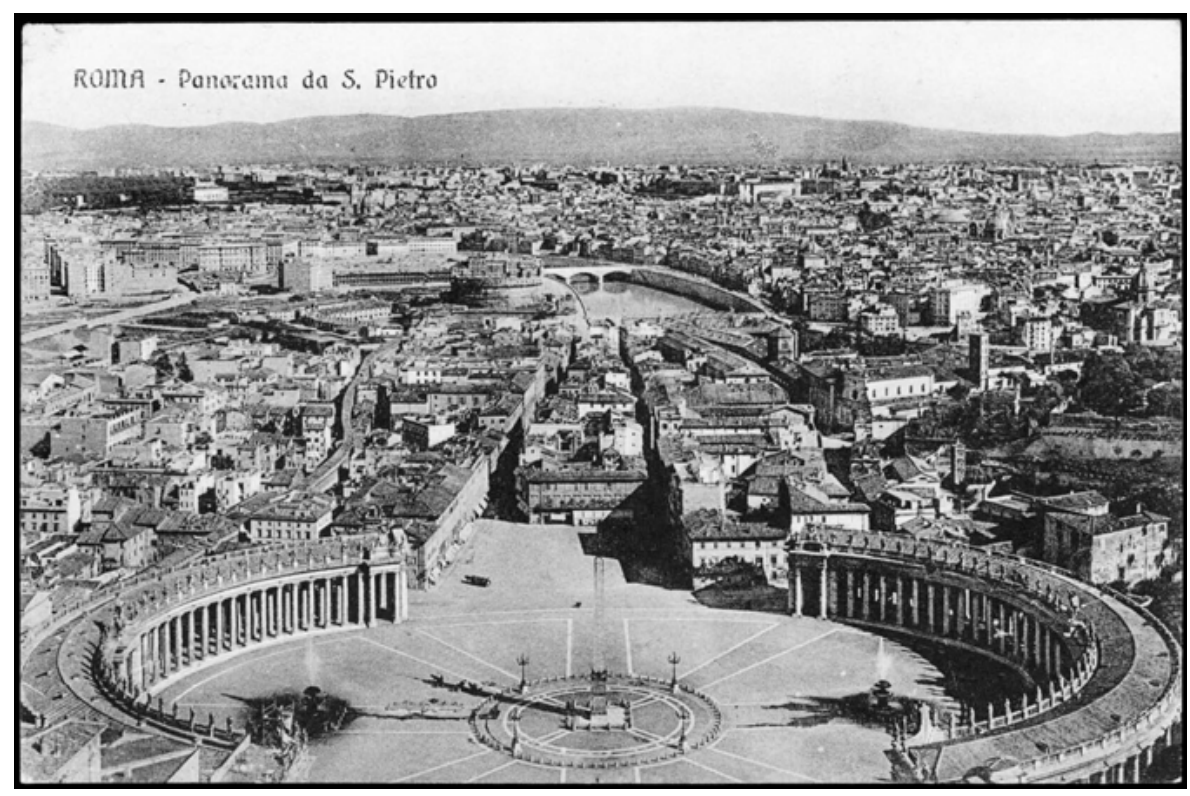

Abb.108 Blick vom Petersdom Richtung Engelsburg über den Borgo und die sogenannte Spina vor der Anlage der Via della Conciliazione, Postkarte, 1914

Zusammenfassung der Parzellen, die großen Baumassen und die überdimensionierten Arkadengänge, erzeugen sie eine deutliche Zäsur.

Ebenso wie Rundfunk und Film war die Architektur für den italienischen Faschismus ein „massenwirksames Medium“, um die Größe und die Leistungen des Regimes zu verdeutlichen, ${ }^{\mathbf{8 9}}$ laut Mattioli ein „Instrument nonverbaler Kommunikation“90. Der Rückbezug auf die glorreiche, imperiale Vergangenheit und die Anspielungen auf die Antike äußerten sich in der Architektur in unterschiedlicher Art und Ausprägung - besonders explizit bei Repräsentationsbauten: in der Wahl der Raumform und der Monumentalität der Gebäude, in der städtebaulichen Lage der Gebäude zueinander (zumeist in eine symmetrische Gesamtkonzeption eingepasst) ${ }^{\mathbf{9}}$, in bisweilen stark abstrahierten Zitaten antiker Bauelemente (Zahnschnittmotiv bei ausladenden Kranzgesimsen, Säulenreihen etc.) bis hin zur Verwendung traditioneller Baustoffe (Ziegel, Travertin,

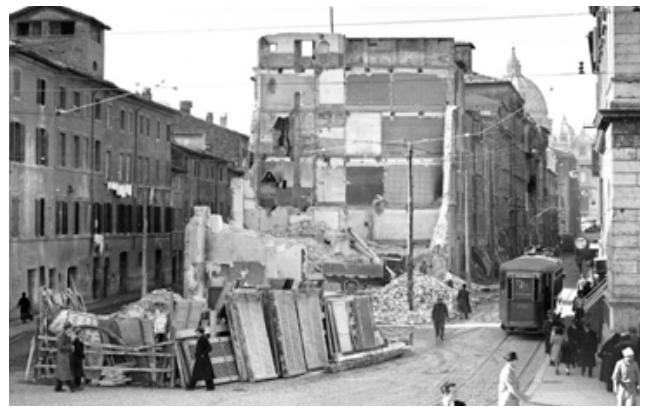

Abb.109 Beginn der Abbrucharbeiten an der Spina zur Anlage der Via della Conciliazione, im Hintergrund der Petersdom, Jänner 1937
Marmor etc.) und bestimmter Ziegelstrukturen an den Fassaden (opus testaceum nachahmend). Anhand der Neubauten um das Augustus-Mausoleum wird nicht nur die Vorliebe für Monumentalkomplexe, sondern auch die Rolle des Fassadenschmucks deutlich. Mal expliziter, mal abstrakter in der Form, bediente man sich einer entsprechenden Symbolik, angelehnt an die römische Antike. Sehr häufig begegnet das Liktorenbündel (fascio littorio), Symbol für die Unbesiegbarkeit der römischen Legionen und nun Sinnbild für die Revolution.92 Daneben findet man vor allem an staatlichen 


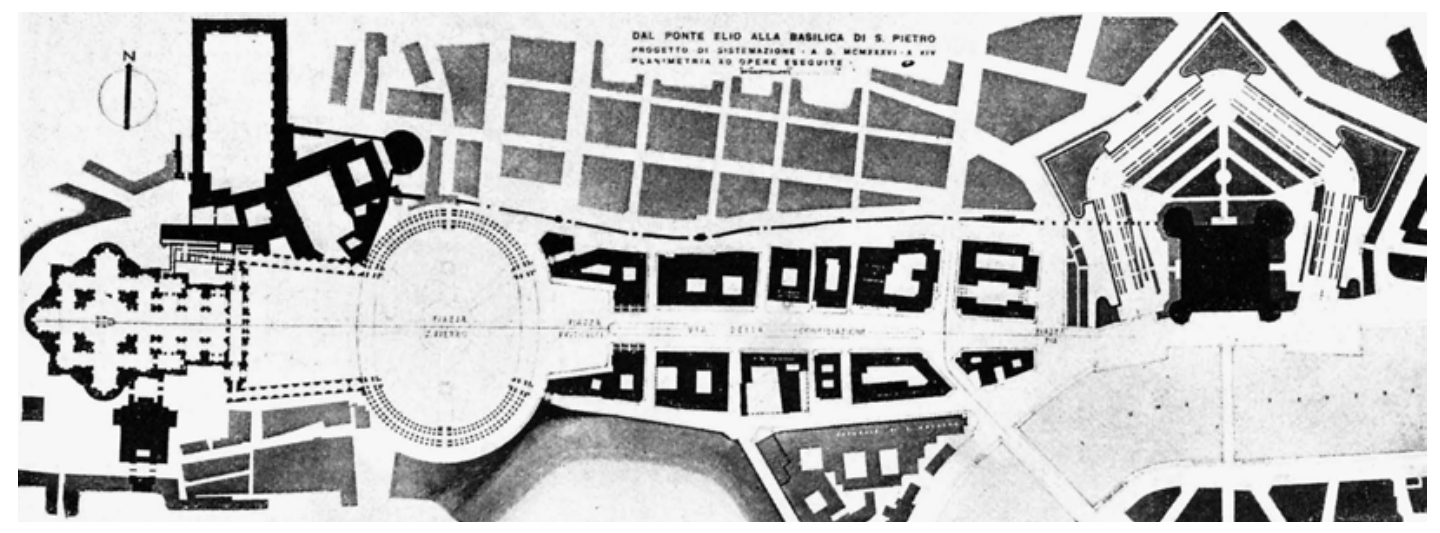

Abb.110 Marcello Piacentini und Attilio Spaccarelli, Ausführungsentwurf, 1936

Repräsentationsgebäuden Figurenschmuck, Reliefs und Wandbilder in klassizistischer Manier und häufig überdimensionale Schriftzüge mit leicht verständlichen Botschaften. Die Neubauten von Morpurgo schufen durch Einsatz dieser Symbolik und Architektursprache einen architektonischen Rahmen für das freigelegte Mausoleum und die Inszenierung Mussolinis als vermeintlich legitimen Nachfolger des römischen Kaisers Augustus. ${ }^{93}$

Im Zusammenhang mit der Frage nach der Gestaltung der Neubauten in den Sanierungsgebieten sei hier nochmals der Durchbruch der Via della Conciliazione erwähnt. Die triumphale Achse, ausgerichtet auf die Hauptfront des Petersdoms, machte den Abbruch eines lang gestreckten Altstadtensembles (die sogenannte Spina, Abb. 108) erforderlich. Trotz großer Proteste und kritischer Stimmen, vor allem jener von Gustavo Giovannoni, wurde diese „Radikalsanierung“ umgesetzt. Zahlreiche Enteignungen waren auch hier notwendig. Den Abbruch rechtfertigte man wiederum mit den „ungesunden“ Wohnverhältnissen in den historischen Gebäuden. Der Umbau des Altstadtbereiches erfolgte nach Plänen von Marcello Piacentini und Attilio Spaccarelli, die am Ende der breit angelegten, auf den Petersdom zulaufenden Achse einen monumentalen Übergang zum Petersplatz und zu Berninis Kolonnaden realisierten (Abb.109, 110).94 Eine „barocke Idee“ wurde hier mit einer relativ unscheinbaren, wenn auch monumentalen, historisierenden Architektur (zum Teil Rekonstruktionen an veränderten Standorten) ${ }^{\mathbf{9 5}}$ entlang eines neu ange-

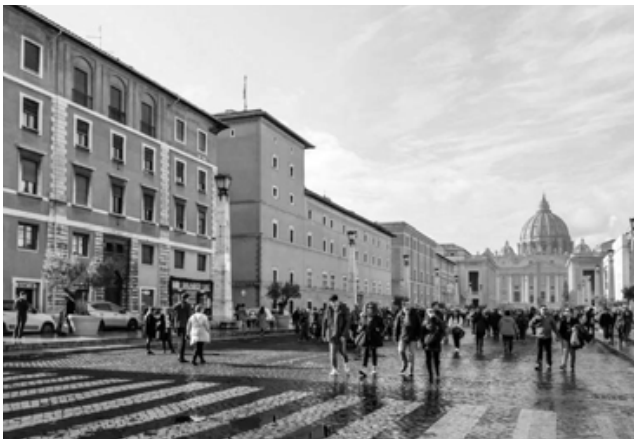

Abb.111 Rom, Neubauten der 1930er-Jahre an der Via della Conciliazione, Aufnahme Dezember 2019 legten Straßenzugs umgesetzt. Die Neubauten entsprechen der traditionalistischen Linie der faschistischen Architektur, die vor allem für staatliche Repräsentationsbauten bevorzugt wurde. ${ }^{96}$ Vor allem durch ihre Dimensionen heben sie sich von der umgebenden Altstadt ab (Abb.111).

Auch in zahlreichen anderen italienischen Städten wurden ähnlich radikale Eingriffe in die Struktur und Gestalt der Altstadt getätigt. Bestes Beispiel dafür ist wohl die Anlage der 


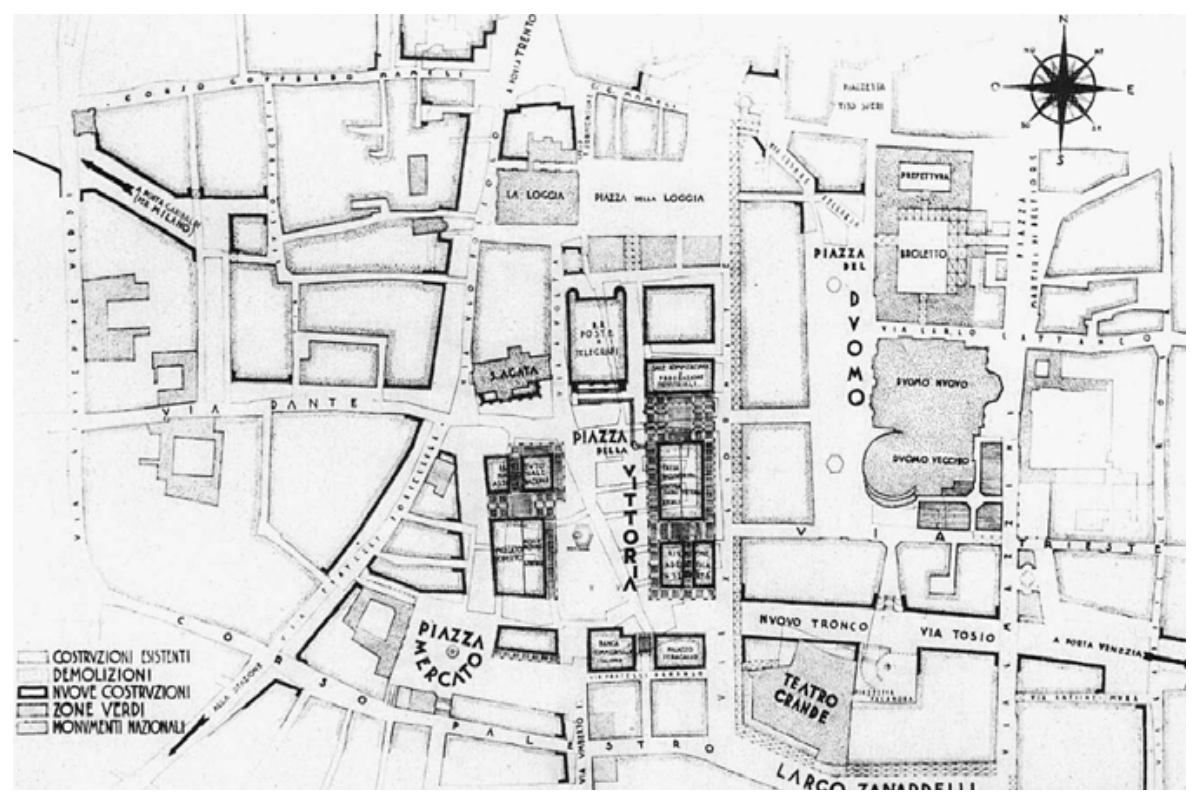

Abb. 112 Marcello Piacentini, Altstadt von Brescia im Grundriss mit der neuen Piazza della Vittoria, in einer Publikation von 1933

Piazza della Vittoria im Zentrum von Brescia mit ihren angrenzenden, überdimensionalen Neubauten (Abb.112,113). Sie entstand im Auftrag der Kommune und wiederum nach einem städtebaulichen und architektonischen Gesamtkonzept Marcello Piacentinis. ${ }^{97}$ In Brescia erfolgte nur eine bedingte Einbindung des „Neuen“ in das „Alte“. Nicht ohne Grund bezeichnete man den Platz und seine angrenzenden Bauten als „nuovo elemento urbanistico inserito nella città vecchia“98 (Abb.114). Im Stadtgrundriss schaffte man durchaus eine Verbindung der neuen Platzanlage mit der historischen Umgebung. In der dritten Dimension erfolgt jedoch eine bewusste formale Zäsur, auch wenn Piacentini durch die Auflösung der Erdgeschosswand mit Arkadengängen und abstrahierten „Palladio-Motiven“ an die norditalienische Architekturtradition anknüpfte.

Auch den Umbaumaßnahmen im historischen Zentrum von Brescia gingen, nach Festlegung von Bebauungs- und Sanierungsplänen, Enteignungen und Umsiedlungen

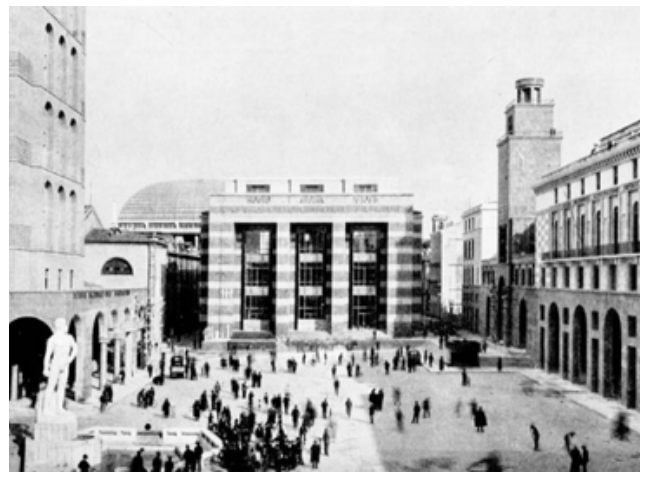

Abb.113 Brescia, die neue Piazza della Vittoria, vor 1935

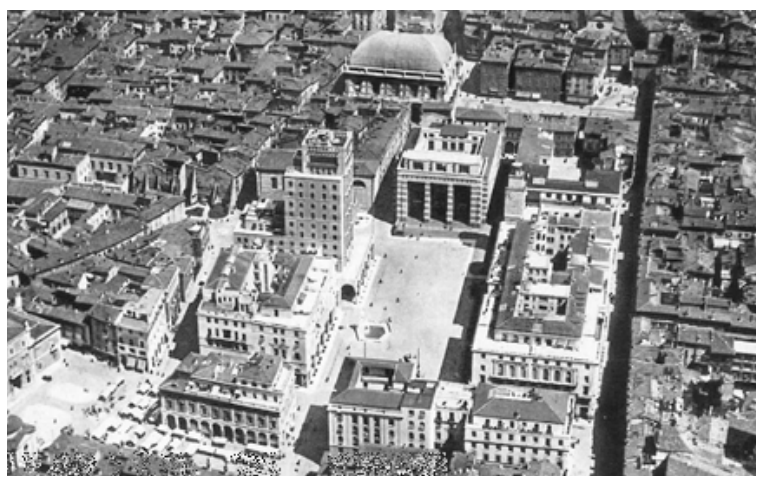

Abb. 114 Brescia, Piazza della Vittoria, Aufnahme vor 1937 
der dort lebenden Menschen voraus. Danach wurden die Grundstücke teils von der Stadtverwaltung selbst für Verwaltungs- und Repräsentationsbauten benötigt, teils wurden sie an Investoren und (halb-)staatliche Unternehmen verkauft und mit markanten Geschäftshäusern neu bebaut.99 Auch bei anderen Beispielen, etwa der Via Roma in Turin, lag den Sanierungsmaßnahmen ein gesamtheitliches städtebauliches und architektonisches Konzept zugrunde - hier ebenfalls ausgearbeitet durch den Berater des städtischen Bauamtes, Marcello Piacentini. ${ }^{\mathbf{1 0 0}}$ Im Falle der mondänen Turiner Geschäftsstraße nahm das Konzept jedoch größere Rücksicht auf die umgebende Bebauung als jenes zur Piazza della Vittoria in Brescia.

In der Gestaltung der Neubauten fand man also auch außerhalb Roms zu ganz unterschiedlichen Lösungen, je nach Auftraggeber, planendem Architekten und den Interessen der Stadtverwaltung und der Investoren (halbstaatliche, staatliche und private Unternehmen). Neben der „starken Hand“ des Staates und der lokalen Verwaltung, die die Enteignungen durchführte, wurde das Bild der italienischen Altstädte in den Jahren des Faschismus auch durch privatwirtschaftlich organisierte bzw. finanzierte Eingriffe in die Stadtstruktur geprägt, so beispielsweise in Bologna.101

\subsubsection{Rom und Wien}

Laut Bodenschatz waren die Diktaturen der 1930er-Jahre keine „introvertierten Inseln“"102. Trotz vermeintlicher Abschottung aufgrund politischer und ideologischer Differenzen fand fachlicher Austausch im Bereich des Städtebaus und der Architektur im Europa der 1930er-Jahre statt. Schauplätze dafür waren in erster Linie die eingangs erwähnten internationalen Städtebaukongresse. Die jeweiligen Fachleute verfolgten die international geführten Diskurse und auch im Deutschen Reich sah man Italien vor allem zu Beginn des Jahrzehnts als Vorbild. ${ }^{103}$ Es stellt sich daher die Frage, ob und inwiefern man sich in Wien auch im Bereich der Stadtregulierung an Italien und im Speziellen an Rom orientierte und in welcher Intensität der Austausch stattgefunden haben mag.

Die kulturellen Beziehungen mit Italien wurden durch das im Jahr 1935 unterzeichnete österreichisch-italienische Kulturabkommen ${ }^{104}$ gefestigt. In den 19 Artikeln des am 2. Februar 1935 in Rom unterzeichneten Vertrages ${ }^{\mathbf{1 0 5}}$ wurde nicht nur die Errichtung von Kulturinstituten festgehalten, auch die Intensivierung der Kontakte im Bereich des Schul- und Hochschulwesens wurde vereinbart, etwa die Förderung der beiden Sprachen als Fremdsprachen im Schulunterricht sowie der Ausbau der jeweiligen Universitätslehrstühle und die Förderung des Studierendenaustausches. Darüber hinaus sollten durch Förderprogramme im Kulturbereich und die Veranstaltung von Ausstellungen an den jeweiligen Kulturinstituten Kenntnisse über das beiderseitige kulturelle Schaffen vermittelt werden. ${ }^{\mathbf{1 0 6}}$ Bereits im Dezember 1934 wurde Francesco Salata von Mussolini mit der Organisation und Gründung eines Italienischen Kulturinstitutes in Wien beauftragt.107 Im Mai 1935 erwarb man dafür das Palais Fürstenberg (urspr. Lützow), das von Giovanni Ponti für die neue Nutzung adaptiert wurde. ${ }^{\mathbf{1 0 8}}$

Ebenfalls im Jahr 1935 starteten die Vorbereitungen für den (Neu-)Bau des Österreichischen Kulturinstitutes ${ }^{\mathbf{1 0 9}}$ in Rom, dessen Planung auf Vorschlag von Minister Hans Pernter110 direkt Karl Holey übertragen wurde. Die Fertigstellung erfolgte im November 1937, im Dezember übersiedelte das Österreichische Kulturinstitut schließlich in den Neubau. ${ }^{111}$ Ausstellungen zu Architektur und Städtebau der beiden Staaten 
wurden in den Jahren des Ständestaats in den beiden Kulturinstituten nicht abgehalten, jedoch war das Italienische Kulturinstitut an der Gestaltung und Organisation der Ausstellung Italiens Stadtbaukunst, gezeigt 1937 in der Wiener Secession, maßgeblich beteiligt, worauf wir später noch zurückkommen werden.

Die Leitlinien des Städtebaus des „Neuen Italiens“ Mussolinis und die bereits seit den 1920erJahren umgesetzten Projekte stießen nicht nur in Deutschland ${ }^{\mathbf{1 1 2}}$, sondern auch in Österreich auf reges Interesse (Abb.115). Ein Austausch fand sicherlich sowohl auf fachlicher als auch auf politischer Ebene statt. Noch während der Zeit des Roten Wien und vor der Machtergreifung der Christlichsozialen erlangten die Entwicklungen im Bereich des Städtebaus in der jungen italienischen Hauptstadt internationale Aufmerksamkeit. Im September 1929 wurde in Rom der bereits erwähnte Kongress des Internationalen Verbandes für Wohnungswesen und Städtebau abgehalten, der unter anderem „Die zeitgemäße Neugestaltung alter und his-

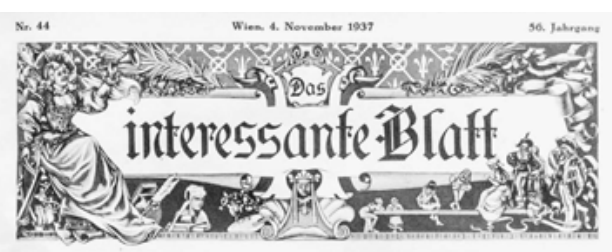

Der Papst vor der freigelegten Peterskirche
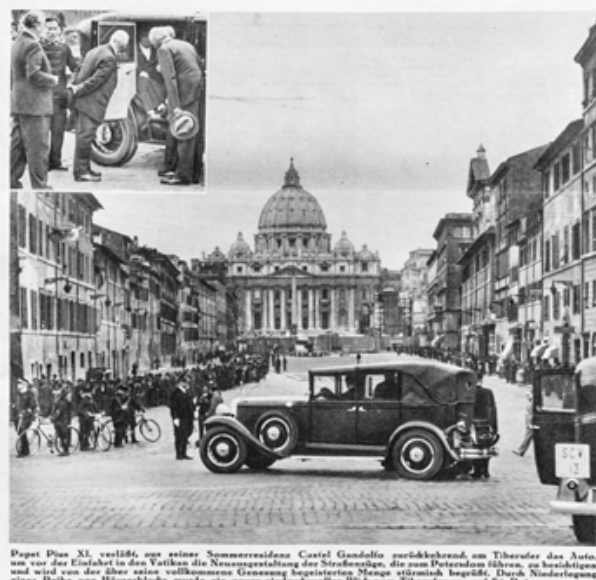

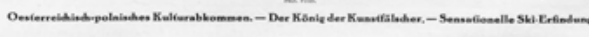

Abb. 115 Titelseite der Wiener Wochenzeitung Das interessante Blatt mit der "freigelegten Peterskirche“, November 1937 torischer Städte“ zum Thema hatte. Unter den 1.200 Kongressteilnehmenden aus 60 Ländern ${ }^{\mathbf{1 1 3}}$, mit Vertretern von Ministerien und kommunalen Planungsbehörden ebenso wie von Universitäten und Städtebauvereinigungen, war auch Franz Musil. ${ }^{\mathbf{1 1 4}}$ Im vorab erarbeiteten Tagungsband berichteten Vertreter zahlreicher Länder mehr oder weniger ausführlich über Methoden und Planungskonzepte sowie aktuelle Regulierungsvorhaben. So erläuterte etwa Luigi Piccinato die Methode des diradamento am Beispiel der Regulierung des Renaissance-Quartiers in Rom. Am Kongress selbst wurden die vorliegenden Berichte im Plenum diskutiert. Diskussionsleiter der Sektion zur „Neuplanung historischer Städte“ war niemand Geringerer als Marcello Piacentini und im Eröffnungsvortrag referierte Gustavo Giovannoni über die Entstehung des Generalregulierungsplanes für Rom. ${ }^{\mathbf{1 1 5}}$

Der Kongress bot somit eine Möglichkeit der Diskussion der damals üblichen Methoden der Stadtregulierung, Beiträge lieferten neben Italien unter anderem die skandinavischen Länder, die Niederlande, England und Deutschland. Anlässlich des Kongresses und der dort diskutierten Themen zeigte man zur selben Zeit im Palazzo delle Esposizioni eine Ausstellung, die neben Regulierungsplänen für diverse andere italienische Städte auch mehrere Vorschläge für einen neuen Generalregulierungsplan für Rom präsentierte und somit auch erstmals einem internationalen Fachpublikum die Umgestaltungspläne für die Hauptstadt offenbarte. ${ }^{\mathbf{1 1 6}}$ Die Wiener Stadtplanung erlangte somit bereits sehr früh Kenntnis über die Regulierungsabsichten in der italienischen Hauptstadt, noch in den Jahren des Roten Wien, als Franz Musil aber bereits als Direktor des Stadtbauamtes tätig war. 
In den Jahren des Ständestaats lässt sich ein reges Interesse am italienischen Städtebau und den Maßnahmen der Altstadtregulierung wahrnehmen, vonseiten der Stadtverwaltung wie auch von Fachleuten für Architektur und Städtebau. Zahlreiche Kongresse und Veranstaltungen sowie gegenseitige Besuche ranghoher Politiker boten Gelegenheit, sich über mögliche und bereits realisierte Maßnahmen auszutauschen. Im Juni 1935 hielt der Kunsthistoriker und Direktor des Amtes für Altertümer und Schöne Künste (Antichità e Belle Arti) des Governatorato di Roma117, Antonio Muñoz, auf Einladung des Italienischen Kulturinstitutes in der Wiener Hofburg einen Vortrag zur städtebaulichen Entwicklung der Stadt Rom. ${ }^{118}$ Muñoz stellte vor allem die Freilegungsarbeiten vor und zeigte, wie man unter Mussolini die in der zweiten Hälfte des 19. Jahrhunderts der alten Stadt „aufgepfropften“ Teile entfernt und damit das „alte Rom" wieder zur Geltung gebracht habe. ${ }^{119}$ Im September desselben Jahres wurde in Rom der 13. Internationale Architektenkongress abgehalten, an dem auch Siegfried Theiss, als offizieller Delegierter Österreichs ${ }^{\mathbf{1 2 0}}$ und zum damaligen Zeitpunkt Präsident der österreichischen Sektion des Comité Permanent International des Architectes (CPIA), teilnahm. In seinem abschließenden Bericht ${ }^{\mathbf{1 2 1}}$ erwähnt er zahlreiche Besichtigungen, die einen „vorzüglichen Einblick in Architektur und Städtebau des neuen Italien“ ermöglicht hätten und betont die internationale Bedeutung des Kongresses. ${ }^{\mathbf{1 2 2}}$ Im Rahmenprogramm waren Besichtigungen in Rom und der Besuch der neu gegründeten Städte Littoria und Sabaudia in den Pontinischen Sümpfen vorgesehen, „um die Herren Kongreßteilnehmer einen klaren Einblick in die konstruktive und architektonische Tätigkeit des Neuen Italiens gewinnen zu lassen, und zwar in Hinsicht auf die Entwicklung moderner Organismen, als auch auf die Wertung der kostbaren von der Vergangenheit überlieferten Kunstgüter im Rahmen des modernen Städtebaus“.'123 Den hohen Stellenwert des Kongresses belegt auch die Tatsache, dass die jeweiligen Länderdelegierten bei Mussolini persönlich zu einem Empfang geladen waren. ${ }^{\mathbf{1 2 4}}$ Der Kongress und die im Rahmen dessen besichtigten Bauleistungen dürften bei vielen Teilnehmern einen bleibenden Eindruck hinterlassen haben. Max Kopp, teilnehmender Schweizer Architekt, schildert seine Wahrnehmung der neuen staatlichen Bauten, des Forum Mussolini (heute Foro Italico) und der Universitätsstadt, wie folgt:

„Wir Hirtenknaben staunen über die Grosszügigkeit [sic!] dieser Anlagen, bei denen die Kostenfrage kaum eine Rolle zu spielen scheint. Ein starkes Streben nach neuen Formen ist erkennbar. Aber ebenso stark scheint die ungeheure Kraft der römischen Tradition. Im Kraftfeld dieser beiden Energien pendelt hier die Baukunst.“"125

Ende Oktober 1936 fand wiederum in Rom zum sechsten Mal der Convegno Volta statt, ein Kongress, veranstaltet von der Königlichen Akademie Italiens, der sich in diesem Jahr mit der Verbindung zwischen Architektur und den bildenden Künsten befasste. Eingeladen waren „22 der hervorragendsten Architekten, Maler und Bildhauer“ Europas, darunter Le Corbusier, Paul Bonatz und Clemens Holzmeister, sowie „20 führende Künstler, vornehmlich Architekten, Italiens“.126 Dass in diesem Rahmen auch ein Austausch über städtebauliche Fragen stattfand, ist mehr als anzunehmen.

Auch auf politischer Ebene fanden zahlreiche Treffen in Wien und Rom statt, die österreichischen Tageszeitungen und die beiden Wochenschauen (Österreich in Bild 


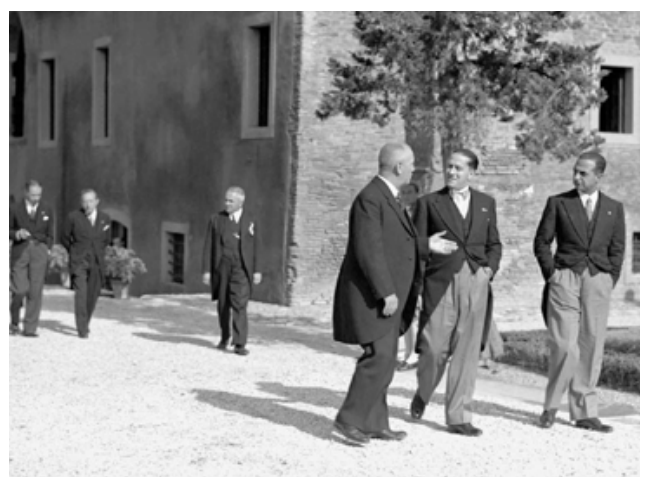

Abb. 116 Giuseppe Bottai (erster von rechts) und Galeazzo Ciano (zweiter von rechts) im Gespräch mit Richard Schmitz in der Casina del Cardinal Bessarione (in den frühen 1930 er-Jahren für Staatsbesuche adaptierte Villa unweit der Caracalla-Thermen), Rom, aufgenommen am 29.9.1936 und Ton ${ }^{\mathbf{1 2 7}}$ und Giornale Luce) berichteten darüber. Von Interesse sind hier die Zusammenkünfte von Bürgermeister Schmitz mit hohen Politikern Italiens. Die Besichtigungen aktueller Bauleistungen und in Bau befindlicher Großprojekte stellten dabei stets zentrale Programmpunkte dar. Im September 1936 hielt sich Schmitz für einige Tage in Rom auf und besichtigte dabei unter anderem neu angelegte Verkehrsstraßen, Notstandsbauten für Arbeiter, die neue Universitätsstadt sowie auch die neu gegründeten Städte Littoria und Sabaudia. Empfangen wurde er bei seinem Besuch nicht nur vom damaligen Bürgermeister der Stadt Rom, Giuseppe Bottai, sondern auch von Außenminister Galeazzo Ciano (Abb.116).128 Berichtet wird auch von einem Treffen mit Mussolini persönlich und dass man anerkennende Worte für die Baupolitik in Wien gefunden habe, die ,auch ausländischen Stadtverwaltungen wertvolle Anregungen" bieten würde. ${ }^{129}$

Vom Besuch des Wiener Bürgermeisters in Rom berichtete unter anderem das Giornale Luce, die italienische Wochenschau, die wie ihr österreichisches Pendant (siehe Kap. 2.3.) in den Kinos gezeigt wurde und eines der wichtigsten Propagandainstrumente des faschistischen Regimes darstellte. Die Wochenschau dokumentierte nicht nur den Besuch Richard Schmitz' in Rom im Oktober $1936,{ }^{\mathbf{1 3 0}}$ sondern berichtete ganz regelmäßig über politische und soziale sowie sportliche und kulturelle Ereignisse in Österreich. ${ }^{\mathbf{1 3 1}}$ So zeigte man Schmitz im regen Austausch mit Galeazzo Ciano und Giuseppe Bottai bei seinem Besuch in der italienischen Hauptstadt im Herbst 1936 (Abb.117) und berichtete im Juli desselben Jahres beispielsweise auch von den Abbrucharbeiten im Freihaus. ${ }^{132}$

Auf der anderen Seite wurden auch Vertreter der italienischen Regierung in Österreich willkommen geheißen und im Rahmenprogramm der Treffen „herausragende Bauleistungen“ besichtigt. Im August 1935 lud man etwa zur Eröffnung der Großglockner Hochalpenstraße $\mathrm{e}^{\mathbf{1 3 3}}$ und im Juni 1937 besuchte der 1936 eingesetzte neue Bürgermeister von Rom, Piero Colonna, vier Tage lang die Stadt Wien, ${ }^{\mathbf{1 3 4}}$ um hier die Höhenstraße, die Seipel-Dollfuß-Gedächtniskirche, mehrere Familienasyle und auch die Assanierungsbauten auf den Freihausgründen zu besichtigen.135 Österreich in Bild und Ton ${ }^{\mathbf{1 3 6}}$ (Abb.118) und das Giornale Luce berichteten. ${ }^{\mathbf{1 3 7}}$

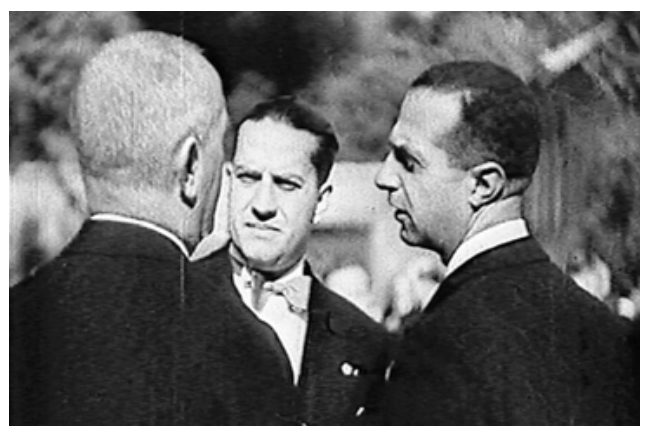

Besondere Aufmerksamkeit soll hier abschließend noch der bereits erwähnten Ausstellung Italiens Stadtbaukunst gewidmet wer-

Abb. 117 Richard Schmitz im regen Austausch mit Galeazzo Ciano und Giuseppe Bottai bei seinem Besuch in der italienischen Hauptstadt im Herbst 1936, Filmstill aus der Wochenschau Österreich in Bild und Ton, 16.10.1936 
den, die von November bis Dezember 1937 in der Wiener Secession gezeigt wurde. Das „Ausstellungskomitee“ stellten der Präsident des Italienischen Kulturinstitutes in Wien, Francesco Salata, Oberbaurat Leopold Bauer, Präsident der Österreichischen Gesellschaft für Städtebau, sowie die Architekten Alexander Popp (zum damaligen Zeitpunkt auch Präsident der Secession) und Karl Holey, damals bereits Rektor der Technischen Hochschule Wien und Mitglied des Bundeskulturrates. ${ }^{\mathbf{1 3 8}}$ Bedauerlicherweise ist $\mathrm{zu}$ dieser Ausstellung kaum Quellenmaterial erhalten. ${ }^{\mathbf{1 3 9}}$ Dank einer zweisprachigen Publikation über die italienische Stadtbaukunst, die als Begleitheft zur Ausstellung gedient haben mag, ${ }^{\mathbf{1 4 0}}$ eines sepa-

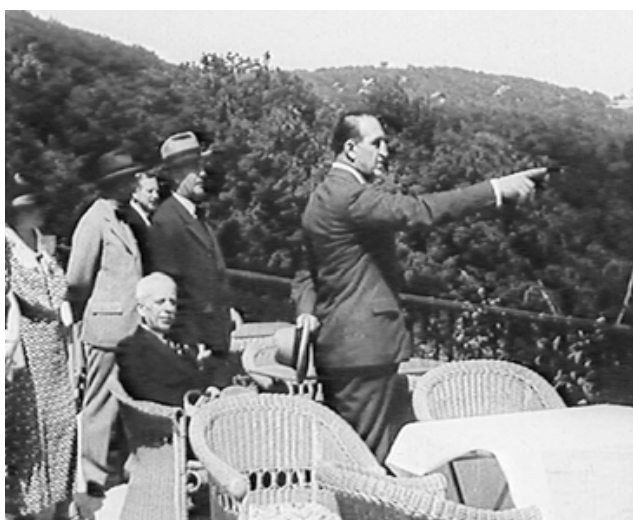

Abb. 118 Fürst Colonna mit Richard Schmitz und anderen auf dem Reisenberg (Am Cobenzl). Colonna zeichnet den Verlauf der Höhenstraße auf den Kahlenberg nach, Filmstill aus der Wochenschau Österreich in Bild und Ton, 11. 6.1937 raten Katalogteils ${ }^{\mathbf{1 4 1}}$ sowie einiger Bildquellen und Berichte in österreichischen Tageszeitungen ${ }^{\mathbf{1 4 2}}$ kann jedoch die Auswahl der gezeigten Exponate rekonstruiert werden. Es handelte sich um eine Zusammenstellung
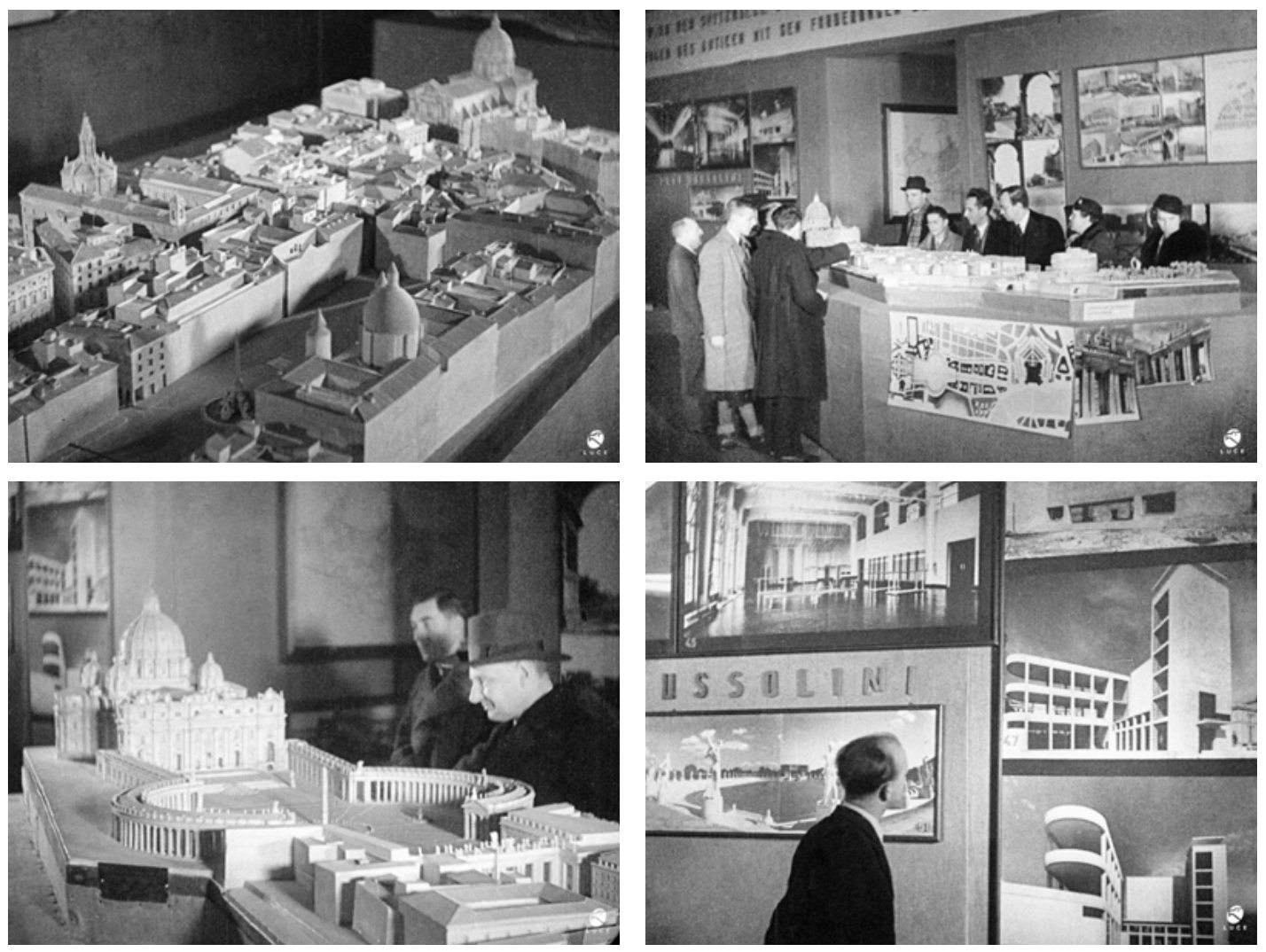

Abb.119 Im Rahmen der Ausstellung Italiens Stadtbaukunst in der Wiener Secession im Jahr 1937 gezeigte Modelle und Entwürfe zu Regulierungsmaßnahmen und Bauprojekten in Italien, Filmstills aus der italienischen Wochenschau Giornale Luce, 15.12.1937 
von Modellen, (Regulierungs-)Plänen, Fotografien, Projektdarstellungen und Diagrammen, die Karl Holey angeblich gemeinsam mit dem Architekten Paolo Rossi de Paoli in Rom ausgesucht und für die Ausstellung arrangiert hatte (Abb. 119). ${ }^{\mathbf{1 4 3}}$

„Besonderes Augenmerk wird auf die speziell in Rom stattgefundenen Regulierungsund Freilegungsarbeiten gerichtet, worüber hochinteressante Modelle, wie zum Beispiel das der Anlagen am Forum Romanum mit der Via dell'Impero und der Regulierung des Stadtviertels vor der Peterskirche, ein interessantes Bild geben.“144

Gezeigt wurden neben den durchgeführten und geplanten Regulierungsarbeiten in zahlreichen Städten auch die neu gegründeten Städte in den Pontinischen Sümpfen. Hauptaugenmerk lag auf den Regulierungs- und Freilegungsarbeiten und den Neubauten des Faschismus in Rom. Siedlungen, Wohnbauten, Verwaltungsbauten sowie Freizeit- und Sportanlagen fanden ebenso Beachtung wie die Gestaltung neuer Parkanlagen. Pläne, Fotografien und Modelle präsentierten die Freilegung des Forum Romanum und des Augustus-Mausoleums und die Regulierung des Stadtviertels um die Peterskirche. Aus dem von Karl Holey verfassten Vorwort zum Katalog der Ausstellung lässt sich seine große Bewunderung für die Regulierungsarbeiten in Rom und generell für die Entstehung dieses „mächtigen Bauwillens“ unter dem „starken Führer“ Mussolini deutlich ablesen. ${ }^{145}$

Mehrere Tageszeitungen berichteten von der Eröffnung der Ausstellung durch Bundeskanzler Kurt Schuschnigg (Abb.120). ${ }^{\mathbf{1 4 6}}$ Einen Beitrag zur Ausstellung brachten im Dezember 1937 sowohl die Österreichische Wochenschau (Österreich in Bild und Ton) ${ }^{\mathbf{1 4 7}}$ als auch das Giornale Luce. ${ }^{\mathbf{1 4 8}}$ Neben Schuschnigg besuchte auch Bürgermeister Schmitz die Schau und wurde dort nicht nur vom Präsidium der Secession, sondern auch vom italienischen Gesandten und „Kulturvermittler“ Francesco Salata empfangen. ${ }^{149}$

Trotz der Aufmerksamkeit durch die politische Führung stellte die Ausstellung in den Medien nur eine Randnotiz dar. Einfluss auf die städtebaulichen Planungen des Ständestaats hatte sie sicherlich nicht. Mit Sicherheit aber kann die Ausstellung als Zeichen für den kulturellen Austausch verstanden werden und als Ausdruck der Bewunderung für ein architektonisches und städtebauliches Werk, zu dem man hierzulande aus wirtschaftlichen und sozialpolitischen Gründen und dafür unzulänglichen gesetzlichen Bestimmungen nicht aufschließen konnte. Die Realisierung der Ausstellung in Wien ist letztlich wohl auch schlichtweg ein Spiegel der Begeisterung Karl Holeys für den Städtebau im faschistischen Italien und nicht zwingend Ausdruck des Strebens nach Gleichartigem durch die politische Führung des Ständestaats.

Spätestens mit 1929 und dem Städtebaukongress in Rom war das Wiener Stadtbauamt über die in der italienischen Hauptstadt geplanten und bereits durchgeführten Maßnah-

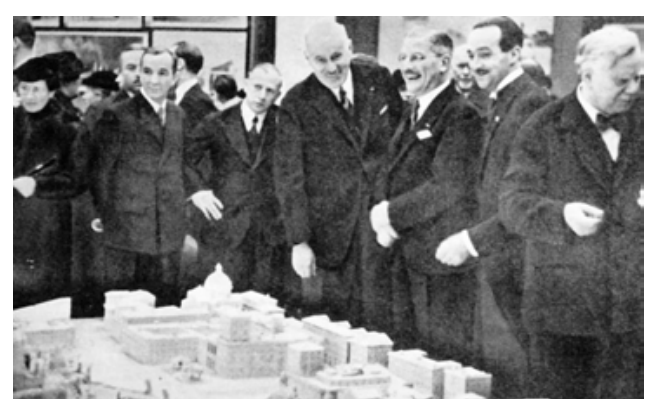

Abb. 120 Eröffnung der Ausstellung Italiens Stadtbaukunst in Wien, 1937. Zu sehen sind Bundeskanzler Schuschnigg (mittig mit verschränkten Händen), zu seiner Rechten Karl Holey und Minister Hans Pernter, zu seiner Linken Architekt und Mitgestalter der Ausstellung Paolo Rossi de Paoli. 
men informiert. Ein Austausch auf fachlicher und politischer Ebene war sowohl vor als auch nach der politischen Distanzierung zwischen Italien und Österreich im Jahr 1936 gegeben, wie die erwähnten Kongresse und gegenseitigen Besuche vermuten lassen. Die in Wien durchgeführte Assanierung unterscheidet sich allerdings in mehreren Punkten entscheidend von den in Rom durchgeführten Sanierungsmaßnahmen (siehe dazu noch Kap. 6.4.).

\subsection{Die „Gesundung“ und „Entschandelung“ der Altstädte im nationalsozialistischen Deutschland}

Das Ziel, dem deutschen Volk ein angemessenes Wohnumfeld zu schaffen, äußerte sich in der Realisierung zahlreicher Siedlungen. Mit den Heimstätten-Siedlungen wurden in der NS-Zeit in ganz Deutschland und auch in Österreich mit sparsamen Mitteln „gute deutsche“ Wohnbauten errichtet. In den schlichten, mit Ziegel oder Schiefer gedeckten Satteldächern und den „,bodenständigen“, „ortsüblichen“ Baudetails komme „eine natürliche Verbundenheit des Menschen mit dem Boden, auf dem er wohnt, und der Landschaft, die ihn umgibt, zum Ausdruck“.150

Aber vor allem auch die Wohnverhältnisse in den deutschen Altstädten sollten eine entsprechende Verbesserung erfahren. In den oftmals noch mittelalterlich geprägten Kernstädten versuchte man unter dem Schlagwort der „Altstadtgesundung“, die Struktur der Stadt zu „ordnen“ und vor allem die Bebauungsdichte aufzulockern. Die „Gesundung“ war allerdings auch eine treffsichere Maßnahme, um sozialpolitische Brennpunkte der Stadt zu entschärfen und politische Gegner und „gesellschaftsfeindliche Elemente“ in leichter kontrollierbare und „gesündere" Wohnanlagen umzusiedeln. ${ }^{151}$ Die „gute deutsche“ Wohnung wurde somit auch als „resozialisierende Maßnahme“152 verstanden, um „die Bevölkerung, die sich hier festgesetzt hatte, [...] in besseren Wohnverhältnissen für die menschliche Gesellschaft wieder zu gewinnen“153. Tatsächlich wohnten in den 1930er-Jahren in den Altstädten vorwiegend sozial „schwache“ Schichten und das unter meist miserablen Wohnverhältnissen.

Erklärtes Ziel war zunehmend aber auch die Generierung eines idealisierten „Ganzen“, eines von allen „Verschandelungen“ bereinigten Altstadtbildes. ${ }^{\mathbf{1 5 4}}$ Darunter verstand man sowohl den Ersatz von „unhygienischen“ und „unpassenden“ Bauten sowie auch die Entfernung von übermäßigem Fassadenschmuck und störender Reklame. Geleitet von einem ideologisch bestimmten Geschichtsbild verstand man unter all diesen Maßnahmen eine ästhetische und substanzielle Aufwertung der Altstädte, schlichtweg eine Verschönerung der „deutschen Heimat“. Kritisiert wurden die „verunstaltenden“, den Gesamteindruck des Stadtbildes störenden Bauten und vor allem die Ornamentik des Historismus explizit auch von der Denkmalpflege. ${ }^{\mathbf{1 5 5}}$ Vergleichbar erscheint dies mit den Aussagen der amtlichen Denkmalpflege in Wien zu den analysierten Stadtbildkorrekturen und den Leitgedanken des Österreichischen Verbandes für Heimatschutz. Unter anderem diesen Fragen wird im folgenden Kapitel nachgegangen.

\subsubsection{Von der Erhaltung der Altstadt zur „Steigerung des Ganzen“}

Bereits in den ersten Jahren der nationalsozialistischen Diktatur wurden zahlreiche kommunale Sanierungsprogramme umgesetzt, etwa in Braunschweig, Frankfurt am Main, Hannover, Weimar oder Kassel. ${ }^{156}$ Fachzeitschriften für Städtebau und Denkmalpflege, allen voran die Monatsschrift Städtebau und die Deutsche Kunst und 

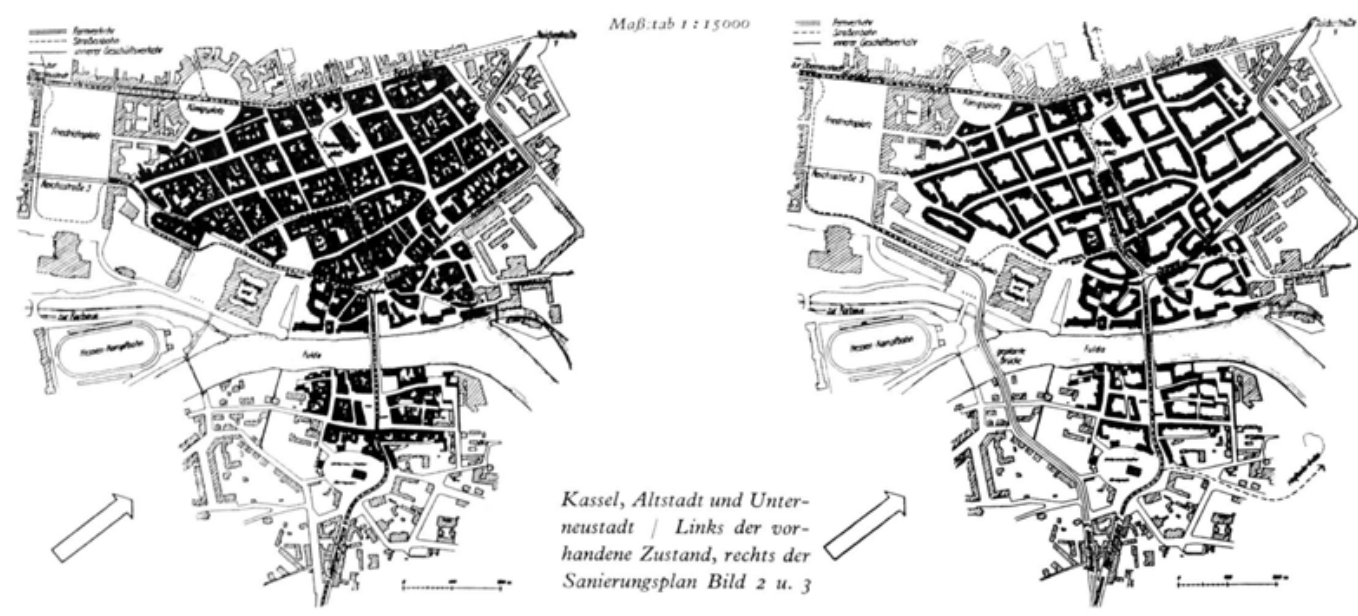

Abb.121 Kassel, Altstadt und Unterneustadt, links der damals vorhandene Zustand, rechts der Sanierungsplan, 1936

Denkmalpflege, berichteten umfassend. Die Maßnahmen der 1930er-Jahre bauten dabei grundsätzlich auf den Vorarbeiten und Überlegungen der 1920er-Jahre auf.157 In den 1930er-Jahren wurde die sozialistisch geprägte „Stadtgesundung“ des vorangegangenen Dezenniums „völkisch interpretiert“ und die dicht bebaute Altstadt, mit ihren engen Gassen und Hinterhöfen, neuerdings für die sozialen Missstände verantwortlich gemacht. ${ }^{\mathbf{1 5 8}}$ Braunschweig war 1933 schließlich die erste Großstadt des Deutschen Reiches, in der eine „Auflockerung“ planmäßig durchgeführt wurde. ${ }^{159}$

Bis 1940 wurden 41 Altstadtsanierungen mit staatlichen Zuschüssen gefördert. ${ }^{160}$ Der Begriff der „Altstadtgesundung“ war dabei breit gefasst und subsumierte unterschiedliche Sanierungsmethoden, von der „Wiederherstellung“ über die strukturelle „Auflockerung“ des Altstadtgefüges bis zu Totalabbruch und Neubebauung ganzer Stadtbereiche. Die Maßnahmen waren also nicht einheitlich und wurden auch in den Fachzeitschriften intensiv diskutiert. ${ }^{\mathbf{1 6 1}}$ Die Neubauten wurden von Architekten geplant, deren Auswahl zumeist aufgrund von Wettbewerben erfolgt war, und von Baugesellschaften ausgeführt. Die „künstlerische Oberleitung“ lag beim städtischen Bauamt, wobei bei Neubauplänen in der Altstadt auch der institutionelle Denkmalschutz hinzugezogen wurde. ${ }^{\mathbf{1 6 2}}$ Wie auch die Wiederaufnahme der Inventarisation und das Einschreiten gegen die zunehmende Außenreklame, war die „Altstadtgesundung“ ab 1933/34 Zeichen eines lange ersehnten Aufbruchs und Ausdruck einer erstarkten Denkmalpflege. ${ }^{163}$ Die „Gesundungsmaßnahmen“ begleiteten gleichzeitig immer lauter werdende Forderungen nach einem neuen Altstadtsanierungsgesetz, das den Zugriff auf privates Eigentum und Boden - und somit auch die Durchführung der Sanierungsund Regulierungsmaßnahmen - erleichtert und beschleunigt hätte. ${ }^{\mathbf{1 6 4}}$

Unter dem Begriff der „Altstadtgesundung“ wurden sowohl regulierende Maßnahmen und strukturelle Änderungen im Stadtgrundriss als auch Eingriffe in die Bausubstanz an sich verstanden. Vielerorts verfolgte man die Methode der „Entkernung“ oder „Auskernung“ der Altstädte. Vor allem im 19. Jahrhundert waren die ohnehin dicht bebauten Altstädte mit zusätzlichen Hofeinbauten oder Aufstockungen weiter verdichtet worden. Gleichzeitig wurden von den Hausbesitzern, aufgrund der geringen Mietein- 
nahmen, kaum Erhaltungsmaßnahmen durchgeführt und die Bausubstanz verkam zunehmend. ${ }^{165}$ Stadtreformer hatten im Rahmen des damaligen Hygiene-Diskurses die Forderung nach einer geringeren Dichte in den Wohnquartieren und einer Auflockerung der Stadtstruktur gestellt und für „Reformblöcke“ mit unbebauten und begrünten Innenhöfen plädiert. ${ }^{\mathbf{1 6 6}}$ In den 1920 er-Jahren wurde diese Idee wieder aufgegriffen: Beispielsweise befasste sich Cornelius Gurlitt in seinem Handbuch des Städtebaues ${ }^{\mathbf{1 6 7}}$ mit der Möglichkeit der Auflockerung der Altstadtstruktur als Methode der „Stadtgesundung“, 1928 plädierte Ernst May ${ }^{\mathbf{1 6 8}}$ am Tag für Denkmalpflege und Heimatschutz in Würzburg für die Beseitigung der „Elendsquartiere“ in den Altstädten mit ihren engen, verwinkelten Innenhöfen, die nahezu gänzlich ohne Licht und Luft auskommen müssten. Die „wertvolleren Teile der Altstadt“ sollten „in den lebendigen Organismus der modernen Großstadt" eingegliedert werden, um sie erhalten zu können.169

Während die deutschen Großstädte sich stärker mit dem Problem der gründerzeitlichen „Mietskaserne“ $\mathbf{1 7 0}$ konfrontiert sahen, waren vor allem in den mittelgroßen und kleineren deutschen Städten die noch dicht bebauten mittelalterlichen Stadtkerne vorzufinden. ${ }^{\mathbf{1 7 1}}$ Durch die Niederlegung von „unhygienischen“, „minderwertigen“ Hofund Hintergebäuden sollte die Stadtstruktur aufgelockert, „die menschenunwürdigen Wohnungen der Altstädte"172 beseitigt und den Wohnungen Licht und Luft zugeführt werden (Abb.121, 122), wie Erich Labes, Oberbaurat und Stadtplaner in Kassel, 1936 skizziert: „Was über das vertretbare Maß hinaus hineingepfropft worden ist, ist wieder soweit auszuräumen, bis ein erträglicher Zustand, wie er etwa Ende des 17. Jahrhunderts in den Altstädten noch bestand, wieder erreicht ist." ${ }^{\mathbf{1 7 3}}$

In Braunschweig trat Hermann Flesche, Professor für Stadtbaukunst an der hiesigen Hochschule, ebenfalls für die Methode der Auskernung ein, da dadurch „Braun-

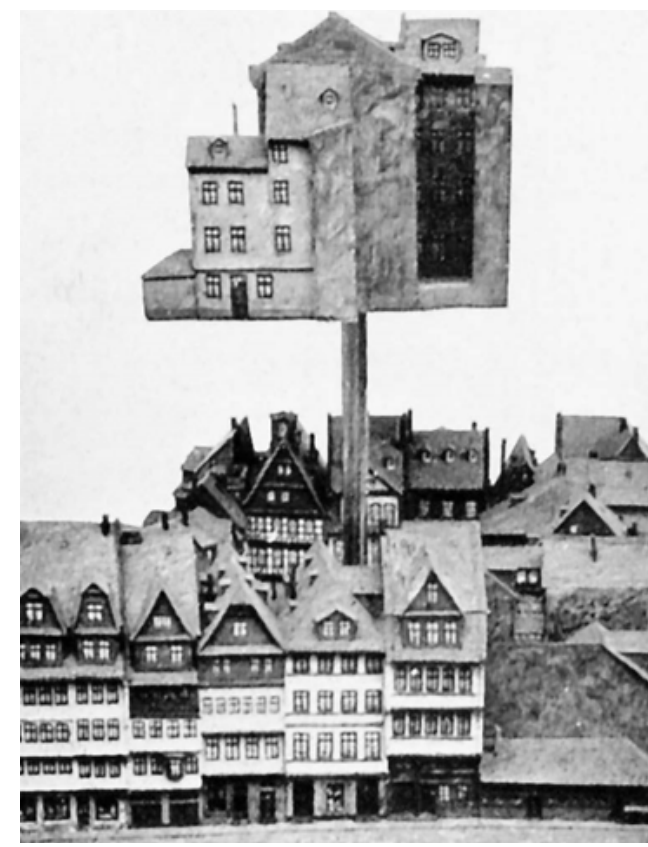

Abb.122 Bewegliches Modell zur Veranschaulichung der Auskernung in der Frankfurter Altstadt, 1939 schweigs Eigenart unangetastet" bleiben und dennoch „vernünftige Wohnungen“ geschaffen würden. ${ }^{\mathbf{1 7 4}}$ Man nahm sich demnach den Stadtgrundriss des vorindustriellen Zeitalters mit kleinen Gärten in den Hinterhöfen als „wiederherzustellendes“ Ideal zum Vorbild. Durch die Freistellung der Innenhöfe unter Erhaltung der Vorderhäuser sollte eine ausreichende Belichtung und Belüftung generiert und dennoch die Altstadt weitgehend erhalten werden. Unter „Erhaltung“ verstand man dabei allerdings auch die „Gestaltung“ der verbliebenen Altbausubstanz. Im Vergleich dazu erfolgte auch bei Giovannonis Methode des diradamento vor der "Auslichtung“ eine - allerdings differenziertere - Bewertung des Bestandes, ehe weniger bedeutsame Bausubstanz zur Verbesserung der Gesamtsituation abgetragen wurde.

Neben Auskernungen wurden auch Straßendurchbrüche durchgeführt. Sie wurden als „schonender“ erachtet als Straßenverbrei- 


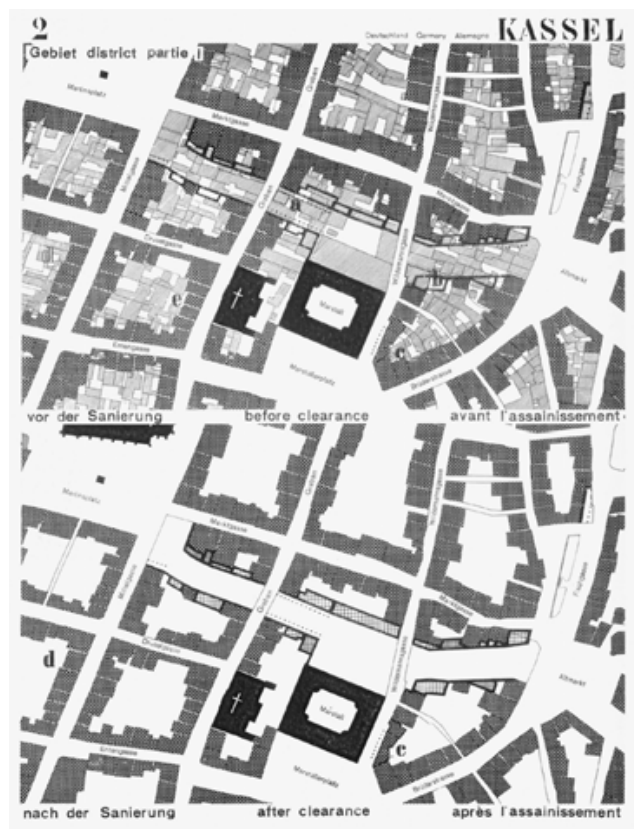

Abb.123 „Altstadtgesundung“ in Kassel, Straßendurchbruch zwischen Martinsplatz und Altmarkt, Publikation von 1935

terungen, durch die „der Stimmungswert der natürlich gewachsenen Altstadt verloren“ ginge. ${ }^{175}$ So wurde in Frankfurt am Main im Rahmen der „Gesundungsmaßnahmen“ zwischen 1936 und 1939 im Bereich der als „hochwertig“ erachteten Altstadt von Verbreiterungen abgesehen, da „durch eine solche Maßstabsänderung und durch die verschiedenartige Form der beiden Platzwände die Einheit des mittelalterlichen Stadtbildes in erheblichem Umfange" gelitten hätte. ${ }^{176}$

Nach Möglichkeit zog man die Durchbrüche, wie hier in Kassel, durch das Blockinnere. Dadurch mussten zwar einige ergänzende Neubauten errichtet werden, aber zumindest waren geringere Abbrüche historischer Substanz erforderlich (Abb.123). Diese Methode ermögliche damit, so Erich Labes, eine weitgehende Erhaltung alter Straßenzüge und ließ "Alt und Neu viel leichter wieder miteinander verwachsen“.177 Die schon von SchultzeNaumburg Anfang des 20. Jahrhunderts abgelehnte „mathematisch gerade Straße“, $\mathbf{1 7 8}$ wie sie im Städtebau des 19. Jahrhunderts zur Befriedigung der Verkehrsbedürfnisse gezogen wurde, vermochte es nur selten, „eine volle Harmonie“ ${ }^{\mathbf{1 7 9}}$ mit der mittelalterlichen, „deutschen“ Altstadt einzugehen. In Kassel wählte man daher für die neu angelegte Straße zwischen Altmarkt und Martinsplatz, „unter Berücksichtigung bestehender erhaltenswerter Gebäude [...] eine dem alten Straßensystem verwandte ungezwungene Führung“. ${ }^{180}$ Die Unregelmäßigkeit im Stadtgrundriss, der „ungezwungene Verlauf der Straßen- und Platzflächen“, angepasst an die natürlichen Gegebenheiten des Geländes, und die schmalen Parzellen, die Satteldächer und Dachgauben wurden als „Eigenart“ der Stadt anerkannt und sollten erhalten werden. ${ }^{\mathbf{1 8 1}}$ In Kassel erfolgte unter der Leitung von Erich Labes eine vergleichsweise rücksichtsvolle Sanierung im Sinne des frühen Heimatschutzgedankens. Der Wandel des Stadtbildes durfte sich seiner Ansicht nach „nur im Rahmen seiner bestimmten Eigenart vollziehen“, bestimmte Bereiche der Altstadt sollten in ihrer „städtebaulichen Einheit“ bewahrt bleiben und insbesondere vor Veränderungen und Zerstörungen geschützt werden. Die „rhythmische Bewegtheit" des Stadtbildes, erzeugt durch die unterschiedliche Gestaltung der Häuser, und das „bunte Auf und Ab“ der unterschiedlichen Gebäudehöhen und Giebelformen dürfe bei der Einfügung neuer Häuser nicht gestört werden. ${ }^{\mathbf{1 8 2}}$

Die bisher skizzierten, in den 1930er-Jahren im nationalsozialistischen Deutschland durchgeführten Stadtsanierungen waren durchaus darauf bedacht, die Struktur der Stadt und den historischen Stadtgrundriss zu erhalten. Neben der Auskernung wurden im Bereich der Altstädte allerdings auch radikalere Maßnahmen getätigt und auch ganze Häuserblocks niedergelegt. Im Falle des „Gängeviertels“ in Hamburg etwa wurden 
weite Bereiche der Altstadt abgebrochen und „in freier Nachahmung“ des Spitzgiebelmotivs der Vorgängerbauten neu bebaut (Abb. 124). ${ }^{\mathbf{1 8 3}}$ Ähnliches erfolgte auch in Frankfurt am Main im Bereich des „neueren, künstlerisch weniger wertvollen Teil[es] der Altstadt“, wo man die Altbauten entlang zweier Straßen demolierte und auf dem Gelände „Neubauten nach den gesunden Grundsätzen des Siedlungsbaues, aber in der aufgelockerten Form einzelner Giebelhäuser" errichtete. ${ }^{\mathbf{1 8 4}}$ In Hannover stellte man, unter der Leitung von Stadtbaurat und Professor Karl Elkart, den ehemaligen „Ballhof“ frei, unter herben Verlusten großer Altstadtbereiche. Man flankierte ihn an beiden Seiten mit „neuen“ Fachwerkbauten, einem Heim für den „Bund Deutscher Mädchen“ und einem ebensolchen für die Hitlerjugend (Abb. 125). Für die Neubauten waren angeblich die alten Fachwerkbauten „sorgfältig auseinander genommen und nach Auswechslung der schadhaften Teile und Beseitigung späterer Zutaten wieder im alten Verband aufgerichtet" worden. ${ }^{\mathbf{1 8 5}} \mathrm{Er}$ -

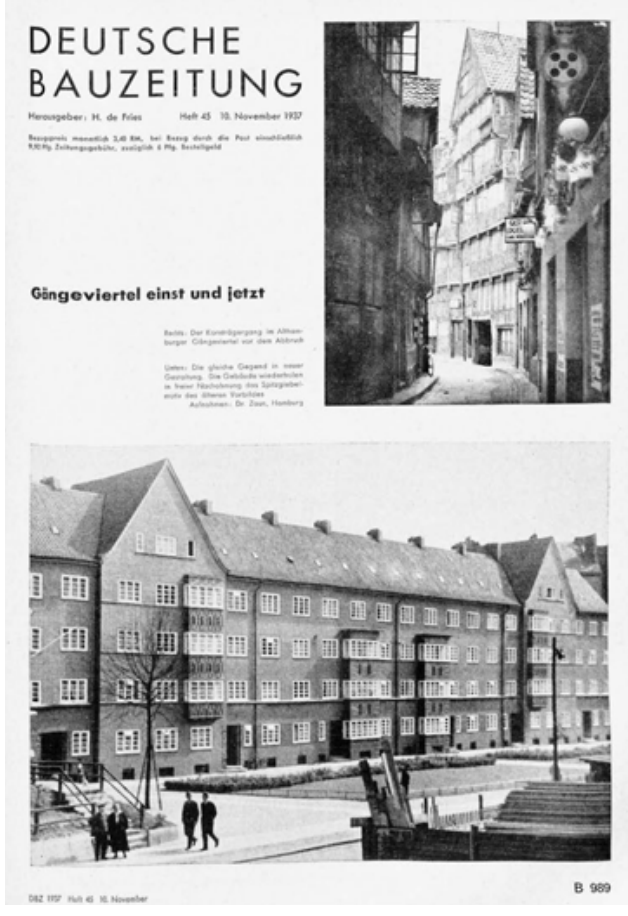

Abb.124 Titelblatt der Deutschen Bauzeitung, Umgestaltung des Gängeviertels in Hamburg, November 1937 gebnis war ein vorgetäuschtes historisch gewachsenes Ensemble aus Fachwerkhäusern, die allein aufgrund ihrer Dimensionen und Anordnung an den Seiten eines viel zu großen Platzraumes kaum aus der Zeit stammen konnten, aus der sie glaubhaft machen wollten, zu sein.

Es sind demnach unterschiedliche Methoden der „Stadtgesundung“ auszumachen, denen - wie das Beispiel Frankfurt zeigt - eine Bewertung der Altstadtbereiche vorausging. ${ }^{186}$ Die „Gesundungen“ waren Teil eines (Alt-)Stadtsanierungs-Programmes $^{\mathbf{1 8 7}}$, folgten jedoch keinem einheitlichen Schema oder einer von einer übergeordneten Stelle ausgearbeiteten Gesamtplanung. ${ }^{\mathbf{1 8 8}} 1940$ publizierte die Deutsche Gesellschaft für Wohnungswesen eine rückblickende Zusammenfassung der Altstadtsanierungen „mit Reichshilfe“ der Jahre 1934 bis 1938, worin sich diese Bandbreite

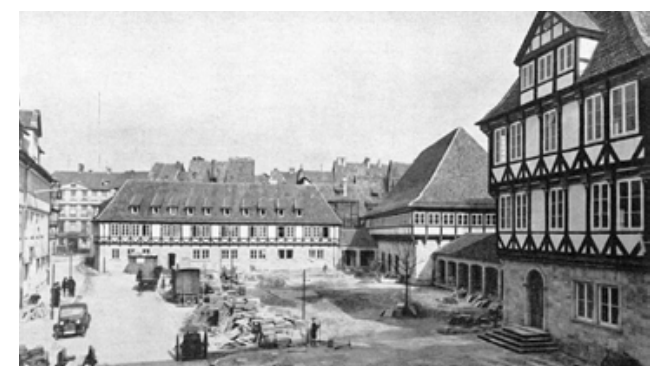

Abb.125 Altstadtsanierung in Hannover, Freilegung des Ballhofes und Errichtung des HJ-Heimes, Aufnahme 1939 der Maßnahmen widerspiegelt. ${ }^{\mathbf{1 8 9}}$ Das breite Spektrum war nicht zuletzt eine Konsequenz der unterschiedlichen, ideologisch motivierten Bewertung des Bestandes: Die noch mittelalterlich geprägten Kernstädte waren Träger der deutschen Identität und blieben von allzu radikalen Eingriffen zumeist verschont. Hingegen wurde die industriell geprägte, kapitalistische Stadt der Gründerzeit mit ihren schlechten Wohnverhältnissen in den „Mietskasernen“ für die sozialen Missstände verantwortlich gemacht. In der Flächensanierung 


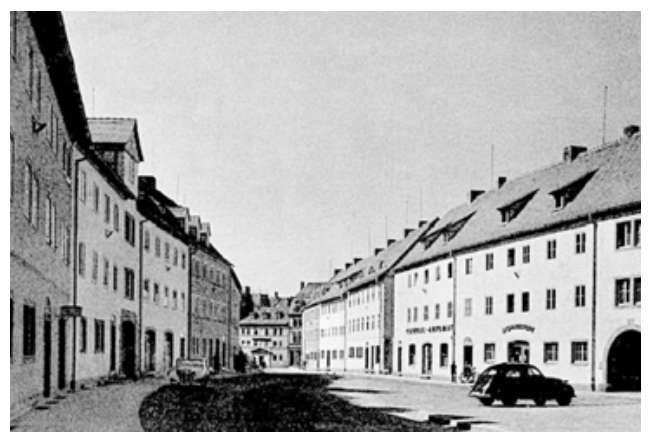

Abb.126 Weimar, Ansicht der X-Straße von Willem Bäumer, Blick nach Süden, 1939 der Gründerzeitviertel, so fasst es Ursula von Petz zusammen, äußere sich die Großstadtfeindlichkeit und letztlich auch die Judenfeindlichkeit des Nationalsozialismus. ${ }^{190}$

Die in den Ursprüngen des Heimatschutzes liegende Absicht, die „Eigenart“ der Stadtbilder zu erhalten, mündete im Nationalsozialismus schließlich in eine - meist rigoros - gestaltende Stadtbildpflege und eine „ästhetische Homogenisierung“, wie es Gerhard Vinken bezeichnet. ${ }^{191}$ Zahlreiche erhaltenswerte Bestandsbauten wurden auf die Form „typischer“ Altstadthäuser „rückgeführt“ und etwa in Geschosshöhe und Giebelform vereinheitlicht. ${ }^{192}$ In dieser Vereinheitlichung der Fassaden und Kubaturen folgte man einem ideologisierten Idealbild der „deutschen“ Altstadt, worauf später noch zurückzukommen sein wird.

Auch die Neubauten sollten sich anpassen und sich dem Gesamteindruck unterordnen. Sie sollten dabei aber, so der Kunsthistoriker Wilhelm Pinder, nicht „Imitationen des Alten“ darstellen, wie die „Sünden des 19. Jahrhunderts“, sondern sollten als „Ausflickungen“ fungieren, die sich durch „den Farbton, die Proportion, den Werkstoff, den Umriss“ an ihrer Umgebung orientierten, im Sinne einer „bescheidenen Begleitung“ des Bestandes, und nicht mit ihr in Konkurrenz traten. ${ }^{\mathbf{1 9 3}}$ Dieselben Intentionen verfolgten die gezeigten Entwürfe Karl Holeys für den Karlsplatz und die Wollzeile.

Bis in die 1940er-Jahre ist in dieser Hinsicht eine gewisse Intensivierung festzustellen. Die Vorgaben zum „richtigen“ neuen Bauen in historischer Umgebung - in der so oft zitierten „Eigenart“ der Städte - wurden zunehmend restriktiv. Willem Bäumer, zum damaligen Zeitpunkt Professor an der von Paul Schultze-Naumburg geleiteten Weimarer Hochschule für Baukunst, ${ }^{194}$ realisierte schließlich bis 1939 die sogenannte $\mathrm{X}$-Straße in Weimar und damit eine „Lehrstraße“ für die Zukunft der Altstadtsanierung (Abb.126,127). In der Art der Gebäude entlang dieser Straße sollten Neubauten in der „deutschen“ Altstadt gestaltet werden - Bäumer gab sozusagen den zur Verfügung stehenden Formenkanon vor:

„In den Einzelheiten - Gesimsen, Dachaufbauten, Fenstern, Türen - sind die Häuser ebenso verschieden wie im großen [sic!]. Hier bietet die X-Straße dem bodenständigen Bauwesen geradezu eine Sammlung von Musterbeispielen für gute, einfache Gestaltung aus den Gesetzen des Baustoffs und Handwerks."195

Auch diese umfassenden Ergänzungen des historischen Bestandes bezeichnete man als Akt der Altstadtsanierung: Die neu angelegte Straße schuf in den Augen

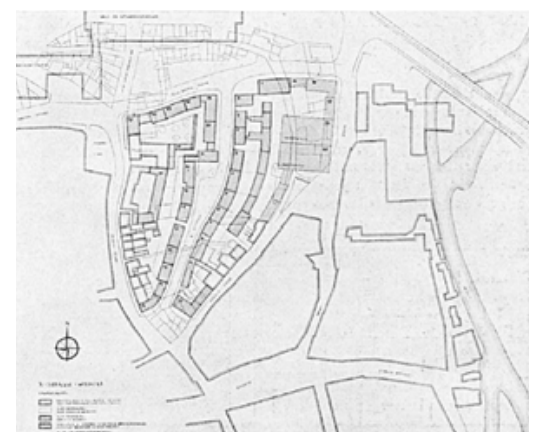

Abb.127 Weimar, Lageplan 1:4000 mit den neuen Straßenzügen von Willem Bäumer über dem historischen Stadtgrundriss (nördlich davon Teile des neuen Gauforums von Hermann Giesler), 1939 
der durchführenden Planer einen „natürlichen Übergang zur vorhandenen Altstadtbebauung“196 - durch die vermeintlich typische, bodenständige, „deutsche“ Architektur und die Wiederaufnahme des „kleinen Maßstab[s] des alten Weimar“.197 Man beabsichtigte anhand dieser Art von Neubauten ein einheitliches, „störungsfreies“ Ganzes zu erzeugen, wobei eine gewisse Vielfalt in der Gestaltung durchaus erwünscht war (Abb.128): „Jedes Haus ist verschieden vom anderen, trotzdem sind alle aus einem Geist und einer Gesinnung herausgewachsen. Es ist wie in einer echten Volksgemeinschaft: Jedes ordnet sich ein und bewahrt doch zur Steigerung des Ganzen seine Eigenart.“198

\subsection{2 „Schöpferischer“ Umgang mit historischer Substanz}

Hinsichtlich des äußeren Erscheinungsbildes der bestehenden Altstadtbauten strebte man zunehmend nicht
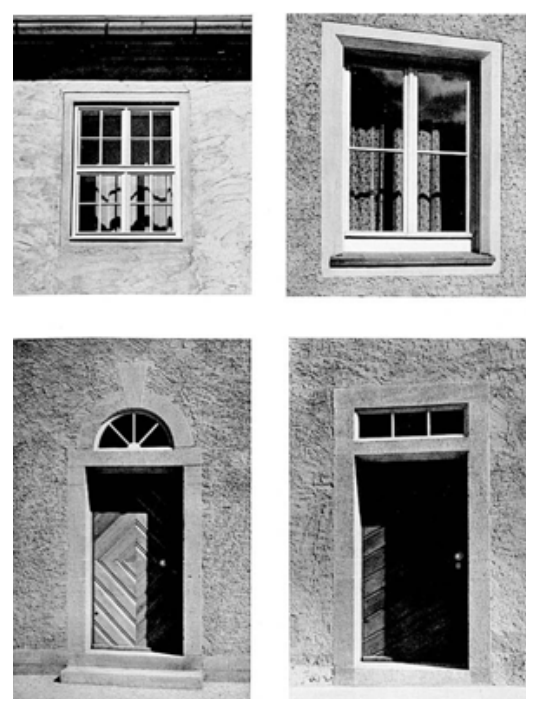

Abb.128 Willem Bäumer, Baudetails von Häusern an der X-Straße in Weimar, 1939 mehr nach Erhaltung, sondern Gestaltung, die sich vordergründig in der Vereinheitlichung von Firsthöhen, Dachformen und Grundstücksbreiten äußerte. Auch eine „angemessene“ Farbigkeit der Fassaden sollte das Straßenbild verschönern und eine „Harmonisierung“ erzeugen (Abb.129). ${ }^{\mathbf{1 9 9}}$ Man versuchte somit, einheitliche Straßenzüge und homogene historische „Ganzheiten“ zu generieren. Die Maßnahmen zeigen demnach eine entschiedene Ablehnung des über Jahrhunderte geformten, Brüche, Unregelmäßigkeiten und Überformungen aufweisenden Stadtbildes, seines Alterswertes und seines „unvollkommenen“ Zustands.

Formuliert wurden diese Ziele und Methoden der „Altstadtgesundung“ bereits am Tag für Denkmalpflege und Heimatschutz im Jahr 1933 in Kassel durch den Kunsthistoriker Wilhelm Pinder. ${ }^{200}$ Die Tagung stand unter einem ebenso programmatischen Titel („Im Wiederaufbau der Nation“) wie der Vortrag Pinders selbst, der sich der „Rettung der Deutschen Altstadt“ widmete. ${ }^{201}$ Pinder stellte die Forderung nach einer „übergeordneten Instanz“, die durchgreife - „verbietend, Schlechtes vernichtend, Neues aufbauend“ -, und nach einem „weitreichende[n] Enteignungsrecht“. ${ }^{202}$ Den Bestand gelte es zu adaptieren, um einstige „Ganzheiten“ wiederherzustellen. Die erstrebenswerten Eingriffe, wie Geschosse abzunehmen oder draufzusetzen, „Verzierungen fortzunehmen“ und „ein neues bescheidenes Gesicht in die Nachbarschaft des Alten zu bringen“, verstand er, wie auch der Titel seines Vortrags unterstreicht, als „Erhaltungsmaßnahmen“ für die Altstadt:203

„[...] das Alte zu erhalten, [...] vor allem durch taktvolle Angleichung der Umgebung; durch Dienst am Alten, durch begleitende Formen! Höhenunterschiede ausgleichen, Umrisse vereinfachen, Farben angleichen, Werkstoffe angleichen, ganz Schlechtes vernichten! Ganzheiten wiederherstellen! Das ist möglich, das ist Pflicht.“204

Im Rahmen dieser „Vereinheitlichung“ war vor allem die Beseitigung von „minderwertigen“ baulichen Ergänzungen und Dekorationen des Historismus das erklärte Ziel, 


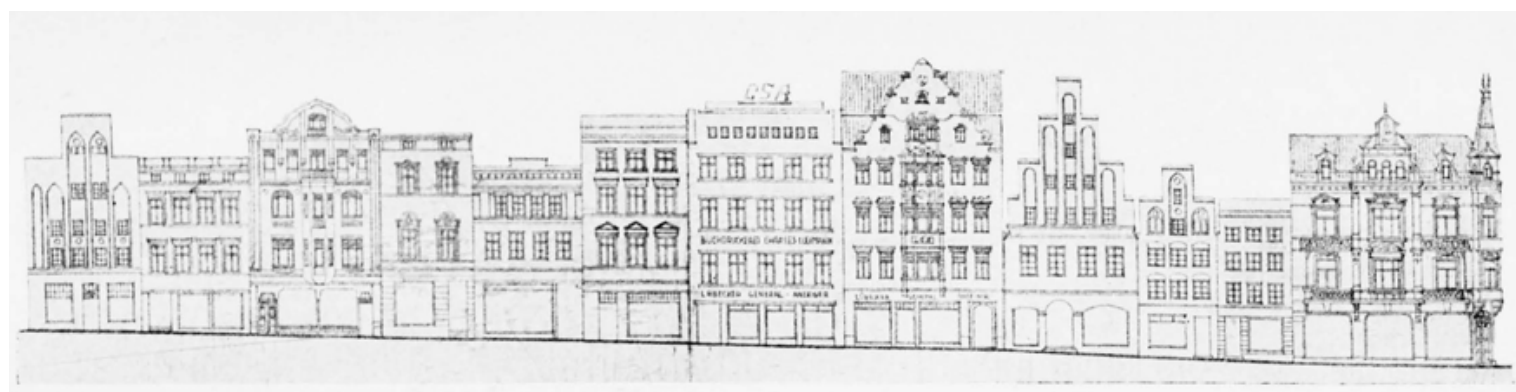

Abb.129 Die Königstraße in Lübeck (Nr. 43-67) vor und nach der „Altstadtgesundung“, Angleichung der Fassaden und Kubaturen nach dem Entwurf von Otto Hespeler, oben der vorhandene Zustand, darunter die Ansicht nach der "Gesundungsmaßnahme“, aus einer Publikation von 1938

wie sie in Deutschland bereits seit den 1920er-Jahren praktiziert wurde. ${ }^{205}$ Die Heimatschutzbewegung und die institutionalisierte Denkmalpflege befürworteten die „Rückführung“ auf vermeintlich „ursprüngliche“ Zustände und die Beseitigung der Spuren des 19. Jahrhunderts. ${ }^{206}$ Nach der Machtergreifung der Nationalsozialisten wurde die Beseitigung des Historismus aus dem Stadtbild fortgesetzt, intensiviert und war fortan vor allem politisch-ideologisch motiviert. Ziel war eine „angemessene“ Gestaltung und „Verbesserung“ des Stadtbildes, im Sinne einer „schöpferischen Denkmalpflege“207. Diese Auffassung der Denkmalpflege als gestaltende Tätigkeit sah die „Einbindung des Denkmals in die Gegenwart“ durch eine aus dem Wesen des Denkmals heraus entwickelte, künstlerische Gestaltung als eine ihrer zentralen Aufgaben. Dem Betrachter sollte das Denkmal verständlich gemacht werden, man ging also weit über eine konservierende Tätigkeit hinaus und zu gestaltenden, aktiv in die Substanz des Bauwerks eingreifenden Maßnahmen über. ${ }^{208}$ Dieser Prozess der Gestaltung und „Verbesserung“ des Bestandes gipfelte in der „Entschandelung“209 ganzer Straßenzüge wie der Semlowerstraße in Stralsund im Jahr 1939 und in der „Eindeutschung“ der Stadtbilder im okkupierten Osten. ${ }^{\mathbf{2 1 0}}$

Schmuckreiche Fassadengestaltungen, vor allem des 19. Jahrhunderts, wurden entfernt, die Architektur auf ihre Grundstruktur hin „bereinigt“ und die Fassaden glatt verputzt (Abb.130). Verputzte Architekturoberflächen mittelalterlicher Bauten wurden hingegen häufig auf Steinsichtigkeit „bereinigt“ und durch die Entfernung späterer Anbauten vermeintliche „Urzustände“ rekonstruiert, die besser in das damalige Mittelalterbild passten. Vor allem die im 19. Jahrhundert erfolgten Eingriffe und „Umbauten“ versuchte man so weit wie möglich rückgängig zu machen und Bauten von ihren historistischen „Verkleidungen“ zu „befreien“.211 Ziel war es, das Stadtbild „von all diesen ungesunden und schlechten Zutaten zu reinigen“, um ihm „den eigenartigen Gesamteindruck wiederzugeben“212, so Otto Hespeler, Oberbaurat von Lübeck.

Aber nicht nur das 19. Jahrhundert war erklärtes Feindbild, auch bei Bauten der „klassischen“ Moderne nutzte man die Sanierung als „historisches Korrektiv“ und setzte beispielsweise Wohnbauten in Hamburg im Rahmen der Stadtsanierung Satteldächer auf. ${ }^{\mathbf{2 1 3}}$ Im Gegenzug dazu galt das Fachwerkhaus, das das Stadtbild zahlreicher deutscher Altstädte prägte, als genuin „deutsche“ Baukunst. Die zweifelhafte und ausufernde Praxis der Freilegung von Fachwerken wurde mit Unterstützung des Deutschen Bundes Heimatschutz seit den 1920ern praktiziert und in den 1930er-Jahren 


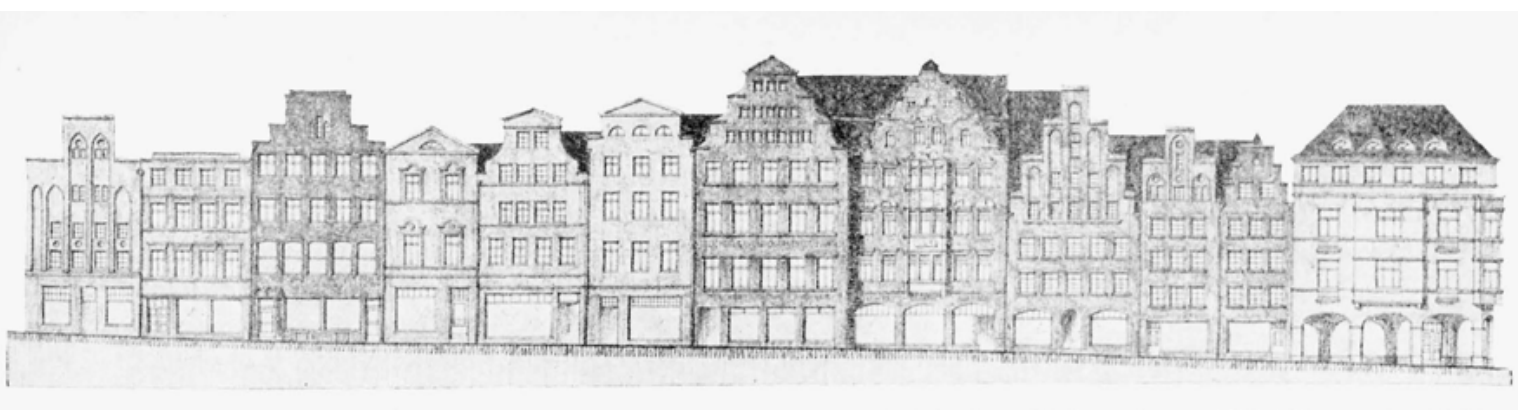

fortgesetzt. ${ }^{214}$ Ungeliebte Bauepochen wurden somit stigmatisiert und andere idealisiert - es etablierte sich, so fasst es Anja Wiese zusammen, ein „normativer Schönheitsbeziehungsweise Hässlichkeitsbegriff“.215

Diese Maßnahmen der Stadtbildkorrektur nach 1933 waren ideologisch motiviert und sollten von der breiten Bevölkerung mitgetragen und umgesetzt werden. Die „deutsche Stadt" sollte so rasch wie möglich einen geordneten, sauberen Eindruck erwecken. Im Mai 1936 veranlasste man daher, im Hinblick auf die Austragung der Olympischen Spiele, eine große „Entschandelungsaktion“, durch die in den Dörfern und Städten jede „Verschandelung“, alles „Unordentliche“ und „Unschöne“ beseitigt werden sollte, um die deutsche Heimat im besten Licht zu zeigen. Mit der Ausarbeitung von Richtlinien für die Aktion wurde Werner Lindner betraut, Fachbeauftragter des Deutschen Bundes Heimatschutz, der in Lichtbildvorträgen die geplanten Maßnahmen vorstellte. ${ }^{216}$

Der Bevölkerung versuchte man anhand der Wanderausstellung Die schöne Stadt ihre Entschandelung und Gestaltung, die ab 1938 im gesamten Reichsgebiet gezeigt wurde, die große Bedeutung dieser Eingriffe nahezubringen. ${ }^{217}$ In der Ausstellung wurden neben Modellen auch zahlreiche Bildtafeln mit Sanierungsbeispielen aus unterschiedlichen Städten gezeigt, in gewohnten und wirkungsvollen Vorher-nachher-Vergleichen und erläutert mit polemischen Bildunterschriften. ${ }^{218}$ Auch Lindners 1939 publiziertes Buch Die Stadt ihre Pflege und Gestaltung, ein von völkischer Gesinnung geprägtes Regelwerk für die „schöne“ Stadtgestaltung, beabsichtigte mit einer Fülle an Beispielen die Veranschaulichung und Verbreitung der propagierten Maßnahmen zur Stadtbildpflege (Abb.131).219 Zumeist werden „gute“ und „schlechte“ Beispiele einander direkt gegenübergestellt und für die ausführlichen Bildunterschriften bewusst unterschiedliche Schriftarten gewählt. Zum Schluss folgen einige gelungene „Entschandelungsaktionen“ und Beispiele vorbildlicher "Gesundungsmaßnahmen“ aus diversen deutschen Städten, etwa Frankfurt am Main, Kassel und Köln (Abb.132). Zu starke optische Brüche in der Fassadengliederung, den Baumassen oder Dachformen werden von Lindner als störend dargestellt. Ein „vollendeter Zusammenklang“ ergäbe sich hingegen durch eine zurückhaltende, flächenhafte Gestaltung, den großen Monumenten „bescheiden dienend“.220 Die Parallelen zu den Inhalten der Wanderausstellung des Österreichischen Verbandes für Heimatpflege (vgl. Kap. 5.2.3.), die bereits seit den 1920er-Jahren gezeigt wurde, sind augenfällig. 

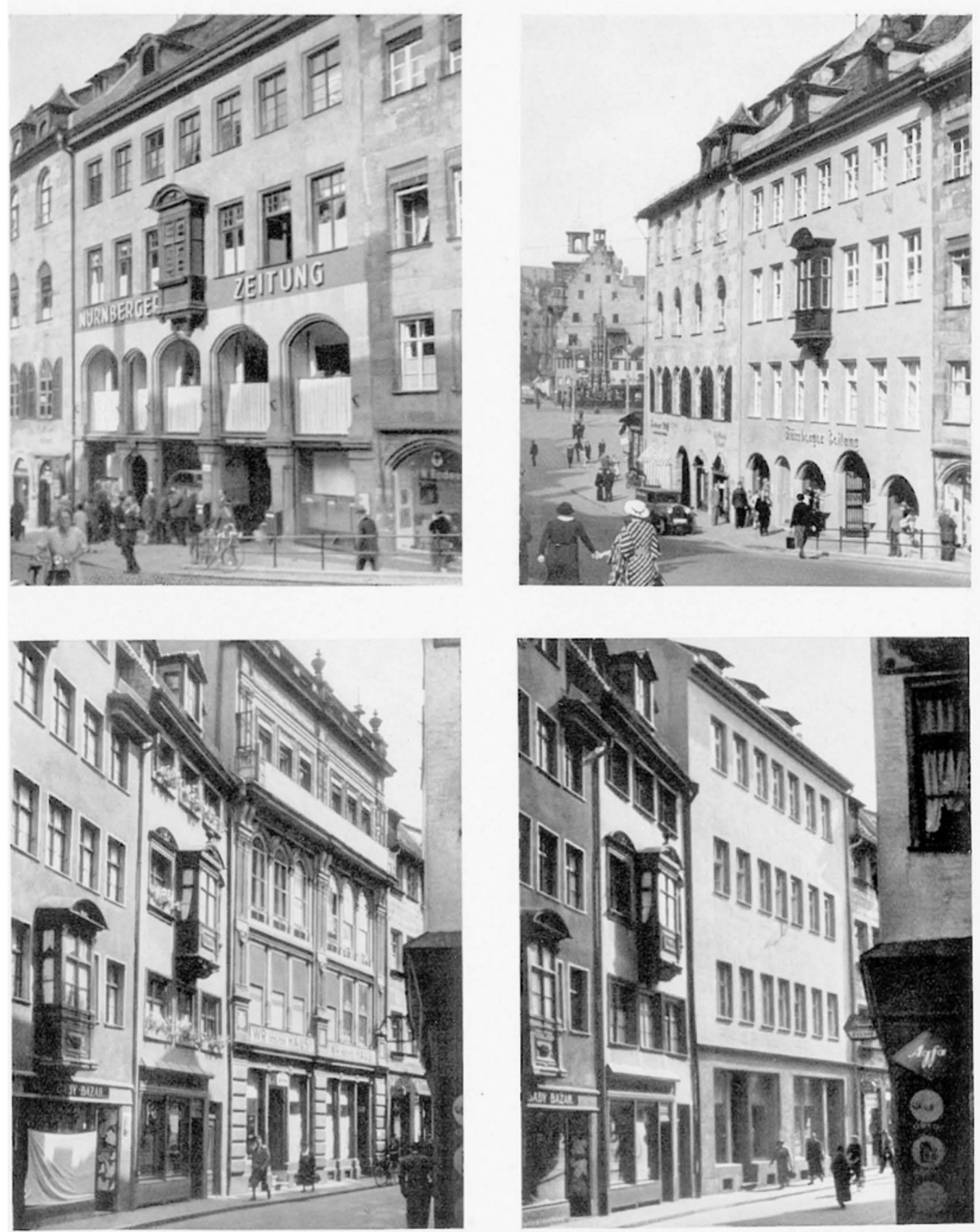

Entichanbelungen in Nürnberg

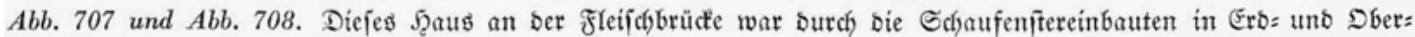

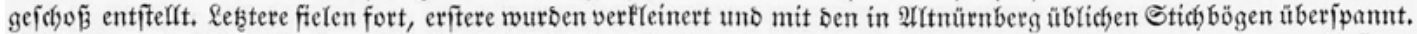

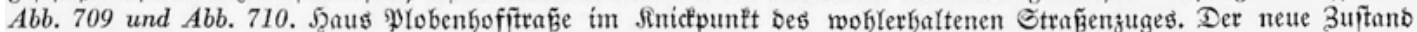

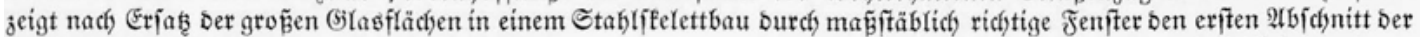

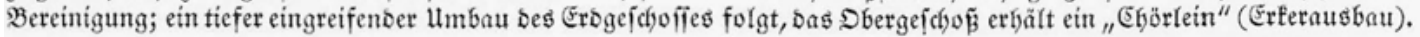



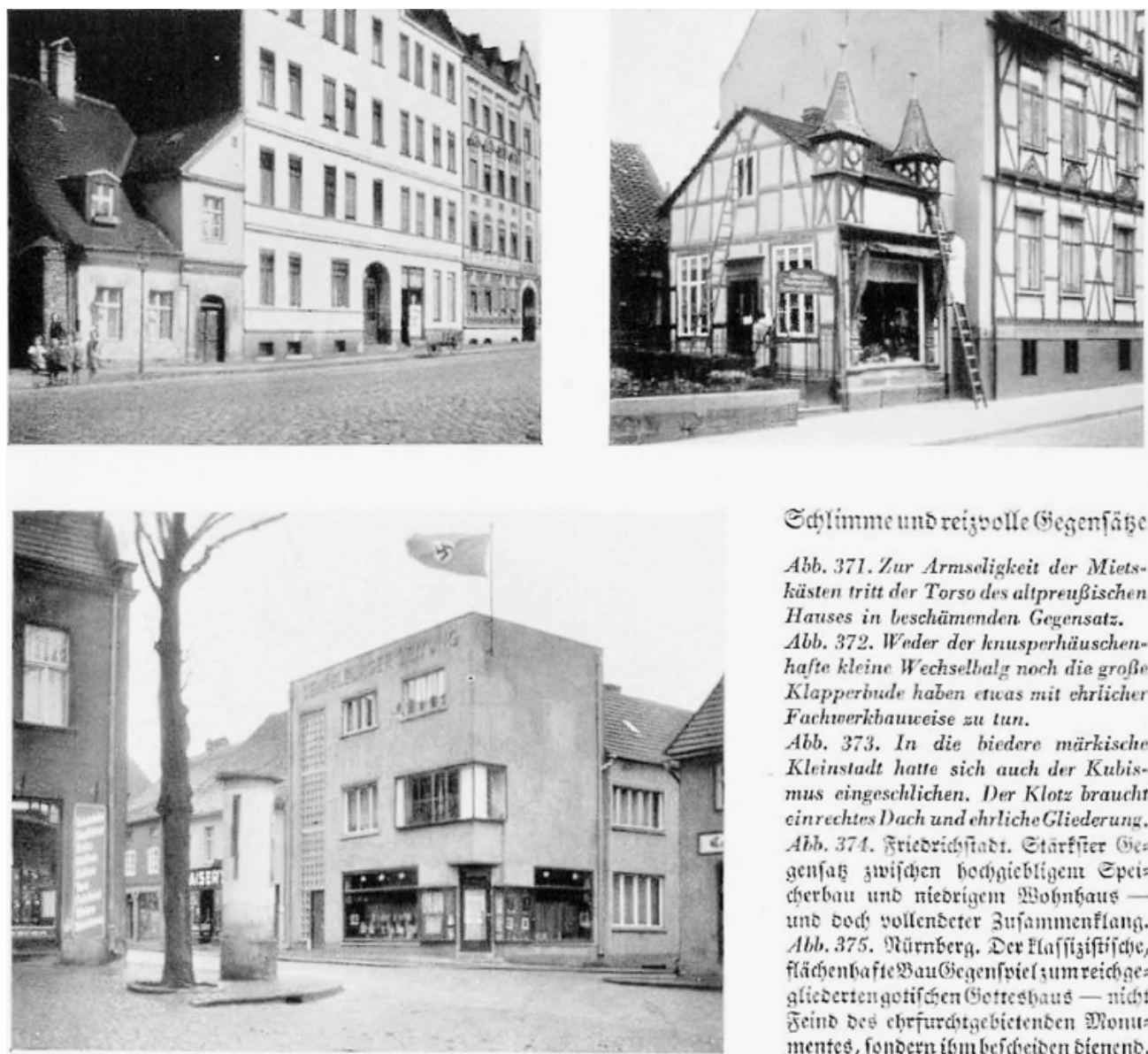

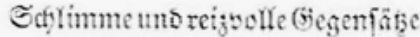

Abb. 371.Zur Armseligkeit der Mietsküsten tritt der Torso des altpreußischen Hauses in beschämenden Gegensatz. Abb. 372. Weder der knusperhäuschenhafte kleine Wechselbalg noch die groß. Klapperbude haben efuas mit ehrilicher Fachoerkbauveise zu tun.

Abb. 373. In die biedere märkische Kleinsladt hatte sich auch der Kubis. mus eingeschlichen. Der Klotz braucht einrechtes Dach und ehrliche Gliederung. Abb. 374. Fricbrichtiabt. Gtärt̂ter Gie: genfab gwifhen bodgaiebligen Epei= cferbau unb niebrigen জisbntyat unb bod vollenseter Bupumenfiang.

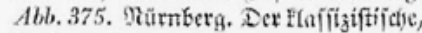
fläbenflafte Baubiegenfviel: um reichge: glicsertengotif dyen Gotteshaus - nid.t Jeino be हbrfurchtgebietenben Divnt: mentes, fondern ifm befideiben sienento.
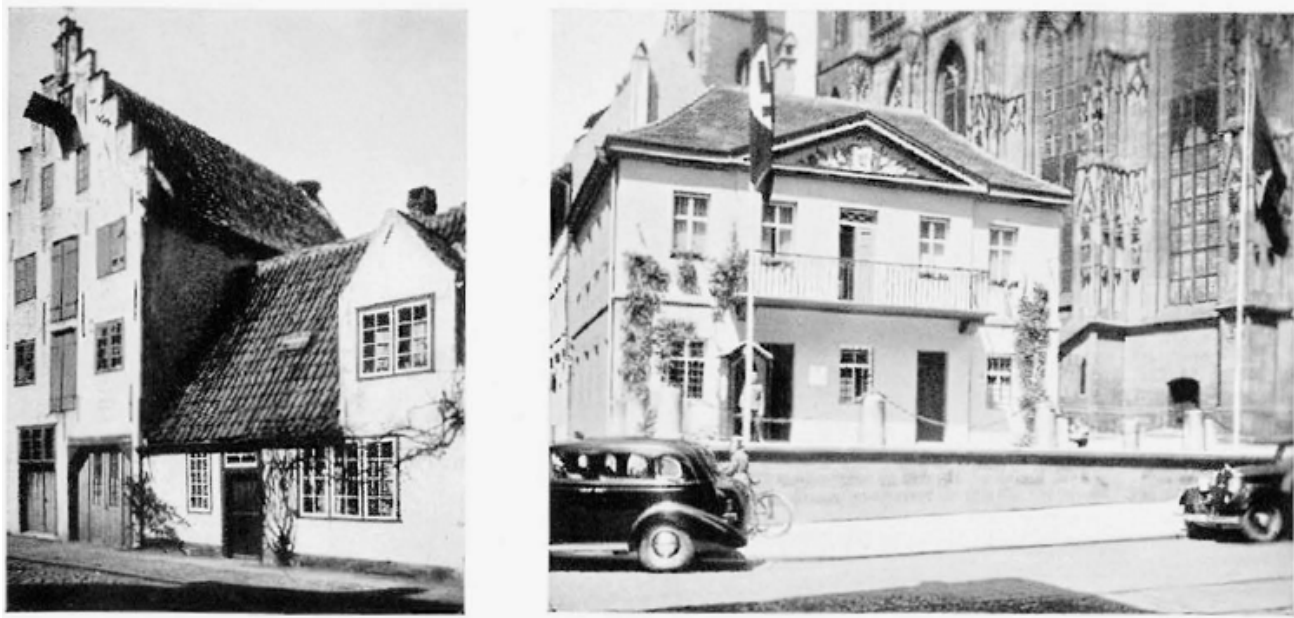

Abb.131 Werner Lindner, Die Stadt. Ihre Pflege und Gestaltung, 1939: „Schlimme und reizvolle Gegensätze“; die jeweilige Bewertung verdeutlicht sich auch in der unterschiedlichen Schriftart des erläuternden Textes. 
Die in Deutschland in den 1930er-Jahren praktizierte, gestaltende Denkmalpflege setzte eine Entwicklung fort, die bereits in der Monarchie ihren Ursprung genommen hatte und in der Weimarer Republik weiterhin gepflegt worden war. Wie Wolfgang Sonne ausführt, wurde das einzelne Objekt als Teil der Stadtstruktur gelesen und eine vordergründig auf die visuelle Wahrnehmung des Denkmals ausgerichtete „denkmalpflegerische“ Praxis vertreten. Im Nationalsozialismus führte man diese Auffassung bruchlos fort und forderte eine Unterordnung des einzelnen Gebäudes im Gesamtbild der Stadt. Die vermeintliche „Verbesserung“ des historischen Bestandes wurde dabei als legitimes Ziel verstanden und äußerte sich in der optischen Angleichung von Fassaden, Giebelformen und Geschosshöhen durch die Überformung einzelner, aus „ungeliebten“ Epochen stammender Objekte bis zur „Harmonisierung“ ganzer Straßenzüge. ${ }^{221}$ Die
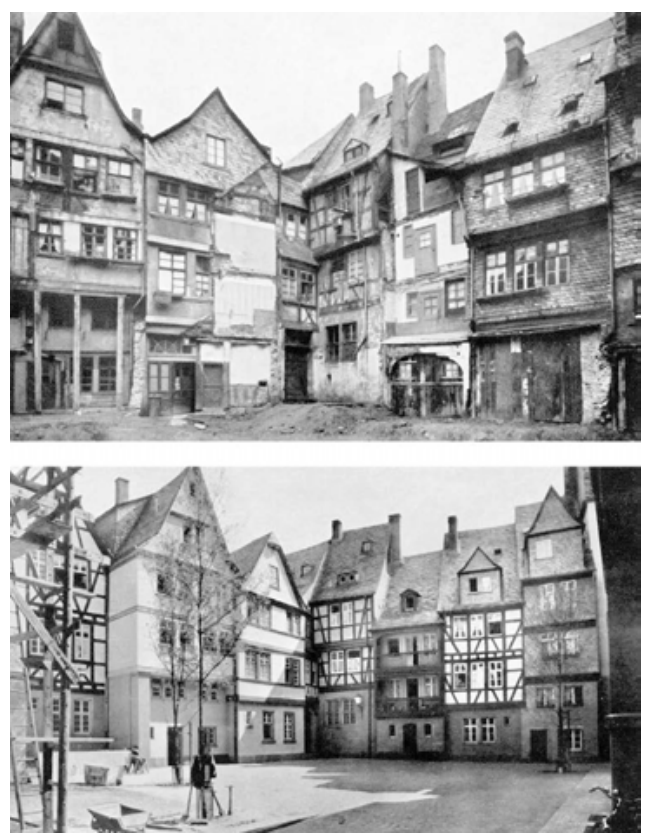

Abb.132 Werner Lindner, Die Stadt. Ihre Pflege und Gestaltung, 1939: „vorbildliche“ Altstadtsanierung in Frankfurt, Auskernung an der kleinen Fischergasse Denkmal- und Stadtbildpflege verstand sich demnach als „schöpferische Instanz“, die einen vermeintlichen Urzustand wiederherstellen oder gar verbessern konnte und es als legitim erachtete, ungeliebte Zeitschichten oder ganze Epochen der Architekturgeschichte aus dem Stadtbild zu entfernen.

Die Denkmalpflege war im Deutschen Reich in den Prozess der „Altstadtgesundung“ miteingebunden. ${ }^{222}$ Der zunehmenden Wertschätzung des städtischen Ensembles seit der Jahrhundertwende, vorbereitet durch Camillo Sitte und die wachsende Bedeutung der Stadtbaukunst, stand nun ein mangelndes Interesse an bzw. ein anderes Verständnis von Authentizität gegenüber. Anpassungen der historischen Substanz im deutschtümelnden Geschmack des Nationalsozialismus wurden von der Denkmalund Stadtbildpflege gutgeheißen. Ein wesentlicher Motor dieser Entwicklung waren die deutschen Heimatschutzverbände, deren „heimatverbundene“, teils reaktionäre Einstellung ab den 1920er-Jahren schließlich in eine nationalistische Haltung umschlug. ${ }^{\mathbf{2 2 3}}$ Hatte der Mitbegründer der Heimatschutzbewegung in Deutschland, Paul Schultze-Naumburg, in seinen Kulturarbeiten von 1906 bei den Ausführungen zum Städtebau noch die „wundervolle Harmonie“ und malerische Wirkung der alten Stadtbilder im „Rhythmus“ der Häuser, dem geschwungenen Verlauf der Straßen, den Unregelmäßigkeiten etwa durch Vorsprünge und dem „mannigfaltig steigernden Aufbau der grossen [sic!] Massen“ erkannt, ${ }^{224}$ verstand man in den 1930er-Jahren unter der „Harmonie“ des Stadtbildes die „Homogenisierung“ der Altstadtsubstanz und eine oftmals radikale Angleichung an ein idealisiertes Bild der „deutschen Heimat“. 


\subsubsection{Heimatschutz - die verbindende Kraft}

Die amtliche Denkmalpflege und die Heimatschutzbewegung in Österreich pflegten auch in den Jahren des Ständestaats enge Kontakte zu den deutschen Kollegen, weshalb hier der Frage des fachlichen Austauschs und einer möglichen Einflussnahme nachgegangen werden soll. Die inhaltlichen Übereinstimmungen zeigten sich bereits im Vergleich der Wanderausstellungen der beiden Heimatschutzorganisationen. Das Ausstellungskonzept des österreichischen Verbandes für Heimatpflege wurde am Anfang Juli 1938 in Hamburg abgehaltenen Tag für Denkmalpflege und Heimatschutz mit dem programmatischen Titel „Heimatpflege in der Stadt“ präsentiert. ${ }^{\mathbf{2 2 5}}$ Es stieß laut Karl Giannoni dort auf reges Interesse und wurde als ein „hervorragendes Werbemittel für Denkmalpflege und Heimatschutz“ bezeichnet, „das in dieser Form im Altreiche unbekannt" sei.226 Diese Aussagen weisen auf eine gewisse Vorbildwirkung der seit 1920 in wechselnder Form in Österreich gezeigten Ausstellung hin.

Vermutlich bereits im Zuge der ersten Gemeinsamen Tagung für Denkmalpflege und Heimatschutz 1911 in Salzburg wurden auch die Kontakte der beiden Heimatschutzbewegungen intensiviert (vgl. Kap.1). In „Koreferaten“ berichteten Paul Clemen und Max Dvořák über die Entwicklungen und Ziele der Denkmalpflege in den jeweiligen Ländern und Paul Schultze-Naumburg und Karl Giannoni über ebensolche des Heimatschutzes. ${ }^{227}$

Nach der erzwungenen Unterbrechung durch den Ersten Weltkrieg setzte sich spätestens ab 1920 mit den nahezu jährlich stattfindenden Fachtagungen (Tag für Denkmalpflege und Heimatschutz) der Austausch fort. ${ }^{228}$ Daran änderte sich, trotz der politischen Differenzen, auch während der 1930er-Jahre nichts. ${ }^{229}$ Am bereits öfter erwähnten Tag für Denkmalpflege und Heimatschutz in Würzburg 1928 mit dem programmatischen Titel „Altstadt und Neuzeit“ wurden die aktuellen Fragen der Altstadterhaltung diskutiert. Am ersten Tag der Konferenz trugen „Altmeister“ Theodor Fischer und der noch junge Ernst May, Stadtbaurat von Frankfurt am Main, zum Thema vor. Fischer forderte „Takt“ bei der Veränderung von Altstädten, von den Architekten gleichermaßen wie von den Bauherren und Behörden. May plädierte für den Abriss „,wertloser“ Altbauten und die Beseitigung der „Elendsquartiere“ in Altstädten sowie für eine ausreichende Belichtung und Belüftung der dichten Altstadtstruktur. ${ }^{\mathbf{2 3 0}}$ Unter den Teilnehmenden waren auch einige Mitarbeiter der Zentralstelle für Denkmalschutz, Fortunat von Schubert-Soldern (damaliger Präsident), Oskar Oberwalder, Baurat Emil Ladewig (Technische Abteilung), Dagobert Frey und Karl Giannoni. ${ }^{231}$

Eine weitere Intensivierung der fachlichen Beziehungen brachte sicherlich die im Mai 1929 in Bregenz als „Gesamtdeutsche Heimatschutztagung“ abgehaltene Jahrestagung des Österreichischen Verbandes für Heimatschutz. ${ }^{\mathbf{2 3 2}}$ Mitveranstaltet vom Deutschen Bund Heimatschutz und der Schweizerischen Vereinigung für Heimatschutz hielt dort Rudolf Esterer seinen wegweisenden Vortrag zur Krise und Zukunft der Heimatschutzbewegung. ${ }^{\mathbf{2 3 3}}$ Die Tagung sollte in Zukunft im Dreijahresrhythmus abgehalten werden, doch als im Jahr 1933 schließlich der Präsident der Schweizerischen Vereinigung für Heimatschutz, Arist Rollier, eine Wiederholung der „DreiländerZusammenkunft“ im Juni desselben Jahres am Bodensee vorschlug, musste Giannoni aufgrund der finanziellen Situation und der mangelnden Zeitressourcen mit großem Bedauern ablehnen. ${ }^{\mathbf{2 3 4}}$ Auch wenn die Wiederholung der gemeinsamen Tagung nicht zustande kam, war in den Jahren davor und danach der gegenseitige Besuch der 
Fachtagungen üblich, ${ }^{\mathbf{2 3 5}}$ wie die Korrespondenz zwischen den Präsidenten der Verbände belegt. Karl Giannoni pflegte mit dem Deutschen Bund Heimatschutz und seinem Geschäftsführer Werner Lindner vor allem seit der gemeinsamen Tagung von 1929 ein freundschaftliches Verhältnis. ${ }^{\mathbf{2 3 6}}$

Einen weiteren Anknüpfungspunkt neben den genannten Tagungen bildete die länderübergreifende Publikationstätigkeit. Ab 1926 wurde die auf Initiative von Dagobert Frey ins Leben gerufene Zeitschrift für Denkmalpflege in gemeinsamer Herausgeberschaft publiziert, ${ }^{\mathbf{2 3 7}}$ dies behielt man auch über die Jahre des Ständestaats hinweg bei, mit zahlreichen Berichten zur aktuellen Denkmalpflegepraxis und zu abgeschlossenen Restaurierungsarbeiten in ganz Österreich. ${ }^{\mathbf{2 3 8}}$ Die 1934 in Deutsche Kunst und Denkmalpflege umbenannte Zeitschrift diente förmlich als ein „gemeinsames Sprachrohr“ der Denkmalpflege in Deutschland und Österreich, auch wenn, so FrodlKraft, Österreich in diesen Jahren vorrangig die reine Berichterstattung zu abgeschlossenen Restaurierungsarbeiten zufiel. ${ }^{\mathbf{2 3 9}}$ Die österreichische Denkmalschutzbehörde, die in Berlin und generell im Deutschen Reich hohes Ansehen genoss, ${ }^{\mathbf{2 4 0}}$ und die in einzelnen Länderverbänden organisierte deutsche Denkmalpflege waren laut FrodlKraft in diesen Jahren in einer „geistigen und kulturellen Zusammengehörigkeit“ verbunden. ${ }^{\mathbf{2 4 1}}$ Vor allem im Zuge der gemeinsamen Publikationstätigkeit erfolgte in den 1920er-Jahren eine Annäherung der österreichischen an die deutsche Denkmalpflege. ${ }^{242}$ Von 1926 an wurden in der Denkmalpflege-Zeitschrift gleichwertig Berichte aus Österreich und Deutschland gebracht und auch städtebauliche Themen und Fragen zur zeitgenössischen Architektur in der Altstadt behandelt. Auch die „Altstadtgesundungen“ und „Entschandelungsaktionen“ im Deutschen Reich wurden besprochen und waren den österreichischen Kollegen daher sicherlich bekannt. 1934 thematisierte man die Sanierungsarbeiten in Braunschweig, Nürnberg und Kassel, im Jahr darauf sowie 1937 jene in Frankfurt am Main.

Trotz der inhaltlichen Nähe zum reichsdeutschen Heimatschutz und zur dortigen Denkmalpflege kann man nicht von einer speziellen Einflussnahme auf die denkmalpflegerische Praxis und die Stadtbildpflege in Österreich während des Ständestaats sprechen. Vielmehr war der österreichische Heimatschutz dem deutschen Pendant seit den Anfängen in seinen Wertvorstellungen und dem Verständnis seiner Aufgaben und Pflichten eng verbunden. Dies äußerte sich in der vergleichbaren Kritik am Städtebau der Gründerzeit und am Fassadendekor des Historismus oder etwa auch in der Forderung der Unterordnung von Neubauten in der Altstadt, im Sinne einer bescheidenen „Begleitung“ des Bestandes.

Wie die Beiträge und Berichte in den Fachzeitschriften ab 1926 verdeutlichen, wurde auch in Österreich eine „schöpferische Denkmalpflege“ praktiziert, wenn auch nicht landesweit ${ }^{\mathbf{2 4 3}}$ und nicht mit derselben Intensität. Es finden sich zahlreiche Beispiele, vor allem für die durchaus vergleichbare „Enthistorisierung“244. Die Wanderausstellung des Österreichischen Verbandes für Heimatpflege zeigte vergleichbare Inhalte wie Werner Lindners Publikation Die Stadt. Ihre Pflege und Gestaltung (1939). Eine Sektion der Ausstellung hieß beispielsweise „Entschandelungen - eine Zeitforderung“ und verurteilte übermäßige Werbung und schlechte Bauzustände (Abb.133). Eine andere brachte Beispiele von „Geschmackswidrigkeiten“ aus dem späten 19. Jahrhundert (vgl. Kap. 5.2.3.). 


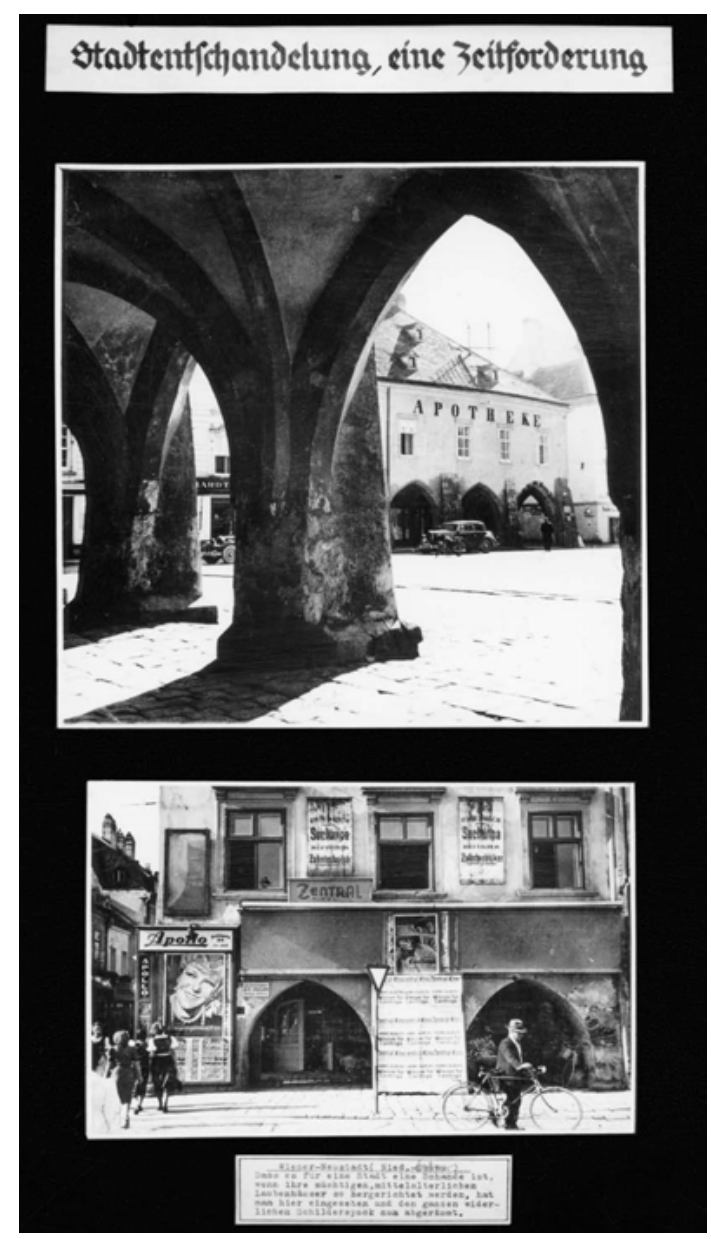

Abb.133 Fotografie eines Ausstellungsplakates zum Thema „Stadtentschandelung, eine Zeitforderung“ aus der Wanderausstellung des Österreichischen Verbandes für Heimatpflege, vor 1940
Im Unterschied zum Deutschen Reich waren Denkmalpflege und Heimatschutzverband aber nicht aktiv in den Prozess der „Altstadtgesundung“ eingebunden. Vorschläge für "Gesundungsmaßnahmen“ oder Auskernungen bleiben aus.

Offenbar wollte sich die Denkmalpflege jedoch nach dem „Anschluss“ im Frühjahr 1938 am deutschen Modell orientieren und fortan eine aktivere Stadtbildpflege betreiben. In einem gewandelten Verständnis der eigenen Aufgaben und Pflichten prophezeite man selbstbewusst einen „Neuanfang“ der Denkmalund Stadtbildpflege. ${ }^{\mathbf{2 4 5}}$ Man erhoffte sich, das in der Vergangenheit „Versäumte soweit als möglich nachzuholen“ und „die schönsten alten Stadtteile von Wien durch entsprechende Gesundungsmaßnahmen für die Zukunft zu sichern“.246 Die amtliche Denkmalpflege übte nun heftige Kritik an der „rücksichtslose[n] Wohnbaupolitik der Stadtverwaltung " in den Jahren des Ständestaats, durch die „unersetzbare Bauten" verlorengegangen waren und kündigte gleichzeitig für Wien „umfassende Altstadtgesundungsarbeiten“" an. ${ }^{\mathbf{2 4 7}}$

Fachleute der Stadtplanung und des Städtebaus standen in den Jahren des Ständestaats hingegen vermutlich in weniger engem Kontakt mit ihren deutschen Kollegen. Man hatte in Wien jedoch Kenntnis von den bereits durchgeführten und in Planung befindlichen Sanierungsmaßnahmen, wie Artikel in Fachzeitschriften und Tageszeitungen von Karl Holey oder Erwin Ilz verdeutlichen. 1929 präsentierte Jobst Siedler im Rahmen des Städtebaukongresses in Rom Grundgedanken und Leitsätze zur Altstadtsanierung in Deutschland. ${ }^{\mathbf{2 4 8}}$ Unter den Teilnehmenden waren neben Franz Musil als Vertreter des Wiener Stadtbauamtes auch jene Stadtplaner und Stadtbaumeister, die zur Zeit des Nationalsozialismus für die „Gesundungsmaßnahmen“ verantwortlich zeichnen sollten, wie Karl Elkart (Hannover), Hermann Flesche (Braunschweig) oder Otto Hespeler (Lübeck). ${ }^{\mathbf{4 4 9}}$ Im Rahmen des 1935 in Prag abgehaltenen Kongresses des Internationalen Verbandes für Wohnungswesen wurden schließlich bereits in der Umsetzung befindliche oder noch geplante „Altstadtgesundungen“ in Berlin, Frankfurt am Main, Hamburg, Heidelberg und Kassel präsentiert.

Einen intensiveren Austausch mit deutschen Kollegen ermöglichte wohl die im Mai 1937 in Wien abgehaltene Tagung der Deutschen Akademie für Bauforschung ${ }^{\mathbf{2 5 0}}$, 
nachdem man sich zuletzt 1928 ebendort getroffen und diskutiert hatte. ${ }^{251}$ In den Jahren dazwischen seien die „Verbindungen zwischen den Männern des reichsdeutschen und österreichischen Bauwesens nie abgerissen“, sondern die „tiefe Verbundenheit [...] zwischen der Fachwelt der beiden deutschen Staaten“ stets aufrechtgeblieben. ${ }^{\mathbf{2 5 2}}$ Im Rahmen der Tagung wurden von deutschen und österreichischen Referenten über die aktuellen Leistungen im Bereich des Siedlungswesens und über die Wohnungs- und Siedlungspolitik in beiden Staaten berichtet. Einem Vortrag über bereits durchgeführte und noch geplante Altstadtsanierungen in Deutschland von Stadtbaurat Karl Elkart folgte der Bericht von Stadtbaudirektor Franz Musil - wenig überraschend - über „Die Wiener Assanierungsbauten und ihre Finanzierung“. ${ }^{253}$ Spätestens im Rahmen dieser Tagung erfolgte ein intensiver Wissens- und Erfahrungsaustausch - zu spät vermutlich, als dass sich dies auf die Wiener „Stadtgesundung“ im Ständestaat hätte auswirken können.

Nach dem „Anschluss“ 1938 wollte man jedoch offenbar an die Erfahrungen „im Reich“ anknüpfen: Parallel zu den Intentionen der Denkmalpflege kündigte die Stadtverwaltung im Juli 1938 die geplante Auflockerung der Altstadt an, die durch neu geschaffene Wohngebiete am Stadtrand ermöglicht werden sollte. ${ }^{254}$

„Mit der Besiedlung dieser Wohngebiete wird eine Abwanderung aus der Großstadt eintreten, so daß dort alte Häuser mit minderwertigen Wohnungen, deren weitere Erhaltung unwirtschaftlich wäre, abgetragen werden können. So wird es möglich sein, die heute dichtverbauten Stadtteile aufzulockern, Grünflächen anzulegen, und auch dort Sonne, Licht und Luft hinzubringen."255

\subsection{Die „Wiener Assanierung“ im internationalen Kontext}

Die unterschiedlichen „Gesundungsmaßnahmen“ im faschistischen Italien und im Deutschen Reich waren der österreichischen Denkmalpflege und der Wiener Stadtplanung wohl ab den späten 1920er- bzw. frühen 1930er-Jahren bekannt. Die internationalen Städtebaukongresse in Rom (1929), Berlin (1931) und Prag (1935) behandelten das Thema der Altstadtsanierung und die diversen Regulierungsmethoden, vom diradamento über die Auskernung bis hin zu radikaleren Methoden, zumindest als einen von mehreren Tagungsschwerpunkten. Diverse Ausstellungen im Rahmenprogramm dieser Kongresse oder auch unabhängig davon, wie die Schau zum italienischen Städtebau in Wien im Jahr 1937, verbreiteten Informationen zu den in Europa und auch in den USA vorherrschenden Methoden der Altstadtsanierung und verdeutlichen heute, in der Rückschau auf diese Ereignisse, das damalige fachübergreifende und internationale Interesse für das „Problem Altstadt“.

Dass an nahezu allen genannten Tagungen der Denkmalpflege im deutschsprachigen Raum auch Mitarbeiter der Zentralstelle und Vertreter des Heimatschutzverbandes teilnahmen, lässt auf einen regen Informationsaustausch zu Konzepten und Positionen schließen. Der Austausch zu Fragen der Altstadtsanierung und Stadtregulierung zwischen österreichischen und internationalen Fachleuten des Städtebaus war vermutlich weniger intensiv. ${ }^{\mathbf{2 5 6}}$ Die Vertretung Österreichs an den internationalen Städtebaukongressen beschränkte sich, so scheint es, auf einige wenige Personen. An österreichischen Berichterstattern ${ }^{\mathbf{2 5 7}}$ im Rahmen der beiden internationalen Kongresse für Wohnbau und Stadtplanung in Rom und Berlin scheint lediglich Franz Musil auf, 
der allerdings zum damaligen Zeitpunkt als Direktor des Stadtbauamtes Wien bereits sozusagen oberster Städteplanungsbeauftragter der Bundeshauptstadt war, sowie Anton Weber, von 1923 bis 1934 Stadtbaurat für Wohnungswesen. ${ }^{258}$ Die Notwendigkeit, parallel zur Altstadtsanierung „kompensatorische“ Maßnahmen zu setzen, wurde seit den 1920er-Jahren im Rahmen der Städtebaukongresse europaweit diskutiert und auch umgesetzt. ${ }^{259}$ Dass der Architekt Otto Ponholzer in einer Salzburger Tageszeitung im Jahr 1933 die Notwendigkeit des Baus neuer Siedlungen an den Stadträndern bei der Durchführung von Altstadtsanierungen betont, verdeutlicht die Präsenz dieser städtebaulichen Fragen und die Aufnahme international geführter Diskurse auch in österreichischen Fachkreisen. ${ }^{\mathbf{2 6 0}}$

Was aber fand nun in Wien im Vergleich mit den bisher skizzierten Maßnahmen statt? Es verbleibt hier die Aufgabe, die Eingriffe im Wien der 1930er-Jahre in den zuvor skizzierten historischen, internationalen und städtebau-theoretischen Kontext einzuordnen und zu bewerten. Auf die in der Literatur aufgeworfene Frage der „Orientierung an Rom“ und die eingangs vorgebrachte These, dass die in Wien praktizierte „Hausreparatur“ Parallelen zur „Entschandelung“ in Deutschland aufweise, kann nun auf Basis der vorangegangenen Ausführungen abschließend eingegangen werden: Obschon Bundespräsident Miklas seine große Bewunderung für die „städtebauliche Erneuerung Italiens“261 während seines Besuchs der Ausstellung Italiens Stadtbaukunst in der Secession im November 1937 angeblich mehrfach äußerte, kann gerade vor dem Hintergrund der „gesamteuropäischen“ Dimensionen der „Altstadt-Diskussion“ von einer spezifischen Beeinflussung durch die italienische Form der Altstadtsanierung wohl kaum die Rede sein. Dafür zeigen sich in einigen Punkten zu große Unterschiede, etwa in der Tatsache, dass die Stadtsanierung in Rom vor allem durch die „starke Hand des Staates“ (Enteignungen) gesteuert wurde.

Die im Deutschen Reich im Rahmen der „Altstadtgesundung“ erfolgte und ideologisch motivierte „Entschandelung“ fand unter anderen Vorzeichen statt als die „Fassadeninstandsetzung “ in Wien, die praktischen und ästhetischen Überlegungen folgte. Wie die Beispiele in Kapitel 3 zeigten, wurde diese Maßnahme auch in den im späten 19. Jahrhundert entstandenen Arbeitervierteln außerhalb des Altstadtkerns durchgeführt, somit in anderen städtebaulichen Kontexten. Die Ablehnung des überreichen Fassadenschmucks des Historismus - auch in Österreich eine gemeinsame Grundhaltung von Denkmalpflege und Heimatschutzbewegung - verband sich im Deutschen Reich hingegen im Laufe der 1930er-Jahre mit einem ideologisch motivierten Drang zur „Verbesserung“, Harmonisierung und Vereinheitlichung der „deutschen“ Altstadt.

Grundsätzlich muss man daher von der Assanierung der Stadt Wien in den Jahren 1934 bis 1938 als von einem durchaus individuellen Stadtumbauprozess sprechen. Parallelen zu Altstadtsanierungen in anderen Staaten und Städten sind leicht erklärlich, bildeten derartige Eingriffe in den 1930er-Jahren europaweit den wesentlichen Teil der städtebaulichen Praxis. Auskernungen oder Entkernungen wurden ebenso in Stockholm und Zürich wie auch in Frankfurt am Main durchgeführt, mit dem Ziel der „Gesundung“ und Ordnung der historischen Stadt. Auch Karl Holey, Erwin Ilz und Robert Oerley schlugen derartige Maßnahmen vor. Die Assanierung in Wien findet sich mitten im städtebaulichen und denkmalpflegerischen Diskurs im Europa der 1930erJahre um die Zukunft der Altstadt wieder. Die Beseitigung von „unhygienischen“, 
„verunstaltenden“ Altbauten, die sich dem modernen Verkehr und den neuen Baulinien widersetzten und für das „moderne Stadtbild“ angeblich untragbar waren, wurde nicht nur in Wien praktiziert, sondern auch in zahlreichen anderen europäischen (Groß-) Städten. Die Form der Finanzierungshilfe und die Art der Realisierung dieser Regulierungen durch die Privatwirtschaft stellte damals jedoch eher die Ausnahme dar.

Die folgenden Punkte zeigen nun im Detail sowohl die Parallelen wie auch Unterschiede zu den Vergleichsbeispielen auf - hinsichtlich der Rolle von Architektur und Städtebau für das politische System, der gesetzlichen Ausgangslage, den Intentionen von Denkmalpflege und Heimatschutz und dem Verhältnis der Neubauten zur „alten Stadt“.

\subsubsection{Bautätigkeit als Zeichen des wirtschaftlichen und sozialen Aufbruchs}

Konzepte der Altstadtsanierung deutscher Städte lagen schon zur Zeit der Weimarer Republik (1918-1933) vor. Trotz bestehender Enteignungsbestimmungen konnten diese allerdings bis in die 1930er-Jahre aufgrund der wirtschaftlich angespannten Situation nicht durchgeführt werden. ${ }^{\mathbf{2 6 2}}$ Die Lösung der Altstadtfrage wurde sodann von den Nationalsozialisten neuerlich in Angriff genommen und gleichzeitig auch propagandistisch verwertet. ${ }^{\mathbf{2 6 3}}$ In dieser Hinsicht finden sich Parallelen zu Wien: Auch hier war man im Ständestaat - so die Ansicht des Stadtbauamtes - nun endlich wieder „schöpferisch tätig“ geworden. Auf Basis eines gewissen Eigenkapitals und mit Förderungen durch den Assanierungsfonds und später des Kleinwohnungshausförderungsgesetzes sollte die Privatwirtschaft der Hauptstadt ein gesundes und geordnetes Erscheinungsbild verleihen, nachdem man in den Jahrzehnten davor „untätig“ gewesen sei. Man versuchte damit, an die städtebaulichen Maßnahmen der Monarchie anzuknüpfen. Eine propagandistische „Verwertung“ städtebaulicher Planung und eine Instrumentalisierung des Bauwesens fanden auch in Wien statt. In unterschiedlichen Medien (Tageszeitungen, Zeitschriften, Wochenschau Österreich in Bild und Ton) versuchte man, ein Bild des überall tätigen Umbauens zu erzeugen, eine Strategie, die der italienische Faschismus allerdings besser zu nutzen wusste. ${ }^{\mathbf{2 6 4}}$

Die städtebaulichen Rahmenbedingungen für die Altstadtsanierung der 1930erJahre waren in Wien jedoch andere als beispielsweise in Rom und in vielen deutschen Städten. In der Wiener Innenstadt hatte sich bereits im 19. Jahrhundert eine umfangreiche Citybildung vollzogen, die schrittweise die historische Bebauung überformt hatte und vor dem Ersten Weltkrieg nicht abgeschlossen war. Diese Überformung in der Gründerzeit hatte einige „unförmige“ Stadtbereiche und Straßenzüge und vor allem viele einzeln vorspringende Häuser hinterlassen, deren Abbruch man nun ab 1934 durchführen wollte. Auch war die Stadt, seit Jahrhunderten Hauptstadt eines großen Reiches, bereits mehrfach überformt und repräsentativ ausgestaltet worden und ihre Altstadt in Gestalt und Struktur heterogener als die der so jungen Hauptstadt Rom. Im Gegensatz dazu waren die sanierungsbedürftigen Bereiche Roms, die teils großflächig entfernt wurden, noch stärker mittelalterlich geprägt.

Wie in Wien wurden aber auch in Rom gegen Ende des 19. Jahrhunderts bereits entscheidende Regulierungsmaßnahmen durchgeführt. Der Umbau der Altstadt zur Erschließung für den Verkehr und aus Gründen der „Hygiene“ - aber auch zur Repräsentation des neu geschaffenen Nationalstaates - stellten seit der Einigung Italiens und vor allem seit der Hauptstadtwerdung im Jahr 1871 zentrale Themen des Städtebaus in Rom dar. ${ }^{265}$ Im letzten Viertel des 19. Jahrhunderts erfolgten zahlreiche Eingriffe, 
die das Stadtbild entscheidend veränderten, wie die Regulierung des Tiber und die beiderseitige Anlage von Uferstraßen sowie der Durchbruch neuer Erschließungsachsen. Dem Bau des überdimensionalen Denkmals für den ersten König Italiens, Vittorio Emanuele II., an der Piazza Venezia fielen ebenso zahlreiche historische Gebäude zum Opfer. ${ }^{266}$ Auch die ersten „Freilegungen“ am Kapitol, am Palatin sowie am Forum Romanum wurden bereits im 19. Jahrhundert durchgeführt. ${ }^{267}$ Im Faschismus wurde dieses „Regulierungswerk“ mit unglaublicher Intensität fortgeführt. In ihren Dimensionen ist die Wiener „Stadtgesundung“ also kaum mit jener in Rom vergleichbar, im Gegensatz zu Wien wurden dort ganze Straßenzüge oder intakte Altstadtbereiche niedergelegt. Die Eingriffe der 1930er-Jahre in der Altstadt von Wien erfolgten hingegen fast ausschließlich punktuell. Das einzige Großprojekt der Neugestaltung des Freihausareals folgte darüber hinaus keinem architektonischen Gesamtkonzept.

Ein weiterer Unterschied zeigt sich im Verhältnis von Stadterneuerungsmaßnahmen und Siedlungsbau. Im Zuge der Altstadtsanierungen wurden in Rom seit den 1920er-Jahren planmäßig Stadtrandsiedlungen errichtet und Stadterweiterungsgebiete erschlossen, um den notwendigen Ersatzwohnraum zu schaffen. ${ }^{\mathbf{2 6 8}}$ Die in Wien errichteten Siedlungen waren größtenteils Gruppierungen von Einfamilienhäusern und dienten vor allem der Arbeitsbeschaffung. ${ }^{\mathbf{2 6 9}}$ Erst nach dem „Anschluss“ wird für Wien eine baldige planmäßige Umsiedlung der Bevölkerung aus den dichten Altstadtgebieten in die neu zu schaffenden Wohnsiedlungen am Stadtrand bei gleichzeitiger „Auflockerung der Großstadt“ angekündigt. 270

\subsubsection{Die Enteignungsgesetze und die „starke Hand des Staates“}

In den 1930er-Jahren lässt sich in vielen europäischen Ländern infolge der Weltwirtschaftskrise eine stärkere Führungsrolle des Staates im Bereich der Stadtplanung erkennen, nicht nur in Italien und Deutschland, sondern auch in Großbritannien. ${ }^{271}$

Gesteuert wurde (und wird) die Stadtplanung durch gesetzliche Bestimmungen. Bauordnungen, Flächenwidmungs- und Bebauungspläne nahmen auf die Gestaltung der Stadt entscheidenden Einfluss, etwa durch die Vorgaben zu Gebäudehöhen und Mindest-Gebäudeabständen sowie die Festlegung neuer Baulinien. Großen Einfluss erhofften sich Stadtverwaltungen und Stadtplaner von der Möglichkeit der Enteignung, die in manchen Staaten zwar vorhanden war, aber kaum ein praktikables Instrument der Stadtregulierung und -erneuerung darstellte, wie die Beiträge und Diskussionen im Rahmen der Städtebaukongresse der späten 1920er- und frühen 1930er-Jahre verdeutlichen. ${ }^{\mathbf{2 7 2}}$ Hans Bernoulli klagt in seinem Bericht über den Internationalen Städtebaukongress in London im Jahr 1935 über die Tatsache, dass den aktuellen Städtebau ein „einziger Kampf zwischen privaten und öffentlichen Befugnissen“ kennzeichne. Als die wesentlichen Probleme der Stadtverwaltungen allerorts nennt er die „unsachgemäße“ Bebauung, Bodenspekulation, Finanzierungsprobleme und vor allem die mühseligen, langwierigen Enteignungsverfahren. ${ }^{\mathbf{2 7 3}}$

Um die Mitte des 19. Jahrhunderts griffen die städtebaulichen Maßnahmen von Georges Eugène Haussmann in Paris zum ersten Mal in derartigen Dimensionen in die historische Stadtstruktur ein. ${ }^{\mathbf{2 7 4}}$ Ab 1853 realisierte er neben dem Durchbruch breiter und geradliniger Avenuen durch die klein parzellierten, mittelalterlichen Stadtviertel auch eine weitläufige Kanalisation. Seine Prachtboulevards waren nur aufgrund der gesetzlichen Rahmenbedingungen (Zonenenteignung) möglich. ${ }^{275}$ 
Auch im „Dritten Reich“ sah man durch die autoritäre Staatsform nun die Zeit für einen „wirklich schöpferischen Städtebau“ gekommen. ${ }^{\mathbf{2 7 6}}$ Fortan konnte und sollte der Blick auf „das Ganze“ gerichtet, aber auch für den „gedeihlichen Fortbestand der Altstadt“" als einheitliches Gesamtkunstwerk gesorgt werden. ${ }^{277}$ Bereits 1918 war das Preußische Wohnungsgesetz verabschiedet worden, das Enteignungen im Interesse der Allgemeinheit und zur Verbesserung der Wohnverhältnisse ermöglichte. Im Jahr 1931 änderte man das Gesetz zugunsten eines stark abgekürzten Enteignungsverfahrens. ${ }^{278}$ Auch im Parteiprogramm der NSDAP wurde 1935 die Möglichkeit der unentgeltlichen Enteignung für gemeinnützige Zwecke, die schließlich eine einfachere und weniger kostenintensive Inbesitznahme von privatem Grund und Boden ermöglichen sollte, sowie die rasche Enteignung großer, zusammenhängender Stadtbereiche festgeschrieben. ${ }^{\mathbf{2 7 9}}$ Großflächige „Altstadtgesundungen“, geplant durch die jeweiligen Stadtbauämter, konnten letztlich nur durch die Androhung von Repressalien und durch Einschüchterung der Hausbesitzer und Mieter umgesetzt werden. ${ }^{\mathbf{2 8 0}}$

In Italien wurden bereits im Jahr 1865 durch ein neues Gesundheitsgesetz erste Enteignungsbestimmungen festgelegt, ${ }^{\mathbf{2 8 1}}$ die es Gemeinden mit einer Bevölkerungszahl über 10.000 ermöglichten, zugunsten der Allgemeinheit, zur Verbesserung der Verkehrsverhältnisse und der hygienischen Bedingungen Enteignungen durchzuführen, allerdings nur bei jenen Gebäuden, die direkt an die zur Debatte stehende Straße grenzten. Noch ausgedehntere Befugnisse wurden nach den Epidemien in Neapel erteilt. 1885 folgte ein neues Gesetz, das die Enteignung unabhängig von der Lage des Gebäudes möglich machte, Steuererleichterungen gewährte und die Entschädigungsregelung neu definierte. ${ }^{\mathbf{2 8 2}}$ Trotz dieser weitreichenden Enteignungsbestimmungen waren in Italien nach dem Ersten Weltkrieg aus wirtschaftlichen Gründen keine großflächigen Sanierungen möglich. ${ }^{\mathbf{2 8 3}}$ Die Durchführung der zum Teil radikalen Sanierungsmaßnahmen in Rom in den 1920er- und 1930er-Jahren mit zahlreichen Enteignungen, Demolierungen ganzer Altstadtbereiche und der Umsiedlung tausender dort ansässiger Menschen in die sogenannten borgate war letztlich nur aufgrund der politischen Situation und der „starken Hand des Staates“ möglich. Die weitgehende „Ausschaltung der kommunalen Autonomie“ nennt Bodenschatz als wesentliche Grundlage für die Durchsetzung eines „zentralistischen Städtebaus“. Der Governatorato war für die Durchführung der staatlich gelenkten städtebaulichen Projekte verantwortlich. Anders als im nationalsozialistischen Deutschland verabschiedete man jedoch keine städtebaulichen Sondergesetze. ${ }^{\mathbf{2 8 4}}$

In Österreich wurden erst im Jahr 1929 die seit 1919 bestehenden Enteignungsbestimmungen überarbeitet und wesentlich erweitert - zu einem „Gesetz betreffend die Enteignung zu Wohn- und Assanierungszwecken“. Die neuen Enteignungsbestimmungen kamen in Wien in den 1930er-Jahren allerdings vor allem aus wirtschaftlichen Gründen nicht zur Anwendung. Nur in Einzelfällen konnte die Stadt Wien Objekte zu Assanierungszwecken aufkaufen, um sie danach abzureißen. Die „starke Hand“ war in Wien also kaum gegeben bzw. ließ die wirtschaftliche Situation keine planmäßige Durchführung der Stadterneuerung zu. Jenen Hausbesitzern, die Mittel aus dem Assanierungsfonds einwarben, kam man allerdings mit neu geschaffenen gesetzlichen Bestimmungen entgegen, vor allem mit der Möglichkeit der unmittelbaren Kündigung der Mieter (siehe Kap. 3.1.3.). 


\subsubsection{Die „Entschandelung“ der Altstadt}

Angesichts der vorgestellten Beispiele stellt die Assanierung in Wien eine vergleichsweise schonende, weil nicht großflächig eingesetzte Form der "Stadtgesundung“ dar - bzw. war der Stadtumbau bereits im 19. Jahrhundert entscheidend vorangetrieben worden. In vielen Straßenzügen wurden im Zuge der Assanierung der 1930er-Jahre die letzten vor der Gründerzeit erbauten Althäuser entfernt. In Rom wurden in den 1920er- und 1930er-Jahren ganze Altstadtteile abgetragen, Plätze neu gestaltet und monumentale Straßenzüge angelegt, kein Vergleich also mit dem Umfang der in Wien getroffenen Maßnahmen, sieht man von der Neubebauung der Freihausgründe ab. In den als „Altstadt“ bezeichneten Bereichen der historischen Kernstadt und der umliegenden Bezirke wurden nur punktuell Assanierungen und gleichsam „Harmonisierungen“ des Stadtgrundrisses umgesetzt. Dennoch wurde dadurch eine „Zeitschicht“ der Stadtbaugeschichte zunehmend entfernt. Vor allem jene Assanierungen, die innerhalb der Ringstraße (Wollzeile, Singerstraße) durchgeführt wurden, wurden von der amtlichen Denkmalpflege und der Öffentlichkeit hart kritisiert.

Die Förderung des Hausreparaturfonds zielte auf eine sachliche, schlichte Fassadenneugestaltung und die Entfernung von unnötigem, histori(sti)schem Fassadenschmuck ab - in ihrem Ergebnis also durchaus vergleichbar mit der Praxis der „Entschandelung“ im Deutschen Reich, aber anders als dort nicht ideologisch motiviert. In Wien waren das „Problem Altstadt“ und die Intentionen der Denkmalpflege und Heimatschutzbewegung anders gelagert. Die malerische Unregelmäßigkeit der Altstadtensembles wurde von der Denkmalpflege nicht abgelehnt, sondern als Stimmungswert anerkannt. Es wurde keine Vervollständigung und Verbesserung des Altstadtbildes durch „Entschandelungen“ und formale Angleichung der Neubauten an einen „unspezifischen Heimatstil“285 gefordert. Die Ablehnung des Historismus im Stadtbild kann man hingegen als Gemeinsamkeit in der Städtebau- und Denkmalpflegepraxis der 1930er-Jahre sehen und letztlich als Ausdruck ihrer Zeit. Den aufdringlichen, „pompösen“, protzigen Fassadenschmuck des 19. Jahrhunderts lehnte man auch in Österreich ab. Die Heimatschutzbewegung und etwa auch Max Dvořák hatten hier schon im frühen 20. Jahrhundert, im Einklang mit den deutschen Kollegen, „angemessene Neubauten“286 und eine Unterordnung der Bürgerhäuser „ohne falsche und überflüssige Verzierungen“287 in das Gesamtbild der Stadt gefordert. Die in Wien durchgeführten

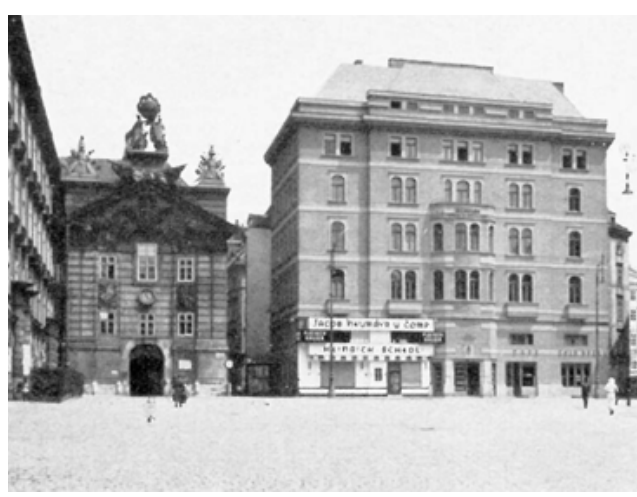

Abb. 134 Das „Kugelhaus“, Am Hof 11, nach der „Entstuckung“ der neobarocken Fassade, 1934
„Fassadeninstandsetzungen“ müssen als „Entstuckungen“ bezeichnet werden. Die Maßnahmen wurden auf freiwilliger Basis der Hauseigentümer durchgeführt und waren nicht flächendeckend oder planmäßig organisiert.

Praktiziert wurden Fassadenerneuerungen bereits vor 1934 und nicht nur an Wohngebäuden. Durch den Hausreparaturfonds wurden sie zusätzlich gefördert. Bereits 1933/34 „vereinfachte" man die neobarocke Fassade des „Kugelhauses“ am Hof (Abb.134), was von der Denkmalpflege damals als großer Gewinn für das Stadtbild und "nachahmenswerte“ Tat bezeichnet wurde. ${ }^{\mathbf{2 8 8}}$ Die „aufdringliche[n] 

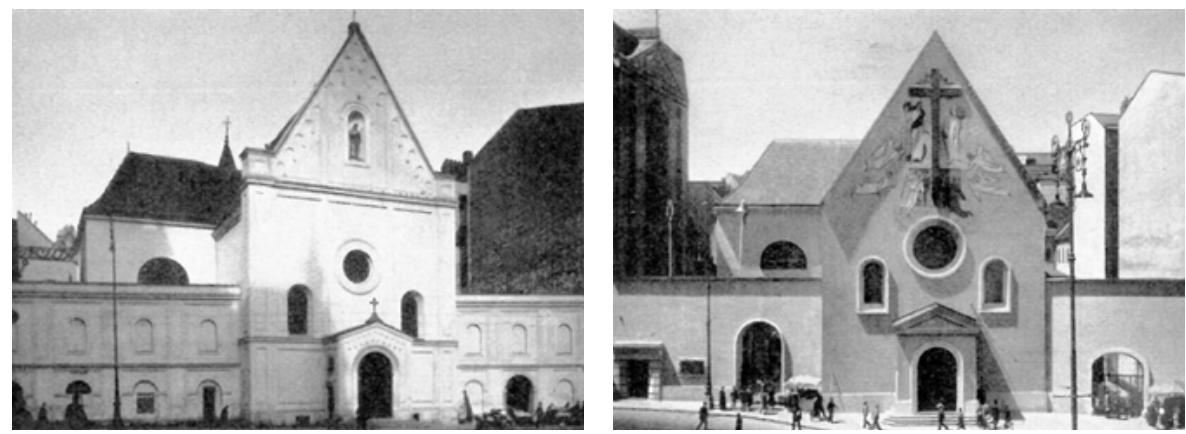

Abb.135 Neugestaltung der Fassade der Kapuzinerkirche, 1935

Stukkierungen und Dachfenstergiebel“ und der „überladene Reichtum an geschwungenen Gesimsen und üppig gehäuften Ornamenten“ konnten zugunsten der „stillen Vornehmheit" der Platzwand entfernt werden, wie man in der Zeitschrift Deutsche Kunst und Denkmalpflege berichtete. ${ }^{\mathbf{2 8 9}}$ Auch die schöpferische Neugestaltung der Fassade der Kapuzinerkirche kann hier als Beispiel angeführt werden. Die Fassade war in den Augen der Denkmalpflege der 1930er-Jahre im Jahr 1842 „nicht sehr günstig“ erneuert worden. Die frühhistoristischen Dekorelemente wurden nun etwa 90 Jahre später, in Abstimmung mit der Zentralstelle, wieder entfernt und die Fassade sachlich klar, „bei Weglassung aller kleinlichen Details“ und mit „künstlerischem Feingefühl“ gestaltet (Abb. 135). ${ }^{290}$ Der Beseitigung der „Spuren“ des ausgehenden 19. Jahrhunderts aus dem Stadtbild konnte man also auch hierzulande etwas abgewinnen.

Ein Blick in die Bundesländer zeichnet allerdings ein anderes Bild der Stadtbildpflege der 1930er-Jahre in Österreich. Zahlreiche Beispiele von Entstuckungen und Fassadenumgestaltungen brachten eine „Anpassungsarchitektur" oder eine sachlich-traditionalistische Heimatschutzarchitektur ${ }^{\mathbf{2 9 1}}$ hervor, jeweils in Abhängigkeit vom städtischen oder ländlichen Kontext. Bei Letzterem verfiel man aber in keine „rohe Nüchternheit“, wie es Rudolf Esterer der Neuen Sachlichkeit zum Vorwurf machte. ${ }^{292}$ Das sachliche Moment, die „Rückkehr zu Einfachheit und Zweckmäßigkeit“, wurde zumeist mit traditionalistischen Elementen wie Wandmalereien, hölzernen Fensterläden und Satteldächern verbunden.

In Salzburg wurde in den frühen 1930erJahren eine gestaltende Stadtbildpflege praktiziert und an vielen Gebäuden unpassende

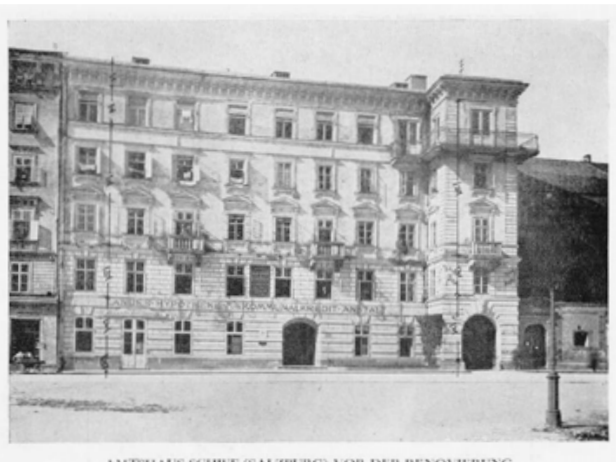

AMTSHAUS SCHHF (SALZEURG) VOR DER RENONHEUNG

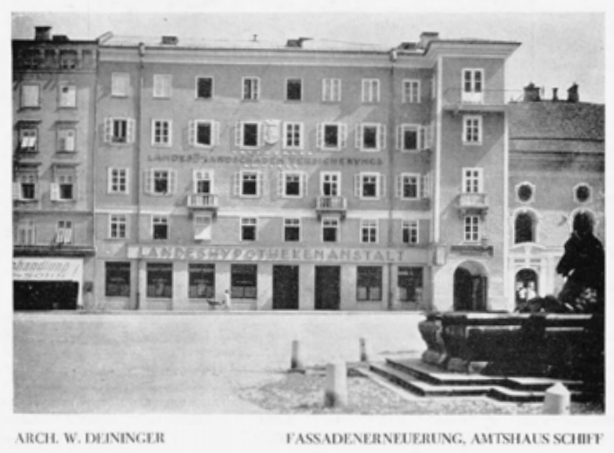

Abb. 136 Salzburg, Fassadenerneuerung von Wunibald Deininger, vor 1930 

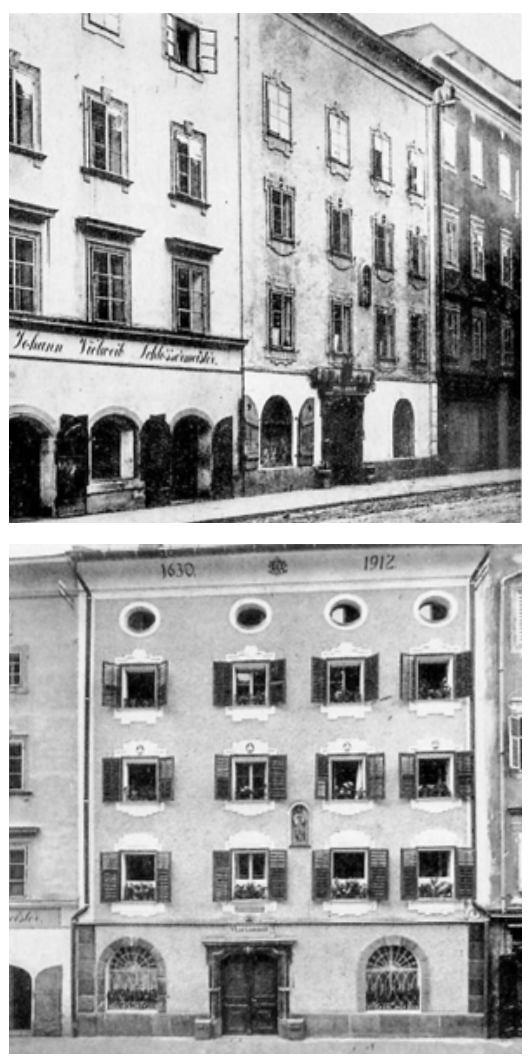

Abb.137 Beispiel einer „Vorbildlichen“ Stadtbildpflege-Maßnahme in Salzburg im Vorher-nachher-Vergleich, um 1930

Elemente und übertriebener Dekor des 19. Jahrhunderts entfernt. Kaj Mühlmann ${ }^{\mathbf{2 9 3}}$, ein in Salzburg geborener Kunsthistoriker, bekennender Nationalsozialist und nach dem „Anschluss“ 1938 Staatssekretär für innere Angelegenheiten und Kunst, verfasste 1932 einen Bildband mit kurzem einleitendem Text zur Altstadtsanierung in Salzburg durch den dortigen Stadtbaumeister Franz Wagner. ${ }^{294}$ Darin charakterisiert er den seit dem 17. Jahrhundert bestehenden Typus des Salzburger Bürgerhauses mit seinem typischen Grabendach und seiner bis zum Dachfirst (oder darüber hinaus) gezogenen Giebelwand ${ }^{\mathbf{2 9 5}}$ mit meist geradem Abschluss oder Hohlkehle. Die Fassaden beschreibt er als typischerweise sehr flächig und mit nur geringem Dekor versehen. ${ }^{296}$ Die bescheidene Fassadengestaltung der Salzburger Bürgerhäuser kam Mühlmanns Schönheitsideal eines gleichmäßigen Stadtbildes sehr entgegen. „Das einzelne Haus taucht als Individuum unter in der strengen Baulinie der Gasse und in der durchlaufenden Giebellinie der Dächer" und forme damit in der Ansammlung eine homogene Stadtstruktur und „wohltuende Gleichförmigkeit“. Mühlmann forderte daher die Beseitigung von Unregelmäßigkeiten und „Bausünden“ des 19. Jahrhunderts, vor allem der „pompösen“ und „schwülstigen“ Fassaden - „eine dankbare Aufgabe gemäß der wiederkehrenden Besinnung auf die gute alte Bauweise Salzburgs“.297 Die Fassadenerneuerungen von Wunibald Deininger (Abb. 136) und die Entfernung der „verfehlten Pracht“ des 19. Jahrhunderts stellten in seinen Augen eine Bereicherung für das Stadtbild dar. ${ }^{298}$

Mühlmann spricht also bereits vor Pinders Vortrag im Rahmen des Tages für Denkmalpflege und Heimatschutz in Kassel im Jahr 1933 - wenn auch nicht wortwörtlich - von einer notwendigen „Entschandelung“ des Salzburger Stadtbildes und von einer Rückbesinnung auf das „Typische“, die in formale Anpassungen und fast plakative Stereotypen mündete. Auch die Erdgeschosszone der Altstadt wurde in vielen Bereichen „im Sinne Alt-Salzburgs“ umgestaltet, vereinfacht, Holzvertäfelungen des 19. Jahrhunderts wurden entfernt, mittelalterliche Steinmauern oder Maßwerkfenster freigelegt oder als oberer Abschluss die für Salzburg typischen Hohlkehlen (wieder-) hergestellt (Abb. 137). Die „entstuckten“ „Wiener“ Fassaden kennzeichnet hingegen - in Anpassung an die großstädtische Umgebung - eine sachlich-klare Architektur, die auf regionaltypische, traditionalistische Elemente verzichtet. Gemein ist allen Beispielen nur die Ablehnung des historistischen Fassadendekors.

Das im Deutschen Reich für die Heimatschutzbewegung so zentrale Thema der „Bereinigung“ des Stadtbildes von übermäßiger Reklame wurde von der in Wien tätigen Denkmalpflege hingegen bereits in den 1920er-Jahren aufgegriffen. ${ }^{299}$ Möglichkeiten 
zu ihrer Einschränkung hielt man im ersten Denkmalschutzgesetz von 1923 fest. ${ }^{300}$ Eine große Entschiedenheit der Zentralstelle im Kampf gegen die Werbung im Stadtbild lässt sich aber erst ab den späten 1930er-Jahren ausmachen. ${ }^{\mathbf{3 0 1}}$ Eine gemeinsame Aktion von Zentralstelle, Stadtverwaltung und Kulturamt zur „Reinigung des Stadtbildes von groben Verunstaltungen“ sollte in Wien schließlich 1939 stattfinden. ${ }^{\mathbf{3 0 2}}$ Viele „Entschandelungen“ dürften hier allerdings nicht umgesetzt worden sein, denn den Vorschlag, in Wien eine Ausstellung zum Thema abzuhalten, hält Karl Giannoni 1940 noch für verfrüht. In Wien sei an „Entschandelungen“ und an „vorbildlich Neuem“ - auch bedingt durch den Krieg - „noch so wenig erfolgt, dass dies gegenüber einem so gewaltigen Stadtbilde wie Wien fast nicht in Erscheinung“ trete. Man müsse erst „Entschandelungen“ vornehmen, ehe man in einer derartigen, „höchst wünschenswerten Ausstellung “ darauf hinweisen könne. ${ }^{\mathbf{3 0 3}}$ Deutlich hervor geht daraus die Absicht des Heimatschutzes, in die Gestaltung des Stadtbildes nun verstärkt und aktiv eingreifen zu wollen.

\subsubsection{Neue Architektur in der historischen Stadt}

Die im Zusammenhang mit dem „Stadtgesundungsprozess“ stehende Frage der Gestaltung der Neubauten war in dieser Untersuchung wiederholt Thema und soll hier abschließend nochmals kurz angeschnitten werden.

Die österreichische Heimatschutzbewegung befasste sich nicht nur mit der Ortsbildpflege, ${ }^{\mathbf{3 0 4}}$ sondern auch mit der Weiterentwicklung der heimischen Baukultur und mit der Frage, wie man im historischen Kontext neu bauen sollte. Da man einen Mangel an „gutem Neuen“ feststellte, orientierte man sich an dem „guten Alten“ und forderte eine Rückbesinnung auf die „bodenständige“, „heimische“ Bauweise. Wie auch andere, versuchte Karl Giannoni, das daraus erwachsene Missverständnis aus dem Weg zu räumen, dass sich der Heimatschutz gegen „das Neue“ verwehre. Der Heimatschutz forderte dessen Eingliederung in die Umgebung, eine Anpassung in den Größenverhältnissen, den Umrissen, der Dachform und der Farbe. Es sollte aber weder kopiert werden noch wollte man neue Nutzungen hinter altertümelnden Fassaden verstecken. Die „Einbürgerung neuer Formen“, die Einfügung zeitgenössischer Architektur in das Gesamtbild könne sich bei qualitätsvoller Ausführung durchaus „ohne Schaden vollziehen“. ${ }^{\mathbf{3 0 5}}$ Wie Beispiele aus der Wanderausstellung des Österreichischen Verbandes für Heimatpflege zeigten, fand man auch für sachliche Gebäude des frühen 20. Jahrhunderts lobende Worte.

Die Wiener Assanierungsbauten zeigen zum Großteil eine unscheinbare, zurückhaltend „moderne“, teils aber auch eine durchaus selbstbewusste Architektur. Sie passten sich durch die in der Bauordnung vorgeschriebene Gebäudehöhe an ihre Umgebung an, wenn sie auch wie im Falle des Neubaus an der Bärenmühle teilweise städtebauliche Akzente setzten. Die Gestaltung oblag den planenden Architekten, die keine stilistische Anpassung an das historische Stadtbild oder eine Nachahmung historischer Fassaden versuchten. Ob die Neubauten den Vorstellungen von Denkmalpflege und Heimatschutz entsprachen, muss hier aus Mangel an Quellen unbeantwortet bleiben. ${ }^{306}$ Sicherlich kam der von Lippert, Klaudy und Liebe realisierte Assanierungsbau an der Dominikanerbastei diesen Vorstellungen am nächsten.

Ein neuerlicher Blick nach Rom und ein Vergleich mit Wohnbauten der 1930erJahre, die dort im Zuge von Regulierungsmaßnahmen entstanden, schafft etwas mehr 


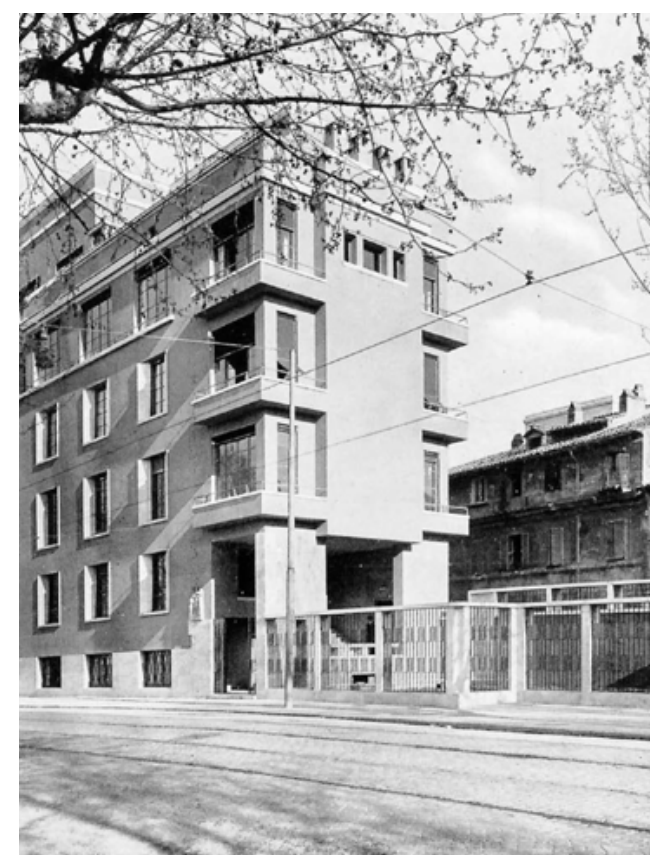

Abb. 138 Marcello Piacentini, Wohnhaus des Architekten in Rom am Lungotevere, Aufnahme 1934
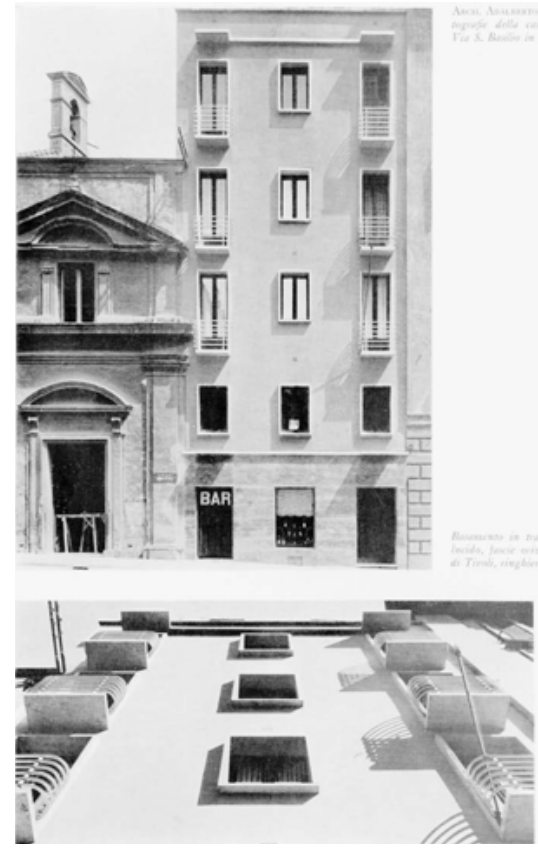

Abb.139 Adalberto Libera, Casa da Pigione, Via di San Basilio 53, Rom, 1931/32, Fotos und Erläuterungen aus der Zeitschrift Architettura

Klarheit über die Qualität der Wiener Assanierungsbauten. Als Vergleichsbeispiele gezeigt werden hier zwei Wohnbauten an der Tiber-Uferstraße, die im 19. Jahrhundert angelegt worden war und zahllose Abbrüche notwendig gemacht hatte. ${ }^{\mathbf{3 0 7}}$ Der neue Piano Regolatore Generale di Roma von 1931 (siehe nochmals Abb.100) sah hier den Abbruch der noch verbleibenden, zu weit vorragenden Altbauten vor.

Marcello Piacentinis privates Wohnhaus am Lungotevere (Abb.138) beschreiben die Monatshefte für Baukunst und Städtebau damals als „eigenwüchsig im römischen Stadtbild“, das sich aber keiner „,ausländischen Kunstformen“ bediene und dadurch gut eingliedere. Eine starke Verbindung zur lokalen Bautradition werde durch die verputzte Fassade und die Gesimse und Sohlbänke aus Travertin hergestellt. ${ }^{\mathbf{3 0 8}}$ Unweit davon entfernt, ebenfalls am Lungotevere ${ }^{\mathbf{3 0 9}}$, wurde 1932 ein Neubau nach Plänen von Cesare Valle realisiert, der ein Althaus zu Regulierungszwecken ersetzte. Dieser sechsgeschossige und daher in seiner Kubatur weitaus wuchtigere Neubau lehnt trotz seiner Lage in der Altstadt jegliche Historisierung ab und zeigt eine schlichte Eleganz. ${ }^{\mathbf{3 1 0}}$

Für Adalberto Liberas Umbau eines Mietshauses in der Via di San Basilio (Nr. 53, Abb.139) musste ein Altgebäude aus der Mitte des 19. Jahrhunderts weichen. ${ }^{311}$ Das schmale, fünfgeschossige Wohnhaus zeigt eine deutliche formale Abgrenzung zum umgebenden historischen Bestand und, wie einige Assanierungsbauten in Wien, Elemente der internationalen Moderne, etwa durch die spezifische Form der metallenen Balkongeländer. Die deutlich vortretenden Fenstereinfassungen aus Travertin und die Verkleidungen des Erdgeschosses mit Travertinplatten stellen bewusst einen Bezug zur lokalen Bautradition her und interpretieren diese neu. Die Zeitschrift Architettura betonte damals die durch den Umbau erzielte „Aufwertung“ und seine Anpassung an 


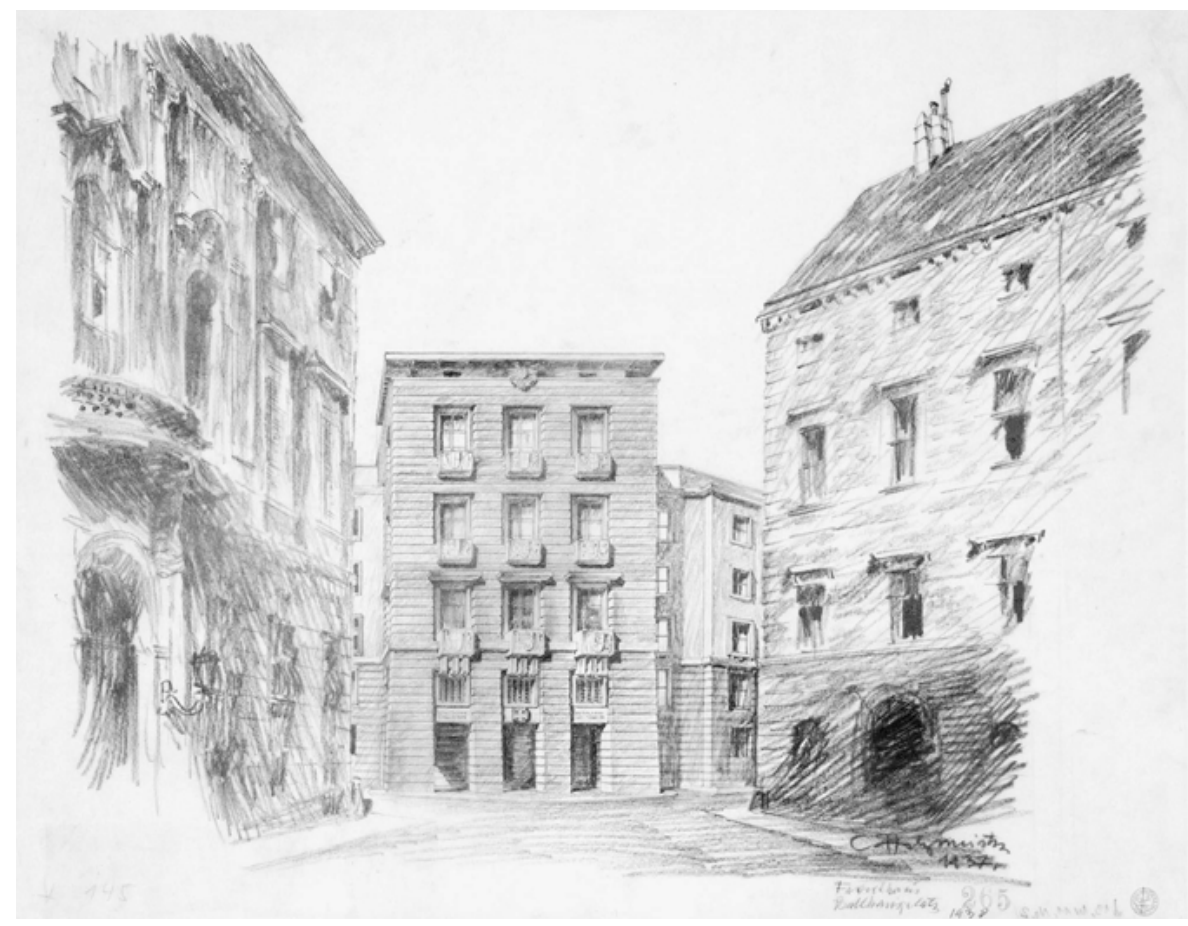

Abb.140 Clemens Holzmeister, Schaubild Fronthaus in umgebender Bebauung, Zeichnung, 1937

die Umgebung: „La nuova facciata si intona perfettamente all'ambiente mantenendo le sue linee modeste e semplici in una elegante veste di lindore e chiarezza.“312

Diese römischen Assanierungsbauten stellen durch die verwendeten Baumaterialien und die Farbigkeit einen starken Bezug zur lokalen Bautradition und zur gebauten Umgebung her. Alle drei Beispiele zeigen aber ebenso ein architektonisches Selbstbewusstsein und auch eine architektonische Qualität, die

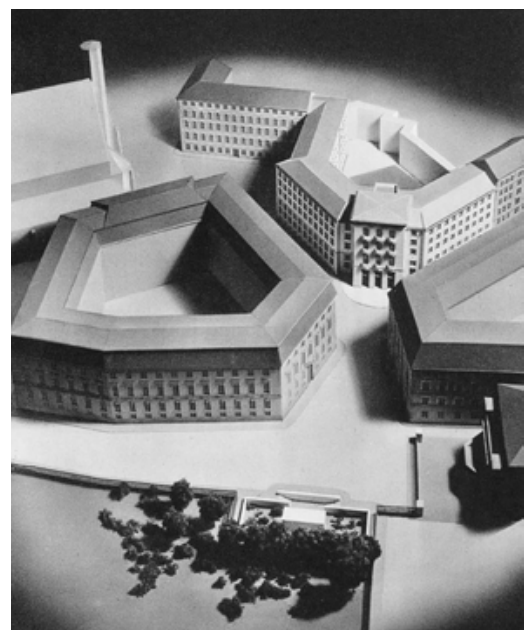

Abb. 141 Clemens Holzmeister, Modell des Fronthauses und seiner nächsten Umgebung, 1937 man in Wien nur an wenigen Objekten aus dieser Zeit finden kann. Die Wiener Assanierungsbauten erscheinen als Stadtbildkorrektur in Form einer zeitgemäßen, zurückhaltenden Ergänzung, ohne Rückgriff auf traditionalistische Gestaltungselemente, aber auch nur selten mit architektonischem Esprit.

Auch im Falle der staatlichen Repräsentationsbauten verfolgte man in Wien eine vergleichsweise zurückhaltende Linie. Der Neubau des nie fertiggestellten Fronthauses, ein Entwurf Clemens Holzmeisters ${ }^{\mathbf{3 1 3}}$ sollte sich mittels einer zurückhaltenden Architektur und einer dennoch gewissen formalen Selbstständigkeit harmonisch in die historisch bedeutsame Umgebung zwischen Michaelerplatz, Amalienburg und dem heutigen Bundeskanzleramt (ehem. Hofkanzlei) einordnen (Abb.140,141). Vor allem die Gebäudehöhe soll- 
te jene der angrenzenden Bauten nicht überschreiten, lediglich der Mittelrisalit mit dem Haupteingang zum Ballhausplatz sollte durch eine geringe Überhöhung und besondere Fassadengestaltung (steinerne Balkonbrüstungen, Pseudorustika und ein massives Kranzgesims) leicht hervortreten und durch den Fassadenschmuck zum Träger politischer Symbolik werden (Abb.142). ${ }^{\mathbf{3 1 4}}$ Der Bau sollte das Stadtbild also nicht dominieren, vielmehr war ein Einfügen in die gebaute Umgebung vorgesehen. Auch der einzige offizielle und auch fertiggestellte Monumentalbau des Ständestaats, das Rundfunkgebäude der österreichischen Radio-Verkehrs-AG (RAVAG) in der Argentinierstraße, ein blockhafter, sachlich-monumentaler Entwurf der Arbeitsgemeinschaft Clemens Holzmeister, Heinrich Schmid und Hermann Aichinger, tritt in der Stadtsilhouette kaum in Erscheinung (Abb. 143). ${ }^{\mathbf{3 1 5}}$

Laut Bodenschatz ordnen sich auch die großen Neubauten des Faschismus im Zentrum Roms den umliegenden Monumenten der Antike und der Neuzeit be-

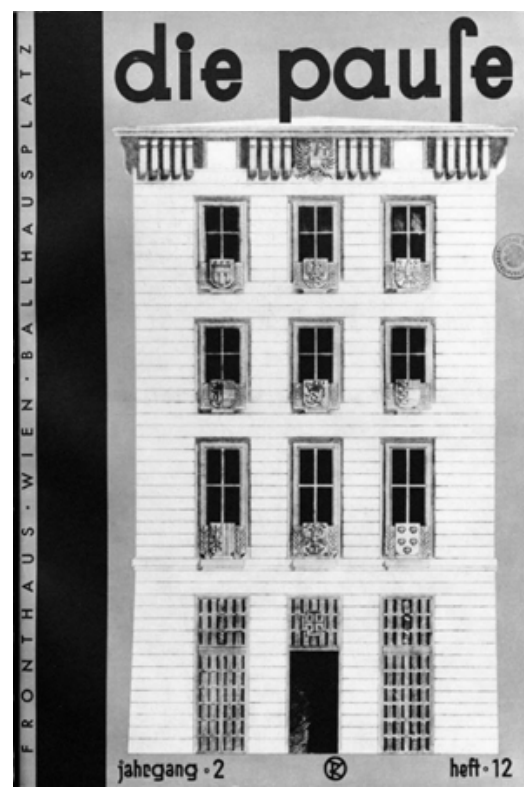
wusst unter. Vorgaben dazu wurden beispielsweise in

Abb.142 Deckblatt Die Pause, H.12, 1937, Ansicht Fronthaus, Haupteingang

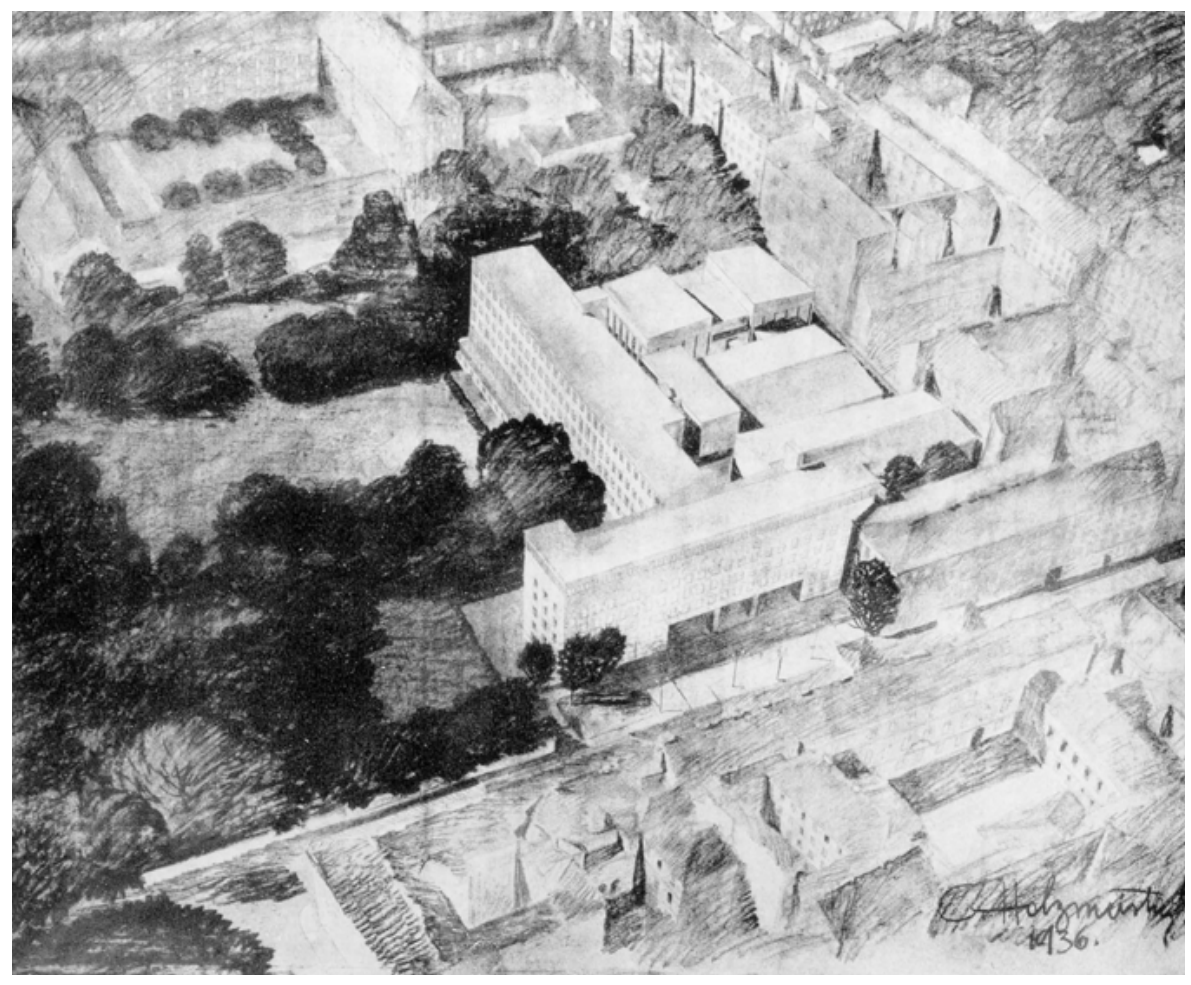

Abb.143 Clemens Holzmeister, Entwurfszeichnung zum Funkhaus der RAVAG, gemeinsamer Entwurf mit Heinrich Schmid und Hermann Aichinger, 1936 


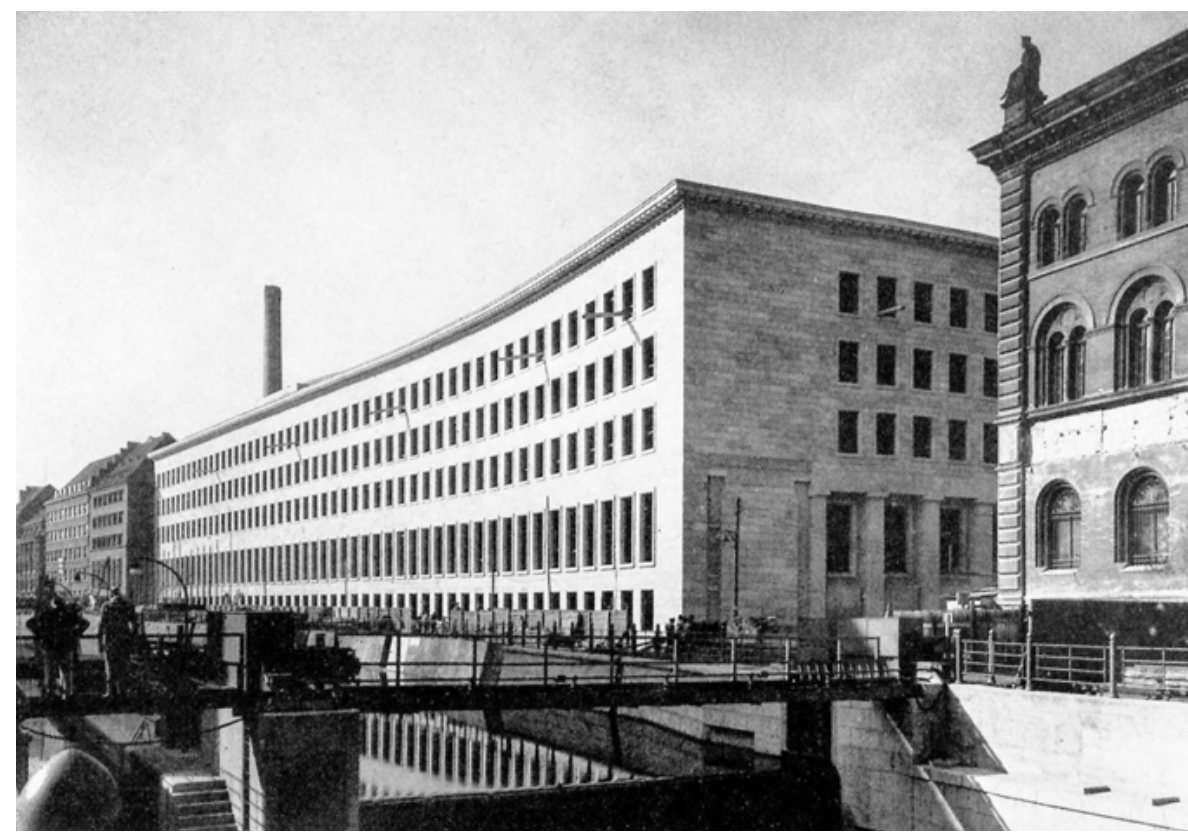

Abb.144 Berlin, Neubau der Reichsbank an der Spree, errichtet 1934-1940

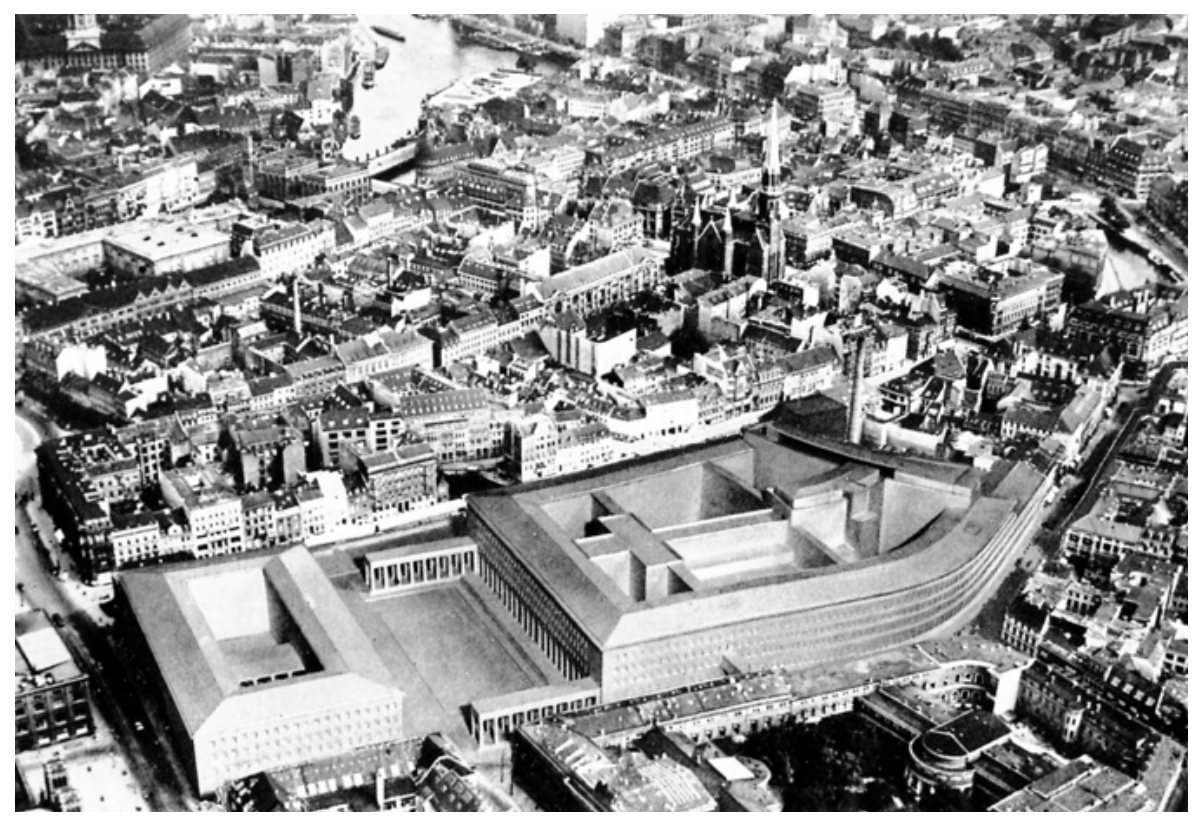

Abb. 145 Collage mit dem Modell des geplanten Reichsbankgebäudes an der Spree in Berlin, ganz links unten die beiden Türme der Friedrichswerderschen Kirche und ein Teil der Bauakademie von Friedrich Schinkel, aus einer Publikation von 1937 
der Wettbewerbsausschreibung für den ursprünglich an der Via dell'Impero angesiedelten Palazzo del Littorio ${ }^{\mathbf{3 1 6}}$ festgehalten. ${ }^{\mathbf{3 1 7}}$ Auch die zum Teil durchaus groß dimensionierten Neubauten in der Altstadt, etwa entlang des Corso del Rinascimento, passen sich dem Stadtbild weitgehend an, ja, treten durch die angepasste Gebäudehöhe, ihre Farbigkeit und historisierenden Elemente kaum in den Vordergrund. ${ }^{\mathbf{3 1 8}}$ Auch die Neubauten um das freigestellte Augustus-Mausoleum treten zwar deutlich als solche in Erscheinung, zeigen jedoch städtebaulich und architektonisch Präsenz, ohne die Umgebung zu dominieren. Dieser weitgehenden Unterordnung stehen die teils monumentalen Neubauten gegenüber, die in anderen italienischen Altstädten, wie etwa in Brescia, im Zuge der Stadterneuerung realisiert wurden. Die Bandbreite der Lösungen wurde in Kapitel 6.2. aufgezeigt.

Die Repräsentationsbauten des Nationalsozialismus erweisen sich zumeist als wuchtige, raumgreifende Gebäude mit geringem Bezug zum historischen Stadtgrundriss und nur bedingter Rücksichtnahme auf die umgebende Bebauung. Der Erweiterungsbau der Reichsbank in Berlin, realisiert in den Jahren 1934 bis 1940, verdeutlicht dies wohl am besten (Abb.144). Für die Errichtung des damals mit Abstand größten Gebäudes der Reichshauptstadt war der Abbruch eines ganzen, kleinteilig bebauten Viertels notwendig (Abb.145). ${ }^{\mathbf{3 1 9}}$ Der monumentale Baukörper folgt zwar im Grundriss dem Spree-Verlauf und passt sich in der Gebäudehöhe an die angrenzenden Bauten an, durch seine Dimensionen und die mit Sandsteinplatten verkleidete Fassade setzt er sich allerdings auch deutlich von der Umgebung ab. Der Bau wurde regelrecht in den damals kleinteiligen Altstadtbereich „hineingepflanzt“, unmittelbar neben der Spreeinsel und in Nachbarschaft zur Friedrichswerderschen Kirche und der Bauakademie Friedrich Schinkels.

Demnach zeigt sich im „Dritten Reich“ ein durchaus ambivalentes Verhältnis zur historischen Stadt. Neben den überdimensionierten Repräsentationsbauten und den Ideen der radikalen Neugestaltung und Neustrukturierung - man denke an die Pläne für Berlin und die übrigen „Führerstädte“320 - verfolgte man im ganzen Land die Praxis der „Wiederherstellung“ beschaulicher, „typisch deutscher“ Altstädte. Die ergänzenden Neubauten sollten sich dabei „dem historisch Gewordenen unterordnen“, in freier Nachahmung „heimischer“ Bauformen. 
1 Siegfried Theiss äußert sich zu Altstadterneuerung bspw. in: „Neue Linien im Wiener Stadtbilde“, in: Reichspost, 25.12.1934, S. 9-10; Karl Holey berichtet über die Stadtregulierung in Rom u.a. in: ders., „Im neuen Rom das alte Rom", in: Mitteilungen des Vereins der Freunde des humanistischen Gymnasiums, H. 33, 1936, S. 51-59; ders., „Staatskunst und Baukunst“, in: Reichspost, 12.4.1936, S. 3. 2 Erwin IIz, „Gegenwartsaufgaben des Städtebaus mit besonderer Berücksichtigung Österreichs, Deutschlands und Italiens“, in: Zeitschrift des Österr. Ingenieur- und Architektenvereines, H.1/2 und 3/4, 1938, Sonderabdruck, S.1-9, hier S.5-6. 3 Zum „europäischen diktatorischen Städtebau“, wie Harald Bodenschatz den Städtebau in Italien und anderen Diktaturen in den 1930er-Jahren bezeichnet, siehe im Detail v.a.: ders., „Diktatorischer Städtebau in der Zwischenkriegszeit. Besonderheiten Italiens mit Blick auf das nationalsozialistische Deutschland und die Sowjetunion“, in: Aram Mattioli, Gerald Steinacher (Hrsg.), Für den Faschismus bauen. Architektur und Städtebau im Italien Mussolinis (Kultur - Philosophie - Geschichte, 7), Zürich 2009, S. 45-64; ders., „Rom - Moskau Berlin: Städtebau und Diktatur“, in: Hans-Jörg Czech (Hrsg.), Kunst und Propaganda. Im Streit der Nationen 1930-1945 (Ausstellungskatalog, Deutsches Historisches Museum, Berlin), Dresden 2007, S. 48-61. 4 Karl Holey, „Zeitgebotene Erneuerungen“, in: Reichspost, 25.12.1937, S. 9. 5 Andreas Suttners Einschätzung, dass man sich bei der "Stadtsanierung“ in Wien an den Beispielen in Rom „angelehnt“ habe, greift etwas zu kurz. Zur Bewertung der Regulierungsmaßnahmen in Rom und hinsichtlich der Frage nach einem etwaigen fachlichen Austausch mit den Planern in Wien werden auch keine Primärquellen angegeben. Siehe: Andreas Suttner, Das Schwarze Wien. Bautätigkeit im Ständestaat 1934-1938, Wien/Köln/Weimar 2017, S.194. 6 Siehe dazu: Angelo Filipuzzi, „Die italienisch-österreichischen Kulturabkommen“, in: Adam Wandruszka, Ludwig Jedlicka (Hrsg.), Innsbruck - Venedig. Österreichisch-italienische Historikertreffen 1971 und 1972 (Veröffentl. der Kommission für die Geschichte Öst., ÖAW, 6), Wien 1975, S. 581-598; allgemein zur Außenpolitik Österreichs im Ständestaat u.a.: Karl Stuhlpfarrer, „Austrofaschistische Außenpolitik - ihre Rahmenbedingungen und ihre Auswirkungen, in: Emmerich Tálos, Wolfgang Neugebauer (Hrsg.), Austrofaschismus. Politik, Ökonomie, Kultur 1933-1938 (Politik und Zeitgeschichte, 1), Wien 2012, S. 322-336. 7 Besonders gut nachvollziehen lässt sich dies an den zahlreichen Artikeln in Architekturbzw. Städtebau-Zeitschriften, vgl. dazu v. a.: Moderne Bauformen und Monatshefte für Baukunst und Städtebau. 8 Eine erste Aufarbeitung der Sanierung im Dritten Reich leistete Ursula von Petz in den späten 1980er-Jahren, siehe dazu: dies., Stadtsanierung im Dritten Reich. Dargestellt an ausgewählten Beispielen (Dortmunder Beiträge zur Raumplanung, 45), Dortmund 1987. Zum Thema äußern sich u. a. auch: Jörn Düwel, Niels Gutschow, Städtebau in Deutschland im 20. Jahrhundert. Ideen - Projekte - Akteure, Stuttgart/Leipzig/Wiesbaden 2001. 2010 wurde von Gerhard Vinken die ab den späten 1920er-Jahren geplante „Gesundung“ des Rheinviertels in Köln im Detail aufgearbeitet: ders., Zone Heimat. Altstadt im modernen Städtebau, Berlin 2010. 9 Bodenschatz 2009, S. 50.
10 Vittorio Magnago Lampugnani, „Das historische Zentrum als Gebrauchsgegenstand, Kulturgut, Lehrstück“, in: ders., Radikal normal. Positionen zur Architektur der Stadt, Ostfildern 2015, S.159-167. 11 Cesare Chiodi, La città moderna. Tecnica urbanistica, Mailand 1935, S. 237-238. 12 Bis zur Zusammenlegung 1938 bestanden zwei Verbände mit ähnlichen Absichten und eigenen Kongressen. Der genannte ältere, 1913 von Ebenezer Howard gegründete Verband hatte seinen Sitz in London, die zweite, erst 1929 gegründete Vereinigung (Internationaler Verband für Wohnungswesen) hatte ihren Sitz in Frankfurt am Main und wollte vor allem eine Wohnungsreform vorantreiben. Nach der Fusion 1938 hatte der neue Verband seinen Sitz in Brüssel. Siehe: „Gründung eines internationalen Verbandes für Wohnungswesen und Städtebau“, in: Österreichische Bauzeitung, 2. Jg., Folge 45, 27.11.1937, S. 543; „Verständigung des Internationalen Verbandes für Wohnungswesen mit der Internationalen Federation für Wohnungswesen und Städtebau“, in: Das Wohnen, 5. Jg., H. 12, 1930, S. 253-254. 13 An der Gründungstagung im Jahr 1928 nahm mit Josef Frank lediglich ein österreichischer Vertreter teil. Zur Liste der Delegierten für die CIAM-Kongresse 1928-1939 siehe: Martin Steinmann (Hrsg.), CIAM. Internationale Kongresse für Neues Bauen (Geschichte und Theorie der Architektur, 11), Basel 1979, S. 213. 14 Vgl. „Die Funktionelle Stadt. Feststellungen und Richtlinien des IV. internationalen Kongresses für neues Bauen“, in: Weiterbauen (Beiblatt zur Schweizerischen Bauzeitung), 1. Jg., H. 1, September 1934, S. 1-4; und die Fortsetzung des Berichts in: Weiterbauen (Beiblatt zur Schweizerischen Bauzeitung), H. 2, November 1934, S. 9-13. 15 Thilo Hilpert, Century of Modernity. Das Jahrhundert der Moderne. Architektur und Städtebau. Essays und Texte, Wiesbaden 2015, S.135. 161933 wurde die Charta von Athen nur in französischer Sprache in der griechischen Fachzeitschrift Annales Techniques veröffentlicht und 1934 in deutscher Übersetzung in der Schweizer Zeitschrift Weiterbauen. Siehe: ebd. 2015, S. 201. 17 Gerd Albers, Zur Entwicklung der Stadtplanung in Europa. Begegnungen, Einflüsse, Verflechtungen (Bauwelt-Fundamente, 117), Braunschweig/ Wiesbaden 1997, S. 195. 18 Ebd., S. 193. Der Verband war aus der 1913 in London gegründeten International Garden Cities and Town Planning Association hervorgegangen. Mit der (neuerlichen) Namensänderung im Jahr 1929 erlangten Fragen des Wohnungswesens zunehmend Bedeutung, während der Gartenstadtgedanke in den Hintergrund rückte. Siehe: ebd., S.157-158, 191. 19 Siehe dazu die zusammenfassende Publikation zum Kongress: International Federation of Housing and Town Planning (Hrsg.), International Housing and Town Planning Congress. Roma 1929, 3 Bde., Rom 1929a. Zu den Intentionen und zum Ablauf des Kongresses siehe v.a. Phillip Wagner, „Zwischen grenzübergreifender Standardisierung und nationalem Lobbying. Der Internationale Kongress für Wohnungswesen und Städtebau in Rom 1929“, in: Christine Beese, Ralph-Miklas Dobler (Hrsg.), L'urbanistica a Roma durante il ventennio fascista, Rom 2018, S. 153-169. 20 In Berlin befasste man sich mit den Themen „Beseitigung verwahrloster Wohnviertel“ und „Das Verkehrsproblem in Beziehung zu Städtebau und Landesplanung“. Siehe: Konrad Hippenmeier, „Internationaler Städtebaukongress in 
Berlin vom 1.-5. Juni 1931“, in: Das Werk, 18. Jg., H. 8, 1931, S. 22-26. 21 Auf die Präsenz des Themas der Stadtsanierung bei den genannten Tagungen verweist auch Karl Kühn. Siehe: ders., Die schöne Altstadt. Ihr Schutz, ihr Umbau, ihre Verkehrsverbesserung. Eine Untersuchung zur praktischen Auswertung der Erkenntnis vom Wesen der alten Stadt, Berlin 1932, S. 5. 22 Marcello Piacentini, „Die Neuplanung alter und historischer Städte im Rahmen moderner Verhältnisse“, in: International Federation of Housing and Town Planning (Hrsg.), International Housing and Town Planning Congress. Roma 1929, 3 Bde., Bd. 2, Programm und Generalberichte, Rom 1929, S. 67-72, hier S.72. 23 Ebenso große Bedeutung hatten Aspekte der Stadterweiterung und des Wohn- bzw. Siedlungsbaus, wobei diese Themen auch mit der Stadtsanierung in Verbindung standen. Bruno Schwan, Deutscher Verein für Wohnungsreform (Hrsg.), Städtebau und Wohnungswesen der Welt, Berlin 1935. 24 Helmut Weihsmann, In Wien erbaut. Lexikon der Wiener Architekten des 20. Jahrhunderts, Wien 2005, S. 52. 25 Brunners Bericht wurde vermutlich spätestens im Jahr 1932 verfasst, als sich Brunner für kurze Zeit in Wien aufhielt. Vgl. ebd.: Brunner wird auch als „Architekt in Wien“ vorgestellt. Die Regulierungsmaßnahmen in Wien (Assanierungsfonds) setzten erst 1934 ein; zum Bericht siehe: Schwan/Deutscher Verein für Wohnungsreform 1935, S. 286-292 (Abbildungen bis S. 293). 26 Siehe dazu die Publikation zur Ausstellung (jeweils ein Text- und Bildband) mit der Beschreibung und Darstellung der einzelnen Sanierungsbeispiele: Internationaler Verband für Wohnungswesen (Hrsg.), Elendsviertelsanierung. Beseitigung von Elendsvierteln und Verfallswohnungen, Stuttgart 1935. 27 Schuster hatte von 1933-1936 dieses Amt inne und war daher auch für den Kongress in Prag mitverantwortlich. Vgl. Architekturzentrum Wien, Architektenlexikon Wien 1770-1945, Franz Schuster, http://www.architektenlexikon.at/de/577.htm (letzter Zugriff 18.4.2021). 28 Internationaler Verband für Wohnungswesen, 1935, S.IX-XII. 29 Franz Schuster in seinem Vorwort in: ebd., S. VII-VIII. 30 Ebd., S. 40. 31 Als Bauunternehmung traten vor allem Wohnungsak tiengesellschaften auf; siehe dazu den finnischen Länderbericht im Rahmen des Städtebaukongresses in Berlin 1931: Yrjö Harvia, „Die Entwicklung der Wohnungswirtschaft in Finnland“, in: Internationaler Verband für Wohnungswesen (Hrsg.), Internationaler Wohnungskongress Berlin 1931. Vorberichte der Länder. Die sozialpolitische Bedeutung der Wohnungswirtschaft in Gegenwart und Zukunft, Frankfurt am Main 1931, S. 238-254. 32 Siehe dazu bspw. die Berichte von Belgien, Dänemark, Deutschland, Italien oder Schweden, in: Internationaler Verband für Wohnungswesen (Hrsg.), Internationaler Wohnungskongress Berlin 1931. Vorberichte der Länder. Die sozialpolitische Bedeutung der Wohnungswirtschaft in Gegenwart und Zukunft, Frankfurt am Main 1931. 33 Zur Tradition der "Stadtgesundungsmaßnahmen“ in Deutschland im 19. und vor allem im frühen 20. Jh. siehe: Petz 1987, S. 28-30. 34 Vgl. dazu die Teilnehmerliste in: Tag für Denkmalpflege und Heimatschutz. Würzburg und Nürnberg 1928. Tagungsbericht mit Sonderbeiträgen zur Heimatund Kunstgeschichte Frankens, Berlin 1929, S.331-338. 35 Der sich auch im Titel der Tagung abzeichnete: „Alt- stadt und Neuzeit“. 36 Nicht zu verwechseln mit der zuvor genannten Charta von Athen der CIAM von 1933. 37 Georg Karo, „Tagung für Denkmalpflege in Athen (21. bis 30. Oktober 1931)“, in: Die Denkmalpflege, 1931, S. 37-40. 38 Charta von Athen zur Restaurierung von historischen Denkmälern (1931), hier zitiert nach: ICOMOS Deutschland u.a. (Hrsg.), Internationale Grundsätze und Richtlinien der Denkmalpflege (Monumenta, 1), Stuttgart 2012, S. 24-31, hier S. 27. 39 Karl Giannoni, „Tag für Denkmalpflege und Heimatschutz", in: Unsere Heimat, Bd.9, 1936, S. 327-329, hier S. 328. 40 Cornelius Gurlitt, Handbuch des Städtebaues, Berlin 1920, S. 240-288. 41 Darin werden Sanierungsmaßnahmen des späten 19. und frühen 20. Jhs. in Innenstädten mehrerer deutscher Städte aufgearbeitet. Die Publikation zeigt Parallelen und „typische Probleme“ in der Umbildung von Altstädten auf und wird auch von Cornelius Gurlitt in seinem Handbuch des Städtebaues als weiterführende Literatur angegeben. 42 Gustavo Giovannoni, Vecchie città ed edizilia nuova, Turin 1931. 43 Karl Friedrich Kühn war Kunsthistoriker und Denkmalpfleger, Landeskonservator in Böhmen und während des Zweiten Weltkrieges Leiter des Denkmalamtes in Brünn. Vgl. Österreichisches Biographisches Lexikon ÖBL, 1815-1950, Bd. 4 (Lfg. 19, 1968), S.322. 44 Kühn 1932. 45 Harald Bodenschatz (Hrsg.), Städtebau für Mussolini. Auf der Suche nach der neuen Stadt im faschistischen Italien, Berlin 2011a. Untersucht wurden Stadterneuerungsprozesse in unterschiedlichen Städten Italiens zuletzt in: Carmen M. Enss, Luigi Monzo (Hrsg.), Townscapes in Transition. Transformation and Reorganization of Italian Cities and their Architecture in the Interwar Period, Bielefeld 2019. Siehe zum Thema auch: Aram Mattioli, Gerald Steinacher (Hrsg.), Für den Faschismus bauen. Architektur und Städtebau im Italien Mussolinis (Kultur Philosophie - Geschichte, 7), Zürich 2009; Giuseppe Pagano, Cesare De Seta (Hrsg.), Architettura e città durante il fascismo, Mailand 2008. 46 Italienische Städtebaukunst im faschistischen Regime, Urbanistica Italiana in Regime Fascista, Rom 1937, S. 5. 47 Ebd., S. 17. 48 Ebd., S.19. 49 Zu Deutsch „lichten, ausdünnen“, im übertragenen Sinn Entkernung oder Auflockerung; zu Giovannonis theoretischem Ansatz und seiner Auffassung eines angemessenen Umgangs mit der historischen Stadt siehe vor allem seine beiden 1913 erschienenen Aufsätze: Gustavo Giovannoni, „Vecchie città ed edilizia nuova“, in: Nuova antologia, Bd. 165 (Mai-Juni 1913), 1913a, S. 449-472; ders., „Il ,diradamento“ edilizio dei vecchi centri. II quartiere deIla Rinascenza in Roma“, in: Nuova antologia, Bd. 166 (JuliAugust 1913), 1913b, S. 53-76. 50 Italienische Städtebaukunst im faschistischen Regime, 1937, S.17. 51 Ebd. 52 Etwa in Cesare Chiodis La città moderna. Tecnica urbanistica wird seine Methode des diradamento im Speziellen hervorgehoben und erläutert. Vgl. Chiodi 1935 , S. 221-222. 53 Aram Mattioli, „Architektur und Städtebau in einem totalitären Gesellschaftsprojekt“, in: ders./ Steinacher 2009, S. 13-43, hier S. 17. 54 Erläuterungen zu Giovannonis „II ,diradamento' edilizio dei vecchi centri“, in: Vittorio Magnago Lampugnani, Katia Frey, Eliana Perotti (Hrsg.), Anthologie zum Städtebau, 5 Bde., Bd. 2.1, Das Phänomen Großstadt und die Entstehung der Stadt der Moderne, Berlin 2014a, S. 144. 55 Zu Giovannonis Städte- 
bautheorie siehe v.a.: Klaus Tragbar, „Die Entdeckung des ambiente. Gustavo Giovannoni und der Beginn der modernen Städtebautheorie in Italien“, in: Christine Beese, Ralph-Miklas Dobler (Hrsg.), L'urbanistica a Roma durante il ventennio fascista, Rom 2018, S. 171-191; ders., „Die Entdeckung des ambiente. Gustavo Giovannoni und sein europäischer Kontext", in: Carmen Enss, Gerhard Vinken (Hrsg.), Produkt Altstadt. Historische Stadtzentren in Städtebau und Denkmalpflege (Urban Studies), Bielefeld 2016, S. 29-41, hier S. 34-35. 56 „Occorre anzitutto determinare [...] quali siano i capisaldi immutabili, cioè gli edifici di carattere storico ed artistico che debbono essere conservati, le opere ed i gruppi di cui deve esser rispettato l'ambiente [...].“ In: Giovannoni 1913b, S.64. 57 Internationaler Verband für Wohnungswesen, 1935, S. 130. 58 Italienische Städtebaukunst im faschistischen Regime, 1937, S. 11. 59 Einen guten Überblick über die Abbruchmaßnahmen in Rom und den Zusammenhang mit der Errichtung der „Ersatzwohnsiedlungen“ am Stadtrand (borgate genannt) bietet Piero Ostilio Rossi, Roma. Guida all'architettura moderna 1909-2011, Bari 2012, S. 74-78. 60 Wolfgang Schieder, „Der Umbau Roms zur Metropole des Faschismus“, in: Mattioli/Steinacher 2009, S.65-86, hier S. 65. 61 Bodenschatz 2011a, S. 41. 62 Ebd. 63 Schieder 2009, S.65-68. 64 Italienische Städtebaukunst im faschistischen Regime, 1937, S. 27. 65 Vgl. etwa: ebd., S. 9: Die Anlage der Via dell'Impero wurde „durch Niederlegung eines ganzen, hässlichen, ungesunden Viertels“ ermöglicht; die ärmlichen Häuser und ihr scheinbar durchwegs äußerst desolater Zustand wurden auch in den offiziellen Publikationen des Governatorato di Roma (Römische Stadtregierung) besonders wirkungsvoll dargestellt, oftmals auch in anschaulichen Vorher-nachherVergleichen. Siehe dazu bspw.: Antonio Muñoz, Via dei Trionfi. Isolamento dell Campidoglio, Rom 1933, Tafelteil. 66 Italienische Städtebaukunst im faschistischen Regime, 1937, S.7. 67 Muñoz 1933, S.22. 68 Italienische Städtebaukunst im faschistischen Regime, 1937, S. 9. 69 Muñoz 1933, S. 22. 70 Bodenschatz 2011a, S. 45. 71 Ebd., S. 106. Verabschiedet wurde ein neuer Generalbebauungsplan für Rom im Juli 1931, im März 1932 erlangte er schließlich Gesetzeskraft. Zur genauen Geschichte, der Ausarbeitung und Bedeutung des Plans siehe: ebd., S. 106-117. 72 In inrem Bericht aus dem Jahr 1924 zur vorläufig letzten Revision des Generalbebauungsplanes von 1909 forderte die Kommission die grundsätzliche Erhaltung der Altstadt, die Dezentralisierung und Errichtung eines neuen Stadtzentrums im Bereich des Hauptbahnhofes sowie die Anlage von Untergrundbahnen und Straßentunnels. Auch Zugeständnisse an die Adaptierung der Altstadt waren in dem Bericht enthalten, die Freilegung einiger antiker Monumente und die Verbreiterung einiger Straßen bzw. der Durchbruch einiger neuer Erschließungswege. Bodenschatz 2011a, S.60-61. Zu den Entwicklungen von 1873 bis in die 1920er-Jahre siehe: ebd., S. 54-59. 73 Enss/Monzo 2019, S. 266. 74 Zur Genese des neuen Generalbebauungsplanes siehe: Bodenschatz 2011a, S. 113-117. 75 Der Generalstadtplan von Rom ist online abrufbar: Roma Capitale, WebGiS, https:// www.comune.roma.it/TERRITORIO/nic-gwt/\#menu (letzter Zugriff 28.4.2021). Unter der Auswahl der Kategorie
„PRG - Sistemi e Regole - 1:5000“ ist der Baualterplan ersichtlich. Die Regulierungsmaßnahmen des 19. und 20. Jhs. sind dunkelorange markiert (T3, ristrutturazione urbanistica otto-novecentesca). 76 Eine gute Zusammenfassung der Regulierungstätigkeit der 1920er-Jahre findet man bei: Bodenschatz 2011a, S. 73-78. 77 Ebd., S. 71-79. 78 Ebd., S. 129. 79 Eine Zusammenfassung der Regulierungstätigkeit der frühen 1930er-Jahre bei: Bodenschatz 2011a, S. 117-129. 80 In den damaligen Bezeichnungen Via dei Trionfi - Via del Mare - Via dei Cerchi, mit den heutigen Namen Via di San Gregorio - Via del Teatro di Marcello - Via del Circo Massimo. 81 Eine Zusammenfassung der Regulierungstätigkeit der späten 1930er-Jahre bei: Bodenschatz 2011a, S.158-166. 82 Italienische Städtebaukunst im faschistischen Regime, 1937, S. 21. 83 Zur Umgestaltung der Piazza Vittoria in Brescia siehe u. a.: Bodenschatz 2011a, S. 298-299. 84 Italienische Städtebaukunst im faschistischen Regime, 1937, S. 9. 85 Ebd. 86 Zu diesem Ergebnis kommt auch Christine Beese hinsichtlich der Neugestaltung der Via Roma in Turin, realisiert nach Plänen von Marcello Piacentini: dies., Marcello Piacentini. Moderner Städtebau in Italien, Berlin 2016, S. 511. 87 Erste Regulierungspläne für das gesamte „Renaissance-Quartier“ publizierte Giovannoni bereits 1913 in seinem Aufsatz „Il ,diradamento“ edilizio dei vecchi centri. II quartiere della Rinascenza in Roma“, siehe: Giovannoni 1913b. 88 Bodenschatz 2011a, S.161-162. 89 Mattioli 2009, S.16. 90 Aram Mattioli, „Edificare per il fascismo'. Macht und Architektur in Mussolinis Italien“, in: Gerald Steinacher (Hrsg.), Faschismus und Architektur. Architettura e fascismo, Innsbruck/Wien 2008, S.17-49, hier S.40. 91 So bspw. im Falle des anlässlich der Esposizione Universale di Roma im Jahr 1942 errichteten Stadtviertels „EUR“. Siehe dazu u.a.: Francesco Garofalo, Luca Veresani, „Die groBen Totems der Revolution. Die Propagandaarchitektur von Adalberto Libera“, in: Jan Tabor, Österreich, Bundesministerium für Wissenschaft und Forschung (Hrsg.), Kunst und Diktatur. Architektur, Bildhauerei und Malerei in Österreich, Deutschland, Italien und der Sowjetunion 1922-1956 (Ausstellungskatalog, Künstlerhaus Wien), Baden 1994, S. 640-645, hier S. 644. 92 Christine Müller, Franco Veremondi, „Die symbolische Form der Zeit. Eine Politik für die Künste“, in: Tabor 1994, S. 612-615, hier S. 613. 93 Bodenschatz 2011a, S. 161-162. 94 Ebd., S. 164-166. 95 Ebd., S.166. 96 Wie Mattioli zusammenfasst, gab es keine offizielle faschistische Staatsarchitektur. Das Regime gab keinen Architekturstil vor, wenngleich Mussolini monumentale Bauten und eine römische Bauweise in zeitgemäßer Form vorschwebte. Die Architekturavantgarde war in Italien in den 1920er-und 1930er-Jahren nicht als „entartet“ deklariert, es entfaltete sich mit dem „Razionalismo“ gar eine eigene avantgardistische Richtung, die vor allem bei Funktionsbauten (wie Bahnhöfen, Postämtern, Parteisitzen etc.) zum Zug kam. Vgl. Mattioli 2009, S. 18-20. 97 Für eine ausführliche Beschreibung von Piacentinis Entwurf und zu dessen Umsetzung siehe v.a.: Beese 2016, S. 433-443; ergänzend auch Bodenschatz 2011a, S. 298-299. 98 Siehe dazu das Luftbild und die zugehörige Bildunterschrift im Tafelteil in: Italienische Städtebaukunst im faschistischen Regime, 1937, o.S. 99 Beese 2016, S. 515-516. Auch in Brescia und Livorno zeichnete 
Marcello Piacentini im Wesentlichen für die Pläne verantwortlich. Zur Neugestaltung der Piazza della Vittoria in Brescia siehe v.a.: ebd., S. 433-452. 100 Siehe dazu: ebd., S.506-511. 101 Der Bericht Italiens in der Publikation des Internationalen Verbands für Wohnungswesen zur „Elendsviertelsanierung“ verweist auf eine „im allgemeinen private Initiative“ in Bologna, die der Stadt - dank der Anwendung der Methode der „Lichtung“ - „die groBen Demolierungen erspart“ habe. Siehe dazu: Internationaler Verband für Wohnungswesen, 1935, S. 180. 102 Bodenschatz 2009, S. 45-47. 103 Vgl. dazu vor allem: Christoph Cornelißen, „Zur Rezeption der italienischen Architektur im ,Dritten Reich““, in: Mattioli/Steinacher 2009 , S. 373-395. 104 BGBI. 138/1935, Übereinkommen mit Italien, betreffend den Ausbau der kulturellen Beziehungen zwischen den beiden Staaten, S. 531-539. 105 Siehe: BGBI. 138/ 1935, S.539; vgl. dazu auch: „Das österreichisch-italienische Kulturabkommen“, in: Salzburger Chronik, 30.1.1935, S.7. 106 Abdruck eines Vortrages von Staatssekretär Hans Pernter: „Die Bedeutung zwischenstaatlicher Kulturabkommen“, in: Salzburger Chronik, 14.5.1935, S. 4-5, hier S. 4; zum Inhalt des Kulturabkom mens siehe auch: Filipuzzi 1975, S. 587-589. 107 „Die Schaffung eines italienischen Kulturinstitutes in Wien“, in: Salzburger Chronik, 7.12.1934, S.11. Am 4.1.1935 wurde der Entwurf des Abkommens im Ministerrat besprochen Vgl. dazu: MRP 978/Top 5, in: Gertrude Enderle-Burcel u. a. (Hrsg.): Protokolle des Ministerrates der Ersten Republik. 1918-1938, Abt. 8, Kabinett Dr. Engelbert Dollfuß, 20. Mai 1932 bis 25. Juli 1934, Wien 1980-1986, 7 Bde., Bd. 2 , 26. Oktober 1932 bis 20. März 1933, Wien 1982, S. 182-184. 108 „Das Italienische Kultur-Institut in Wien“, in: Profil, 4. Jg., H. 3, 1936, S. 104-107, hier S.104. 109 Das Österreichische Kulturinstitut in Rom blickte damals bereits auf eine jahrzehntelange Geschichte zurück. Im Jahr 1881 war das Österreichische Historische Institut in der (damals jungen) italienischen Hauptstadt eingerichtet worden. Zur (Bau-)Geschichte und Architektur des Österreichischen Kulturinstitutes in Rom siehe: Inge Podbrecky, „Das österreichische Institutsgebäude in Rom. Architektur und Identität“, in: Römische Historische Mitteilungen, Bd. 52, 2010 , S. 323-371. 110 Vgl. MRP vom 7.2.1936, 1022/Top 11, in: Gertrude Enderle-Burcel u. a. (Hrsg.), Protokolle des Minis terrates der Ersten Republik. 1918-1938, Abt. 9, Kabinett Dr. Kurt Schuschnigg, 29. Juli 1934 bis 11. März 1938, Wien 1988-2013, 8 Bde., Bd. 4, 2. Dezember 1935 bis 6. März 1936, Wien 2000, S. 352. Die Beauftragung Holeys erfolgte offensichtlich durch Direktvergabe ohne Wettbewerb, wie auch Podbrecky vermutet: dies. 2010, S. 326. Hans Pernter war seit Juli 1934 Staatssekretär im Bundesministerium für Unterricht, ab Mai 1936 Bundesminister für Unterricht (zur Biografie von Hans Pernter siehe u. a. die Biografien ehemaliger Abgeordneter und Minister auf der Internetseite des Österreichischen Parlaments: Republik Österreich, Parlament, „Wer ist Wer?“, https://www.parla ment.gv.at/WWER/ (letzter Zugriff 20.4.2021). 111 Zur Baugeschichte siehe: Podbrecky 2010, S.331-336; hier v.a. S. 334-335. 112 Die Monatshefte für Baukunst und Städtebau oder die Deutsche Bauzeitung berichteten über Entwürfe und Realisierungen von Monumental- und Verwaltungsbauten oder auch über den aktuellen italieni- schen Wohnbau. Die Deutsche Bauzeitung gab im Juli 1938 ein Sonderheft zur "Baukunst des Faschismus“ heraus. 113 Siehe dazu den Abschlussbericht zum Kongress: International Federation of Housing and Town Planning (Hrsg.), International Housing and Town Planning Congress Roma 1929, 3 Bde., Bd. 3, Bericht, Rom 1929d, S. 15. 114 Franz Musil ist auch mit zwei Beiträgen im Tagungsband vertreten: mit Berichten zu den Themen „Die Planung von Wohnhausgruppen in großen Städten in Österreich“ und „Planungsmethoden für die Erweiterung von Städten in Österreich"; International Federation of Housing and Town Planning (Hrsg.), International Housing and Town Planning Congress. Roma 1929, 3 Bde., Bd. 1, Vorberichte, Rom 1929b, S. 157-163 und S. 381-390. 115 Siehe dazu im genannten Tagungsband die Einzelberichte sowie das Programm des Kongresses: ebd. 116 Bodenschatz 2011a, S. 67-69. 117 So nannte man die Stadtregierung Roms zur Zeit des Faschismus. 118 Der Vortrag stand unter dem Titel „Von der Roma quadrata zum Rom Mussolinis“. 119 „Historisches und zeitgenössisches Rom“, in: Salzburger Volksblatt, 14.6.1935, S.6. 120 So berichtet es die Zeitschrift Architettura, einleitend zu Siegfried Theiss' Artikel zur zeitgenössischen Architektur Österreichs: Siegfried Theiss, „Recente architettura austriaca“, in: Architettura, 15. Jg., 1936, S. 213-228, hier S. 212. 121 Siegfried Theiss, „Der XIII. Internationale Architektenkongress in Rom“, in: Profil, 3. Jg., H. 11, 1935, S. 558-560. 122 Die Zahl von 500 Teilnehmenden aus 32 Ländern bestätigt dies (diese Zahlen werden im Pariser Tagblatt gemeldet: „Internationaler Architektenkongress in Rom“, in: Pariser Tagblatt, Nr.663, 6.10.1935, Sonntagsbeilage, S. 3. Außerdem hatte seit 1930 kein derartiger Kongress mehr stattgefunden. Vgl. „Architektenkongress in Rom, 22. bis 28. September", in: Schweizerische Bauzeitung, Jg.105/106, H. 3, 1935, S. 37.123 „Architektenkongress in Rom“, in: Profil, 3. Jg., H. 6, 1935, S. 312. 124 Max Kopp, „Vom XIII. Internationalen Architektenkongress in Rom. 22.-28. September 1935“, in: Das Werk, 22. Jg., H. 11, 1935, S. 390-394, hier S. 391. 125 Ebd. 126 „Convegno Volta Rom 1936“, in: Die Pause, 2. Jg., H. 12, 1936, S. 574. 127 Zu den einzelnen Beiträgen siehe die chronologische Auflistung bei: Michael Achenbach, Karin Moser, „Filmografie - Österreich in Bild und Ton“, in: dies. (Hrsg.), Österreich in Bild und Ton. Die Filmwochenschau des austrofaschistischen Ständestaats, Wien 2002, S. 397-556. 128 „Bürgermeister Schmitz in Rom“, in: Salzburger Chronik, 30.9.1936, S.3. 129 So geschildert im Amtsblatt der Stadt Wien: „Bürgermeister Schmitz in Rom“, in: Amtsblatt der Stadt Wien, 44. Jg., Nr. 20, 15.10.1936, S.1. 130 Archivio Storico Luce, Visita a Roma del borgomastro di Vienna, dottor Schmitz, 7.10.1936, Giornale Luce B/B0967, codice filmato B096706, https://www.archivioluce.com/ (letzter Zugriff 20.4.2021). Denselben Beitrag zeigte die Österreichische Wochenschau: Österreichisches Filmmuseum, Österreich in Bild und Ton, Bürgermeister Schmitz als Gast des Gouverneurs von Rom, 16.10.1936, Ausgabe 42b/36, https://www.filmmuseum.at/sammlungen/film_ online (letzter Zugriff 20.4. 2021). 131 Die Beiträge reichten von Berichten zu Trachtenumzügen und Brauchtumsveranstaltungen über solche zu Konzert- und Ballettaufführungen, Auto- und Radrennen, bis hin zu Staats- 
ereignissen und Aufmärschen und diversen Bauvorhaben. 132 Archivio Storico Luce, La distruzione di un grande edificio della vecchia Vienna, 15.7.1936, Giornale Luce B/ B0919, codice filmato B091903, https://www.archivio luce.com/ (letzter Zugriff 20.4. 2021). Denselben Beitrag zum Abbruch des Freihauses zeigte auch Österreich in Bild und Ton: Österreichisches Filmmuseum, Österreich in Bild und Ton, Ein historisches Bauwerk verschwindet aus dem Stadtbild, 26. 6.1936, Ausgabe 26a/36, https://www. filmmuseum.at/sammlungen/film_online (letzter Zugriff 20.4. 2021). 133 Der Einladung folgte, als „Sonderdelegierter“ und „Vertreter Mussolinis“, Unterstaatssekretär Giovanni Host-Venturi. Vgl. MRP 1004/Top 24, in: Gertrude Enderle-Burcel u.a. (Hrsg.), Protokolle des Ministerrates der Ersten Republik. 1918-1938, Abt. 8, Kabinett Dr. Engelbert Dollfuß, 20. Mai 1932 bis 25. Juli 1934, Wien 19801986, 7 Bde., Bd. 3, 22. März 1933 bis 14. Juni 1933, Wien 1983, S. 186; siehe dazu auch die Berichterstattung in österreichischen (Tages-)Zeitungen: bspw. Die Bühne, H. 406, S. 20 (Bilder zur Eröffnung); „Die Großglocknerstraße dem Verkehr übergeben“, in: Salzburger Chronik, 5.8.1935, S. 1; „Grandioses Rennen am Großglockner“, in: Wiener Sonntags- und Montagszeitung, 5.8.1935, S. 1. 134 "Welt und Stadt“, in: Wiener Salonblatt, Nr.12, 13.6.1937, S. 2-4, hier S. 3-4. 135 „Der Gouverneur von Rom in Wien“, in: Amtsblatt der Stadt Wien, 45. Jg., Nr. 24, 12. 6.1937, S. 16. 136 Österreichisches Filmmuseum, Österreich in Bild und Ton, Besuch des Gouverneurs von Rom. Fürst Colonna, 11.6.1937, Ausgabe 24a/37, https://www. filmmuseum.at/sammlungen/film_online (letzter Zugriff 20.4. 2021). Der Beitrag zeigt u.a. Colonna mit Schmitz auf dem Cobenzl. 137 Archivio Storico Luce, La visita del governatore di Roma, 23.6.1937, Giornale Luce B/B1116, codice filmato B111601, https://www.archivioluce.com/ (letzter Zugriff 20.4.2021). Der italienische Beitrag ist etwas gekürzt. 138 So vermerkt auf dem Deckblatt der Publikation zur Ausstellung: Karl Holey, Ausstellung Italiens Stadtbaukunst (Ausstellungskatalog, Secession Wien), Wien 1937; Katalogteil mit einer Auflistung der gezeigten Modelle, Pläne und Fotoaufnahmen. 139 Bis auf den genannten Ausstellungskatalog konnten sowohl im Archiv der Secession als auch im Archiv des Künstlerhauses leider keine Unterlagen ausfindig gemacht werden. Der Bestand aus dem Secessionsarchiv aus den Jahren 1913 bis 1945 wurde laut Archiv im Zweiten Weltkrieg zerstört. Auch die Suche im Nachlass von Karl Holey im Archiv der Technischen Universität Wien blieb erfolglos. 140 Italienische Städtebaukunst im faschistischen Regime, 1937. Laut Massaretti handelt es sich bei diesem Heft um ein „Werbeheft“, das Mussolini auch bei seinem Staatsbesuch im September 1937 in Deutschland begleitet haben könnte. Pier Giorgio Massaretti, „Modernität und Emphase. Städtebau im italienischen Faschismus", in: Vittorio Magnago Lampugnani, Katia Frey, Eliana Perotti (Hrsg.), Anthologie zum Städtebau, 5 Bde., Bd. 2.2, Das Phänomen Großstadt und die Entstehung der Stadt der Moderne, Berlin 2014, S.1307-1320, hier S. 1307. 141 Holey 1937. 142 Vgl. dazu etwa: „Eine Ausstellung ,Italiens Stadtbaukunst'“, in: Salzburger Volksblatt, 6.11.1937, S. 8. 143 Dies berichtet zumindest die Österreichische Bauzeitung: „Ausstellung italienischer Stadtbaukunst in der
Secession“, in: Österreichische Bauzeitung, 2. Jg., Nr. 45, 27.11.1937, S. 544. 144 „Italiens Stadtbaukunst. Zur Ausstellung in der Secession“, in: Radio Wien, 3.12.1937, S. 10. 145 Holey 1937, S. 5. 146 Siehe dazu u.a.: Das Interessante Blatt, 18.11.1937, S. 5; Zeitschrift Wiener Bilder, Nr. 47, 21.11.1937, S. 3; auch in den Bundesländern wurde darüber berichtet, wie bspw.: „Wiener Ausstellung ,Italiens Städtebaukunst'“, in: Salzburger Chronik, 20.11.1937, S. 10. 147 „Wien. Die italienische Stadtbau-Ausstellung in der Wiener Sezession“, Ausgabe 49b/37 vom 3.12.1937; der Beitrag ist leider in den Archiven des Filmmuseums und des Österreichischen Filmarchivs nicht erhalten. 148 Möglicherweise handelt es sich dabei um denselben Beitrag: Archivio Storico Luce, La Mostra dell'Urbanistica italiana, 15.12.1937, Giornale Luce B/B1217, codice filmato B121701, https://www.archivioluce.com/ (letzter Zugriff 20.4.2021). 149 Schmitz besuchte am 20.11.1937 die Ausstellung. Vgl. „Bürgermeister Schmitz in der italienischen Städtebauausstellung“, in: Amtsblatt der Stadt Wien, 27.11.1937, S.13. 150 „Häuser in deutscher Landschaft“, in: Monatshefte für Baukunst und Städtebau, 18. Jg., H. 3, 1934, S.101-110. 151 Michael Flagmeyer, „Zwischen Nostalgie und sozialer Säuberung. Stadtsanierung im Dritten Reich“, in: Kai Krauskopf, Hans-Georg Lippert, Kerstin Zaschke (Hrsg.), Konzepte einer antimodernen Moderne in Deutschland von 1920 bis 1960 (Neue Tradition, 1), Dresden 2009, S. 221-244. 152 Ebd., S. 231. 153 Theodor Derlam, „Die Frankfurter Altstadtgesundung“, in: Monatshefte für Baukunst und Städtebau, 23. Jg., H. 2, 1939, S. 65-72, hier S. 67.154 Erste gesetzliche Bestimmungen gegen die „Verschandelung“ von Ortsbildern, vor allem durch übermäßige Reklame und unpassende Neubauten, wurden allerdings schon bedeutend früher erlassen; so etwa das „Verunstaltungsgesetz“ von Preußen (.,Gesetz gegen die Verunstaltung von historisch bedeutenden Ortschaften und landschaftlich hervorragenden Gebieten“), verabschiedet im Jahr 1907. Die „Verunstaltungsgesetze" waren ein erster Versuch, den Schutz der Altstadt in den Griff zu bekommen und der öffentlichen Verwaltung hier eine gesetzliche Handhabe zu ermöglichen. Auf diesen Beginn der Ortsbildpflege in Deutschland verweist Hans-Rudolf Meier: „Das Eigene entwickeln - Zeitschichten und städtebauliche Denkmalpflege“, Vortrag im Rahmen der Fachtagung zum Thema „Das Eigene entwickeln - Städtebaulicher Denkmalschutz als Kernelement integrierter Stadtentwicklungspolitik. Zielstellungen, Problemfelder, Lösungsansätze“, Köln, 29./ 30.10. 2009. 155 Birte Pusback, „Wertvorstellungen und Leitlinien der Denkmalpflege in der NS-Zeit“, in: HansRudolf Meier (Hrsg.), Werte. Begründungen der Denkmalpflege in Geschichte und Gegenwart, Berlin 2013, S. 220-229, hier S. 223. Pusback nennt u.a. Görlitz und Rothenburg ob der Tauber als Beispiele. 156 Für eine Übersicht zu den einzelnen Maßnahmen siehe v.a.: Petz 1987. 157 Siehe dazu auch: ebd., S. 28-30. 158 Düwel/ Gutschow 2001, S.106. 159 Flagmeyer 2009, S. 232. 160 Ebd., S. 230. 161 Petz 1987, S. 5-6. 162 Derlam 1939, S. 72. 163 Thomas Scheck, Denkmalpflege und Diktatur. Die Erhaltung von Bau- und Kunstdenkmälern in Schleswig-Holstein und im Deutschen Reich zur Zeit des Nationalsozialismus, Berlin 1995, S. 131. 164 Schon 1934 
meldete sich diesbezüglich der damalige Stadtbaurat von Frankfurt am Main, Reinhold Niemeyer, zu Wort: ders., „Wo bleibt das Gesetz über die Gesundung der Altstädte?", in: Städtebau, 29. Jg., H. 2, 1934, S. 89-94. 165 Diese Entwicklung der Altstädte im 19. Jh. wird eingangs zu Zeitschriftenartikeln zum Thema „Altstadtgesundung“ häufig erläutert, so auch bei: Hermann Flesche, „Die Gesundung der Altstadt Braunschweig“, in: Städtebau, 29. Jg., H. 4 1934, S. 197-204, hier S. 197. 166 Ruth Hanisch, „Die formative Kraft des Faktischen. Erweiterung und Modernisierung der Großstadt“, in: Vittorio Magnago Lampugnani, Katia Frey, Eliana Perotti (Hrsg.), Anthologie zum Städtebau, 5 Bde., Bd. 2.1, Das Phänomen Großstadt und die Entstehung der Stadt der Moderne, Berlin 2014, S. 7-24, hier S.16. 167 Gurlitt 1920, S. 260. 168 Von 1925 bis 1930 Stadtrat und Dezernent für Städtebau in Frankfurt am Main. 169 Siehe dazu den Vortrag von Ernst May zum Thema „Altstadt und Neuzeit" am Tag für Denkmalpflege und Heimatschutz 1928 in Würzburg und Nürnberg in: Tag für Denkmalpflege und Heimatschutz. Würzburg und Nürnberg 1928. Tagungsbericht mit Sonderbeiträgen zur Heimat- und Kunstgeschichte Frankens, Berlin 1929, S. 79-87, hier S. 81-82. 170 Werner Hegemann, Stadtplaner und Herausgeber der Zeitschrift Wasmuths Monatshefte für Baukunst, bezeichnete Berlin im Jahr 1930 als „größte Mietskasernenstadt der Welt“: ders., Das steinerne Berlin - Geschichte der größten Mietskasernenstadt der Welt, Berlin 1930. 171 Flagmeyer 2009, S. 222. 172 „Die Feststellung der Sanierungsentschädigungen“, in: Deutsche Bauzeitung, 71. Jg., H. 32, 1937, S. 634-638. 173 Erich Labes, „Grundsätzliches zur Altstadtsanierung und Altstadterhaltung“, in: Städtebau, 31. Jg., Juni 1936, S. 61-69, hier S. 63.174 Flesche 1934, S. 197. 175 Labes 1936, S. 66 176 Derlam 1939, S. 72. 177 Labes 1936, S. 66. 178 Paul Schultze-Naumburg, Kulturarbeiten, 9 Bde., Bd. 4, Städtebau, München 1909 [Erstausgabe 1906]. 179 Labes 1936, S. 66. 180 Erich Labes, „Planvolle Erhaltung der deutschen Altstädte“, in: Deutsche Bauzeitung, 71. Jg., August 1937, S. 156-160, hier S. 159. 181 Ebd., S.160. 182 Ebd., S. 156-160. 183 So beschrieben auf dem Titelblatt der Deutschen Bauzeitung, H.45, November 1937. Zum Umbau des Gängeviertels siehe u. a.: Scheck 1995, S. 116-119. 184 Derlam 1939, S. 67, 72. 185 „Gesundungsarbeiten in der Altstadt von Hannover", in: Deutsche Bauzeitung, 73. Jg., H. 32, 1939, S. K254-259, hier S. K254. 186 Für eine Ausweisung von „Schutzgebieten“ von „erster, zweiter und dritter Ordnung“, in denen - „je nach ihrem kulturellen und praktischen Werte" - unterschiedlich tiefgreifende Maßnahmen möglich sein sollten, spricht sich bereits Eduard Jobst Siedler im Rahmen des Internationalen Wohnungs- und Städtebaukongresses 1929 in Rom aus. Ders., „Die Neuplanung alter und historischer Städte in Deutschland“, in: International Federation of Housing and Town Planning (Hrsg.), International Housing and Town Planning Congress, Roma 1929, 3 Bde., Bd.1, Vor berichte, Rom 1929, S.307-313, hier S.308. 187 Siehe dazu v.a.: Folckert Lüken-Isberner, „Das Programm zur (Alt-)Stadtsanierung im Nationalsozialismus", in: ders. (Hrsg.), Stadt und Raum 1933-1949. Beiträge zur planungs- und stadtbaugeschichtlichen Forschung II, Kassel 1991, S. 23-43. 188 Scheck 1995, S.129. 189 Hier wird in vier Kategorien unterschieden: die Auflockerung, der Totalabbruch und Neubau, gemischte Verfahren und „Sanierungen besonderer Art“" (Einzelfälle). Vgl. Deutsche Gesellschaft für Wohnungswesen (Hrsg.), Altstadtsanierung mit Reichshilfe 1934-1938, Berlin 1940. 190 Petz 1987, S.10-12. 191 Unter diesem Begriff fasst Vinken die unterschiedlichen Maßnahmen der „Gesundung“ und „Entschandelung“ zusammen, die letztlich demselben Ziel dienten; Vinken 2010; zur „Homogenisierung“ der Altstadt von Köln siehe darin v. a. S. 140-149. 192 Ebd., S. 142-144. 193 Wilhelm Pinder, „Zur Rettung der Deutschen Altstadt", in: ders., Leo Bruhns (Hrsg.), Gesammelte Aufsätze aus den Jahren 1907-1935, Leipzig 1938, S. 192-203, hier S. 200-201. 194 Bäumer war aus der konservativen "Stuttgarter Schule“ hervorgegangen und u.a. Assistent von Paul Schmitthenner gewesen. Werner Durth, Paul Sigel, Baukultur. Spiegel gesellschaftlichen Wandels, Berlin 2009, S. 339. 195 Friedbert Hoefer, „Die Bauten der Altstadtsanierung in Weimar", in: Moderne Bauformen, 40. Jg., H. 12, 1941, S. 513-538. 196 Ebd., S. 533. 197 Ebd., S. 517. 198 Ebd., S. 516. 199 Düwel/Gutschow 2001, S. 109. 200 Ebd., S. 108. 201 Wilhelm Pinder, „Die Rettung der Deutschen Altstadt“, in: Denkmalpflege und Heimatschutz im Wiederaufbau der Nation. Tag für Denkmalpflege und Heimatschutz im Rahmen des Ersten Reichstreffens des Reichsbundes Volkstum und Heimat, Kassel 1933, Berlin 1934, S. 123-133; erneut publiziert wurde Pinders Vortrag in einem Sammelband seiner wichtigsten Aufsätze im Jahr 1938: Pinder 1938. 202 Ebd., S. 197. 203 Ebd., S. 201. 204 Ebd., S. 202. 205 Die Geschichte der „Entstuckung“ am Beispiel Berlin von den 1920er-Jahren bis in die Gegenwart untersuchte im Detail: Hans-Georg Hiller von Gaertringen, Schnörkellos. Die Umgestaltung von Bauten des Historismus im Berlin des 20. Jahrhunderts (Die Bauwerke und Kunstdenkmäler von Berlin, Beiheft, 35), Berlin 2012. Bereits nach dem Ersten Weltkrieg wurden durch den Krieg verwüstete Stadtbilder vereinheitlicht und nach den damaligen Vorstellungen des „echten Eigenen“ und der baukulturellen Tradition korrigiert bzw. „schöpferisch ergänzt“. Siehe dazu: Gerhard Vinken, „Stadt - Denkmal Bild. Wider die homogenen Bilder der Heimat", in: Sigrid Brandt, Hans-Rudolf Meier (Hrsg.), Stadtbild und Denkmalpflege. Konstruktion und Rezeption von Bildern der Stadt (Stadtentwicklung und Denkmalpflege), Berlin 2008, S. 162-175, hier S. 168. 206 Siehe dazu u. a.: Achim Hubel, Denkmalpflege. Geschichte, Themen, Aufgaben. Eine Einführung, Stuttgart 2019, S. 104-106; Pusback 2013. 207 Eingeführt wurde der Begriff 1929 von Rudolf Esterer im Rahmen seines Vortrags „Heimatschutz und neue Baugesinnung“, gehalten am Tag für Denkmalpflege und Heimatschutz in Bregenz, für die damals übliche denkmalpflegerische Praxis. Zum Begriff der „schöpferischen Denkmalpflege“ siehe v. a.: Sigrid Brandt, "Schöpferische Denkmalpflege? Anmerkungen zu einem Schimpfwort“, Vortrag anlässlich des Symposiums „Nachdenken über Denkmalpflege“, Hundisburg, 16.11.2002, in: Denkmalpflege, H.1, 2003, abgerufen über www.kunsttexte.de (letzter Zugriff 20.4.2021); Susanne Fleischner, „Schöpferische Denkmalpflege“. Kulturideologie des Nationalsozialismus und Positionen der Denkmalpflege (Beiträge zur Denkmalpflege und Bauforschung, 1), Münster 1999, 
v. a. S. 21-22; Hubel 2019, S. 122-132. 208 Siehe dazu u. a.: Brandt 2003, S.1. 209 Zum Begriff der „Entschandelung“ siehe v.a.: Wolfram Lübbeke, „Entschandelung. Über einen ästhetisch-städtebaulichen Begriff der ,Denkmalpflege “im Nationalsozialismus“, in: Die Denkmalpflege, Bd. 65, H. 2, 2007, S. 146-156. 210 Düwel/Gutschow 2001, S. 109-110. 211 Pusback 2013, S. 223-224. 212 „Der Umbau der Lübecker Altstadt“, in: Städtebau, 33. Jg., Mai 1938, S. 37-40, hier S.39. 213 Flagmeyer 2009, S. 231-232. 214 Hubel 2019, S. 107-108. 215 Anja Wiese, „,Entschandelung und Gestaltung als Prinzipien nationalsozialistischer Baupropaganda. Forschungen zur Wanderausstellung ,Die schöne Stadt' 1938-1943“, in: Die Denkmalpflege, Bd.69, H.1, 2011, S.34-41, hier S.34. 216 Ebd., S. 34-35. 217 Die Wanderausstellung unter dem Titel Die schöne Stadt - ihre Entschandelung und Gestaltung wurde in den Jahren von 1938 bis 1943 abgehalten, Näheres dazu im Beitrag von Anja Wiese. 218 Wiese 2011, S. 37. 219 Vgl. dazu Werner Lindner, Die Stadt. Ihre Pflege und Gestaltung (Die landschaftlichen Grundlagen des deutschen Bauschaffens, 2), München 1939. Hinsichtlich der Gestaltung von Neubauten äußert sich Lindner über „passende“ Fenster, Türen und Dachformen sowie über die richtige Gestaltung von Putzoberflächen. Ebenso bringt er Beispiele sowohl für "gute Schaufensterformen“ und angemessene Reklame und Beschilderungen als auch für „schlechte und gute ,Platzmöbel“'. 220 Lindner 1939, S. 180. 221 Wolfgang Sonne, „Stadterhaltung und Stadtgestaltung. Schönheit als Aufgabe der städtebaulichen Denkmalpflege“, in: HansRudolf Meier (Hrsg.), Werte. Begründungen der Denkmalpflege in Geschichte und Gegenwart, Berlin 2013, S. 158-179, hier S.169-172. 222 Zur Rolle und den Leitlinien der Denkmalpflege in der NS-Zeit siehe v.a. Pusback 2013. 223 Zu dieser Entwicklung und zum Einfluss der Heimatschutzbewegung auf die Denkmalpflege in Deutschland siehe etwa eine Zusammenfassung bei Hubel 2019, S. 96-114; vgl. auch: Verena Jakobi, „Die Heimatschutzbewegung und die Entdeckung des Ensembles“, in: Ingrid Scheurmann (Hrsg.), Zeitschichten erkennen und erhalten. Denkmalpflege in Deutschland, München/Berlin 2005, S.120-123. 224 (Hier die zitierte 2. Auflage) SchultzeNaumburg [1906] 1909, S. 22-27 und S. 279-282. 225 „Tag für Denkmalpflege und Heimatschutz 1938“, in: Deutsche Kunst und Denkmalpflege, 5.Jg., 1938, S.80. 226 BDAArchiv, Heimatschutz, Karton 5, Ausstellungen 1920-1940, Fasz. 1, 2046/Dsch/1938, Schreiben Karl Giannoni an die Zentralstelle, 1.7.1938. 227 Gemeinsame Tagung für Denkmalpflege und Heimatschutz. Salzburg 14. und 15. September 1911, stenographischer Bericht, Berlin 1911; zum Programm siehe: ebd., S. 27-28. 228 Vgl. BDAArchiv, Heimatschutz, Karton 3a, Vereinskorrespondenz, Fasz. 3 (1922-1940). 229 Laut den Teilnehmerlisten nahmen an den österreichischen Heimatpflege-Tagungen allerdings nur vereinzelt Fachleute aus Deutschland teil (mit Ausnahme der Österreichischen Bundestagung für Heimatschutz im Mai 1929 in Bregenz). Zu den Tagungen siehe: BDA-Archiv, Heimatschutz, Karton 10, Tagungen und Kongresse (1934-1941). 230 Siehe dazu die Niederschrift der beiden Vorträge im Tagungsband: Tag für Denkmalpflege und Heimatschutz. Würzburg und Nürn- berg 1928, 1929. 231 Vgl. dazu die Teilnehmerliste in: ebd., S. 331-338. 232 Zum Programm der Tagung und Korrespondenz im Vorfeld derselben siehe: BDA-Archiv, Heimatschutz, Karton 9, Tagungen und Kongresse (19291933), Fasz. 1 (1929). 233 Rudolf Esterer, „Heimatschutz und neue Baugesinnung“, Vortrag, gehalten auf der Heimatschutztagung in Bregenz am 18. Mai 1929 von Oberregierungsrat R. Esterer, Wien 1929. 234 BDA-Archiv, Heimatschutz, Karton 9, Tagungen und Kongresse (19291933), Fasz. 5 (1933), Korrespondenz mit Arist Rollier, 22. 2. und 28.3.1933. Die finanziellen Engpässe und die teils aus der eigenen Tasche zu bezahlenden Tagungs- und Reisekosten werden von Giannoni auch in anderen Briefen an Werner Lindner festgehalten. Ebd., Brief vom 21.3.1933. 235 Vgl. auch: Eva Frodl-Kraft, Gefährdetes Erbe. Österreichs Denkmalschutz und Denkmalpflege 1918-1945 im Prisma der Zeitgeschichte (Studien zu Denkmalschutz und Denkmalpflege, 16), Wien u.a. 1997, S. 76. 236 Dies bezeugen zahlreiche Briefe im BDA-Archiv, Heimatschutz, Karton 9, Tagungen und Kongresse (1929-1933). 237 FrodlKraft 1997, S. 93. 238 Zur Geschichte und Herausgeberschaft der Zeitschrift siehe: ebd., S. 90-103 und S. 122-124. 239 Ebd., S. 122. 240 Otto Demus, „Die österreichische Denkmalpflege“, in: Egon Loebenstein (Hrsg.), 100 Jahre Unterrichtsministerium 1848-1948, Festschrift des Bundesministeriums für Unterricht in Wien, Wien 1948, S. 393-411, hier S. 405. 241 Frodl-Kraft 1997, S. 124. 242 Siehe dazu auch: Sandro Scarrocchia, Max Dvořák. Schriften zur Denkmalpflege. Gesammelt und kommentiert von Sandro Scarrocchia (Studien zu Denkmalschutz und Denkmalpflege, 22), Wien u. a. 2012, S.172. 243 Ebd., S. 124-125. Frodl-Kraft vergleicht hier die unterschiedlichen Generationen an Denkmalpflegern, die in diesen Jahren tätig waren, teils noch stark dem Heimatschutzgedanken und dem schöpferischen Moment zugewandt, teils schon die Denkmalpflege als sachliche, objektive Disziplin verstehend. 244 Etwa die „Rückführung“ der Innenräume der romanischen Pfarrkirche von Schöngrabern; siehe dazu: ebd., S. 212-215. 245 Dies geht aus den zeitgenössischen Berichten von Mitarbeitern der Zentralstelle in der Zeitschrift Deutsche Kunst und Denkmalpflege hervor, siehe dazu u. a.: Herbert Seiberl, „Die Österreichische Denkmalpflege in der Systemzeit und ihre Aufgaben für die nächste Zukunft“, in: Deutsche Kunst und Denkmalpflege, 5. Jg., 1938, S. 125-128; Karl Ginhart, „Das österreichische Denkmalamt in der Systemzeit und in der Gegenwart", in: Deutsche Kunst und Denkmalpflege, 5. Jg., 1938, S. 257-259. 246 Seiberl 1938, S. 125-126. 247 Ebd., S.126. 248 Siedler 1929. 249 Siehe dazu das (provisorische) Teilnehmerverzeichnis in: ebd., S. 2-11. 250 Der ehem. „Deutsche[r] Ausschuss für wirtschaftliches Bauen“ wurde 1923 gegründet, 1933 u mbenannt und bestand im Jahr der Tagung in Wien aus elf deutschen und sämtlichen österreichischen Fachorganisationen des Hochbaus, aus Vertretern der Behörden, der Bau(stoff)industrie, der Baugenossenschaften, der technisch-wissenschaftlichen Institute und Lehranstalten. Siehe: „Tagung der deutschen Akademie für Bauforschung in Wien“, in: Salzburger Volksblatt, 20.5.1937, S. 8; „Tagung der Deutschen Akademie für Bauforschung in Wien“, in: Zeitschrift des österreichischen Ingenieur- und Architektenvereines, 89. Jg., H. 17/18, 1937, 
S. 102-103, hier S.102. 251 Einen ausführlichen, mehrteiligen Bericht zur Tagung (mit der Wiedergabe einzelner Wortmeldungen) findet man in der Zeitschrift des österreichischen Ingenieur- und Architektenvereines (alle unter dem Titel „15. Tagung für wirtschaftliches Bauen“ in ZÖIAV, 89. Jg., 1937): H. 23/24, S. 163-165; H. 25/26, S. 181-184; H. 27/28, S. 198-200. Seit neun Jahren war es das erste Zusammentreffen mit 250 Teilnehmern aus Deutschland und über 400 aus Österreich; siehe: H. 23/24, S. 163. 252 „Die Wiener Tagung der Akademie für Bauforschung“, in: Deutsche Bauzeitung, 71. Jg., H. 22, 1937, S. 399-400, hier S. 400. 253 Ebd. 254 „Die neue Wohnbaupolitik in Wien. Auflockerung der Großstadt", in: Neues Wiener Tag blatt, 31.7.1938, S.6. Auf die geplanten Maßnahmen für Wien nach dem „Anschluss“ verweist auch bereits LükenIsberner 1991, S. 35, 38. 255 Ebd. 256 Auch bleibt es fraglich, ob diese Kongresse tatsächlich zum Austausch dienten und Beeinflussungen zur Folge hatten: „Was wir ,verhandelt' haben? Oh - da waren ja die Berichte, die natürlich jeder gelesen hatte und über die man sich nun aussprechen sollte. Viele Höflichkeiten, sehr allgemeine Wahrheiten und etliche Sprachschwierigkeiten. In angenehmstem Rahmen.“ Siehe: Hans Bernoulli, in: „Skizzen vom Internationalen Wohnungs- und Städtebaukongress London 1935“, in: Das Werk, 22. Jg., H. 9, 1935, S. 327-330, hier S. 329. 257 Im Rahmen des eigentlichen Kongresses wurden keine Vorträge gehalten, sondern die vorab eingereichten Länderberichte durch einen Experten zusammengefasst und unter dessen Leitung diskutiert. 258 Auf der Teilnehmerliste für Rom scheint aus Wien auch die Zentralvereinigung für Architekten auf sowie eher unbekannte Namen wie Wilhelm Baumgarten oder Wilhelm Bonczak; vgl. das (provisorische) Teilnehmerverzeichnis in: International Federation of Housing and Town Planning, 1929b, S. 2-11. Auf deutscher Seite begegnen bedeutende Namen wie Cornelius Gurlitt, Ernst May, Fritz Schumacher oder Joseph Stübben. Vgl. Renzo Riboldazzi, „The IFHTP congresses between the wars. A source for studies on modern town planning", in: The Town Planning Review, Vol. 84, Nr. 2, 2013, S. 159-170, hier S.161. 259 Zur Bedeutung von Fragen des Wohnungswesens in der Stadtplanung der 1920er- und 1930er-Jahre siehe: Albers 1997, S. 191-192 und S. 204-205. 260 Otto Ponholzer, "Siedlung und Altstadt-Assanierung", in: Salzburger Volks blatt, 9.12.1933, S. 11-12. 261 So vermeldet es zumindest die Tageszeitung Salzburger Chronik, „Wiener Ausstellung ,Italiens Städtebaukunst““, 20.11.1937, S.10. 262 Flag meyer 2009, S. 235. 263 Ebd., S. 225-226. 264 So etwa auch in der Zeitschrift ÖWB. Österreich in Wort und Bild (Monatshefte des Heimatdienstes). 265 Zum Stadt-Um bau Roms im 19. Jh. siehe: Giorgio Piccinato, „Hygiene und Stadt-Umbau. Das Spannungsfeld zwischen Staat, Gemeinden und privaten Unternehmern: Rom als Beispiel“, in: Gerhard Fehl, Juan Rodríguez-Lores (Hrsg.), Stadt-Um bau. Die planmäßige Erneuerung europäischer Großstädte zwischen Wiener Kongreß und Weimarer Republik, Basel 1995, S. 97-113; Britta Hentschel, „Der Corso Vittorio Emanuele II. Städtebau im Rom des 19. Jahrhunderts“, in: Vittorio Magnago Lampugnani, Matthias Noell, Stadtformen. Die Architektur der Stadt zwischen Imagination und Konstruktion, Zürich 2005, S. 190-202. 266 Boden- schatz 2011a, S. 44-45. 267 Ebd., S. 73-75. 268 Ebd. S.81-97. 269 Zum Siedlungsbau im Ständestaat siehe: Suttner 2017, S.128-165. 270 Siehe dazu nochmals „Die neue Wohnbaupolitik in Wien. Auflockerung der Großstadt“, in: Neues Wiener Tagblatt, 31.7.1938, S.6. 271 Albers 1997, S. 198-199. 272 In Deutschland wurde vor allem in den Fachzeitschriften und Tagungsberichten zu Städtebaukongressen die Gesetzeslage zur Enteignung intensiv diskutiert, vor allem die Frage der gerechten Berechnung des Grundstückswertes und der Entschädigung der Eigentümer. Siehe dazu v.a. das November-Heft der Zeitschrift Städtebau mit mehreren Gesetzesentwürfen zur „Altstadtgesundung“ und einem Beitrag über die Entschädigung bei Enteignungsverfahren: Städtebau, 29. Jg., 1934, S. 549-560. 273 Bernoulli 1935, S. 327-330. 274 Die Rezeption der Haussmann'schen Maßnahmen beginnt im 19. Jh. Zur neueren Kritik, aus einer entscheidenden zeitlichen Distanz heraus, siehe v. a.: Leonardo Benevolo, Die Geschichte der Stadt, Frankfurt am Main, 2007 [ital. Erstausgabe: Storia della città, Bari 1978]; Gottfried Kiesow, Gesamtkunstwerk - Die Stadt. Zur Geschichte der Stadt vom Mittelalter bis in die Gegenwart, Bonn 1999, S. 216-217; Charles Delfante, Architekturgeschichte der Stadt. Von Babylon bis Brasilia, Darmstadt 1999, S. 177-179. 275 Philipp Sarasin, „Die moderne Stadt als hygienisches Projekt. Zum Konzept der ,Assanierung der Städte im Europa des 19. Jahrhunderts", in: Vittorio Magnago Lampugnani, Stadt \& Text. Zur Ideengeschichte des Städtebaus im Spiegel theoretischer Schriften seit dem 18. Jahrhundert, Berlin 2011, S. 99-112, hier S. 109-110. 276 Hans Reichow, „Altstadtgesundung. Zielsetzung, Finanzierung und Rechtsordnung für Altstadt- und Wohnungsgesundungen", in: Städtebau, 29. Jg., H. 4, 1934, S.193-196, hier S. 193. 277 Labes 1937, S. 156. 278 Beitrag zu Frankfurt am Main in: Internationaler Verband für Wohnungswesen, 1935, S. 64. 279 Flagmeyer 2009, S. 229. 280 Scheck 1995, S.130. 281 Siehe dazu: Piccinato 1995, S. 97. 282 Internationaler Verband für Wohnungswesen, 1935, S. 176-178. 283 Ebd., S. 177. 284 Bodenschatz 2011a, S. 49, 429. 285 Vinken 2010, S. 83. 286 Karl Giannoni, „Entwickelung und Ziele des Heimatschutzes in Österreich“, in: Gemeinsame Tagung für Denkmalpflege und Heimatschutz. Salzburg 14. und 15. September 1911, stenographischer Bericht, Berlin 1911a, S. 83-97, hier S. 92. 287 Max Dvořák, Katechismus der Denkmalpflege, Wien 1918 [1. Auflage 1916], S.1. 288 Das Haus zur Goldenen Kugel war in den frühen 1880 er-Jahren anstelle mehrerer schmaler Altstadthäuser errichtet worden, ein sechsgeschossiges Gründerzeithaus mit neobarockem Dekor. Siehe: Andreas Lehne, Gabriele Roithner, Wiener Stadtjuwelen im Wandel der Zeit. 34 Orte, die Geschichte schrieben von Albertina bis Westbahnhof, Wien 2015, S. 57. 289 Karl Ginhart, „Berichte aus Österreich. Wien“, in: Deutsche Kunst und Denkmalpflege, 1. Jg., 1934, S. 89-90, hier S. 90. 290 Fortunat von Schubert-Soldern, „Kapuzinerkirche. Neugestaltung der Fassade und Aufstellung einer AvianoStatue“, in: Deutsche Kunst und Denkmalpflege, Jg. 1935, S. 216. 291 Zur Entwicklung und Definition des Begriffs „Heimatschutzarchitektur“ (1920er- und 1930er-Jahre), auch im Verhältnis zum „Heimatstil“ (Ende 19. Jh.), siehe v.a.: Andreas Lehne, „Heimatstil - zum Problem der 
Terminologie“, in: ÖZKD, 53. Jg., H. 3/4, 1989, S. 159-164; Géza Hajós, „Heimatstil - Heimatschutzstil“, in: ÖZKD, 53. Jg., H. 3/4, 1989, S. 156-158. Elisabeth Crettaz-Stürzel arbeitete in ihrem umfassenden Werk zur Entwicklung des Heimatstils in der Schweiz (1896-1914) auch die Begriffsunklarheiten auf. Vgl. dies., Heimatstil. Reformarchitektur in der Schweiz 1896-1914, 2 Bde., Wien u.a. 2005. 292 Esterer 1929, S.12. 293 Eigentlich Kajetan Mühlmann. 294 Kaj MühImann, Stadterhaltung und Stadterneuerung in Salzburg. An Beispielen der Restaurierungen Franz Wagners, München/Wien 1932. 295 Auch als Vorschussmauer bezeichnet. 296 Eine ähnliche Charakterisierung findet man auch im „Georg Dehio-Handbuch der deutschen Kunstdenkmäler" von 1933. Stuckaturen beschränkten sich auf Fensterumrahmungen, Lauben und Erker fehlten im Salzburger Stadtbild fast vollständig. Vgl. Dagobert Frey, Karl Ginhart (Hrsg.), Handbuch der deutschen Kunstdenkmäler. Österreich [hrsg. von Georg Dehio], Bd.1, Die Kunstdenkmäler in Kärnten, Salzburg, Steiermark, Tirol und Vorarlberg, Berlin 1933, S. 144-145. 297 Kaj Mühlmann, „Neue Kunst in Salzburg. Architektur und Kunstgewerbe", in: Österreichische Kunst, 1. Jg., H. 9 , 1930, S.12-19. 298 Ebd. 299 Siehe dazu etwa: BDAArchiv, Top. Mat., Karton Wien I. Bezirk, Profan allg., 3065/ Dsch/1925. Auch in Zeitschriften wurde das Thema der Reklame im Stadtbild und die „richtige“ Gestaltung von Geschäftseinbauten und Schaufenstern behandelt. Siehe dazu bspw.: „Schach der Zügellosigkeit. Ein Protest wider der Unsitten im Ladenbau“, in: Profil, 2. Jg., H. 8, 1934, S. 256-261. 300 Sowohl bei der österreichischen Heimatpflege-Tagung 1930 in Eisenstadt sowie bei jener 1934 in Gmunden stellte das Thema der Reklame in Dorf und Großstadt einen wesentlichen Tagungspunkt dar. Vgl. Wilhelm Ambros, „Die österreichische Bundestagung für Heimatpflege 1930“, in: Die Denkmalpflege, 1930, S. 183-185. Tagungsprogramm und nähere Ausführungen: BDA-Archiv, Heimatschutz, Karton 10, Tagungen und Kongresse (1934-1941), Fasz. 1 (1934); ebd., Karton 1a, Verwaltungsakten 1923-1940, 1190/Dsch/1934. 301 Ab März 1938 wird in den Akten des Bundesdenkmalamtes sehr häufig von „das Stadtbild verunstaltenden Reklamemalereien“ gesprochen, vgl. dazu bspw. Akten zum Objekt Liechtensteinstraße 93, 1090 Wien. 302 „Störende Reklameschriften müssen verschwinden“, in: Neuigkeits-Welt-Blatt, 24.12.1938, S. 4. 303 BDA-Archiv, Heimatschutz, Karton 5, Ausstellungen 1920-1940, Fasz. 25a (Wien), Brief Karl Giannoni an Franz Wogl (?), Wien, 19.12.1940. 304 Crettaz-Stürzel 2005, S. 127-129. 305 Karl Giannoni, „Heimatschutz. Gegenwartsstellung und Zukunftsaufgaben“, in: Die Denkmalpflege, 7. Jg., 1933c, S. 142-151, siehe v.a. 144-146. 306 In den Akten des BDA endet die Beurteilung der „Abrissfälle“ mit dem Entscheid für einen ebensolchen, die danach errichteten Assanierungsbauten werden nicht kommentiert. $\mathbf{3 0 7}$ Die Regulierung des Tiber samt der Anlage breiter Uferstraßen stellte eine der frühesten und bedeutendsten Regulierungsmaßnahmen des 19. Jhs. in Rom dar und war zu Beginn der faschistischen Herrschaft nahezu abgeschlossen. Vgl. dazu die Regulierungspläne von 1887, 1883 und 1909 bzw. 1931 (bei Bodenschatz 2011a) und den Fortschritt der Regulierung bzw. die jeweils noch geplanten Neubauten. 308 Luigi Lenzi, „Neue Bauten von Marcello Piacentini. Das eigene Haus des Architekten in Rom", in: Monatshefte für Baukunst und Städtebau, H. 11, 1934, S. 531-532, hier S. 532. 309 Lungotevere Marzio Nr. 9.310 Rossi 2012, S. 79. 311 Ebd., S. 80. 312 „Piccola casa da pigione“, in: Architettura, 12. Jg., H. 10, 1933, S. 637-639, hier S. 637. 313 Die Planung und Ausführung des Prestigeprojektes wurde ohne Ausschreibung eines Wettbewerbes an Clemens Holzmeister vergeben, siehe Suttner 2017, S.188. 1938 stoppte die NS-Verwaltung die weitere Ausführung (ebd., S. 191-192). Im Frühjahr 1939 wurden die Bauarbeiten wiederaufgenommen und man plante die Unterbringung der Büros des „Reichsnährstandes“. Siehe: „Fronthaus wird Nährstandszentrale“, in: Neues Wiener Tagblatt, 18.3.1939, S. 10. 314 „Das Haus der Front“, in: Die Pause, 3. Jg., H.12, 1937, S. 44-47. 315 Friedrich Achleitner, Österreichische Architektur im 20. Jahrhundert. Ein Führer in drei Bänden, 3 Bde., Bd. 3.1, 1.-12. Bezirk, Salzburg u.a. 2010, S. 149-150; zum Wettbewerb im Jahr 1935 siehe u.a.: „Die Grundlagen zum Funkhauswettbewerb“, in: Profil, 3. Jg., H. 8, 1935, S. 394-407. 316 Der Palazzo del Littorio war ursprünglich als Parteizentrale des Partito Nazionale Fascista geplant, wurde später und wird heute immer noch als Außenministerium genutzt. 317 Bodenschatz 2011a, S.130. 318 Ebd., S. 40. 319 Matthias Donath, Landesdenkmalamt Berlin (Hrsg.), Architektur in Berlin 1933-1945. Ein Stadtführer, Berlin 2007, S. 61-66. Die an die alte Reichsbank angrenzenden Grundstücke wurden vom Reichsbankdirektorium ab 1913 sukzessive aufgekauft. Heinrich Wolff, „Der Erweiterungsbau der Reichshauptbank", in: Monatshefte für Baukunst und Städtebau, 27. Jg., H. 9, 1937, S. 290-298, hier S. 290-291. 320 Im Oktober 1937 wurde das „Gesetz zur Neugestaltung deutscher Städte" verabschiedet, womit der Staat seine Pläne zur großflächigen Neugestaltung historischer Stadtzentren konkretisierte und die rechtlichen (Enteignung), administrativen und ökonomischen Bedingungen dafür schuf. Siehe dazu u. a. Vittorio Magnago Lampugnani, „Laubenidylle und Monumentalachsen. Städtebau im Deutschland des Nationalsozialismus“, in: ders., Die Stadt im 20. Jahrhundert. Visionen, Entwürfe, Gebautes, Bd. 2, Berlin 2010b, S. 581-611, hier S. 597-598. 


Kapitel 7 